\title{
UNDERSTANDING THE EFFECTS OF MATERNAL UNDERNUTRITION IN EARLY GESTATION ON PLACENTAL DEVELOPMENT IN LATE GESTATION
}

\section{A Dissertation}

presented to

the Faculty of the Graduate School

at the University of Missouri-Columbia

In Partial Fulfillment

of the Requirements for the Degree

Doctor of Philosophy

by

GERIALISA ALLISON MARCELLA VAN GRONIGEN CASE

Dr. Laura Schulz, Dissertation Supervisor

DECEMBER 2018 
The undersigned, appointed by the dean of the Graduate School, have examined the dissertation entitled:

"UNDERSTANDING THE EFFECTS OF MATERNAL UNDERNUTRITION IN EARLY GESTATION ON PLACENTAL DEVELOPMENT IN LATE GESTATION" presented by GERIALISA ALLISON MARCELLA VAN GRONIGEN CASE, candidate for the degree of Doctor of Philosophy and hereby certify that, in their opinion, it is worthy of acceptance

Dr. Laura Schulz

Dr. Michael Garcia

Dr. Susan Nagel

Dr. Rocio Rivera

Dr. Kristen Taylor 


\section{DEDICATION}

I would like to dedicate my dissertation to the village that got me through. To my mom for instilling the value of an education and your many sacrifices to ensure I received an outstanding one. It is because of this I can now use my education to make an impact in other lives. To my sister, thank you for always being my rock, my motivator, my inspiration; because of you l'm a better person. To my dad, thanks for always telling me to "try man" in that cool, carefree manner of yours that embodied Brother Bob's "3 little birds". To my uncle Lennard King for his steadfast support. A special thank you to my undergraduate advisors Drs. Carroll and Catapane, who ensured I had the opportunity to do research and thus my realizing my passion. For the first time I was doing something because I loved it and not because it was expected of me. To the numerous family and friends thank you for your support throughout this process. Most importantly thanks to God, our most gracious savior for bringing me through. Hebrews 11:1 "Now faith is the confidence that what we hope for will actually happen; it gives us assurance about things we cannot see" 


\section{ACKNOWLEDGEMENTS}

I am beyond grateful to my adviser Dr. Laura Schulz for the belief she has in me. On days when I wanted to push pause, she has pushed me through, thank you, thank you, thank you. To my committee members Drs. Susan Nagel and Rocio Rivera, thank you for setting the example of what confident, female scientist are. Dr. Kristen Taylor, thank you for all your advice and expertise. To Dr. Garcia, thank you for being a great mentor since my PREP years and for paying me what I now value as the greatest compliment, of being too stubborn to quit. I would like to say a special thanks to the Schulz lab members: Drs. Kathleen Pennington, Kelly Pollock, Arin Kettle Oestreich, Omonseigho Talton and Megan Sheridan, and Rowan Karvas, Jenna DeCata, Keenan Bates, Kylie Hohensee, Jennifer Kaiser. A special thank you to Lauren Parmeley, an undergraduate who took a part on my project and made it her own, Sarah Khan, a high school student and Jihaan Adonis, a master's student. These later three provided immeasurable help to my projects and the invaluable experience for me to be a mentor. I would also like to thank Alexei Stuckel, Sadia Akter and Yoanna McDowell for their technical expertise. 


\section{TABLE OF CONTENTS}

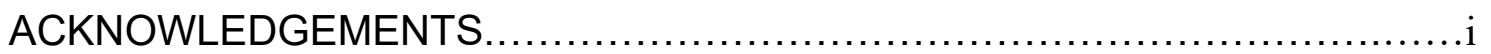

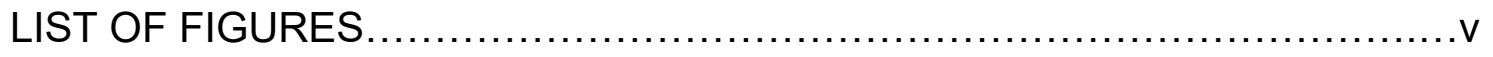

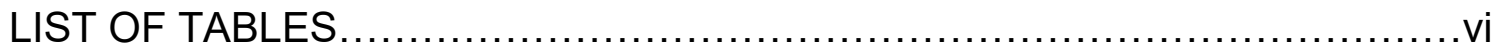

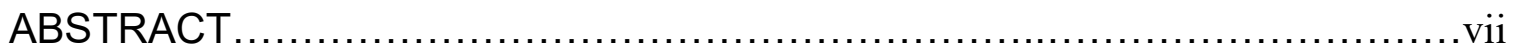

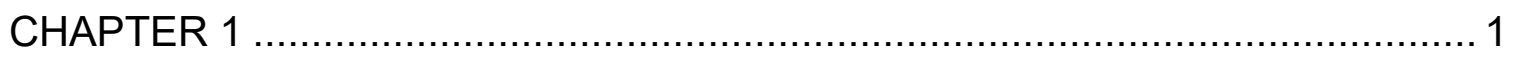

EARLY MATERNAL UNDER NUTRITION PROMOTES ADULT DISEASE .......... 2 MATERNAL NUTRITION DURING PREGNANCY AND CARDIOVASCULAR

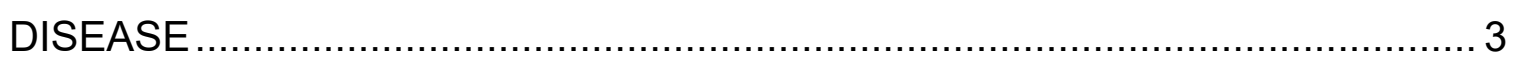

MATERNAL NUTRITION DURING PREGNANCY AND OBESITY .................... 5

MATERNAL NUTRITION DURING PREGNANCY AND GLUCOSE

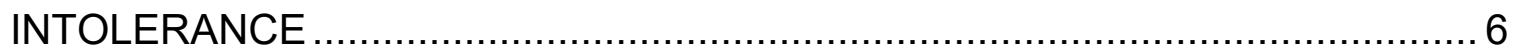

THE ROLE OF THE PLACENTA TO PROMOTE ADULT DISEASE .................. 8

COMPARISON BETWEEN THE MOUSE AND HUMAN PLACENTAE .............. 9

TIMING OF THE MATERNAL NUTRTION INSULT IS IMPORTANT ................. 12

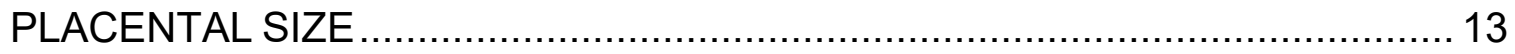

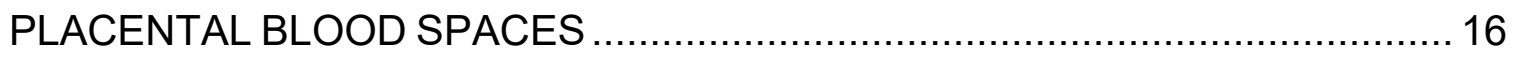

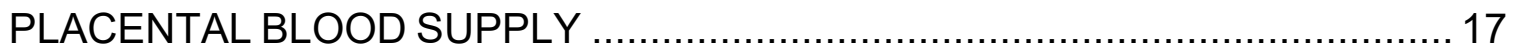

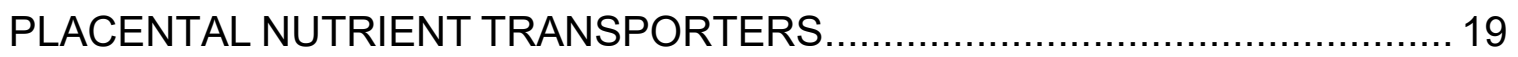

THE ROLE OF LEPTIN IN THE DEVELOPMENT OF ADULT DISEASES ..........22

MATERNAL NUTRITION AND DNA METHYLATION ................................... 25 


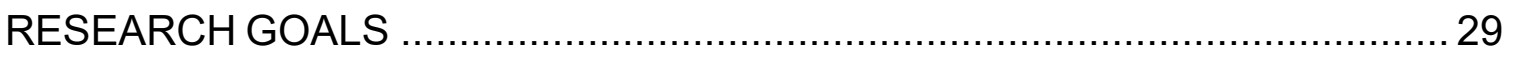

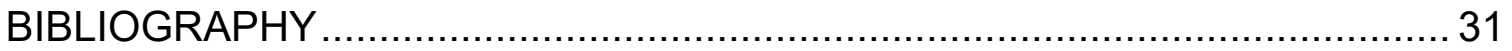

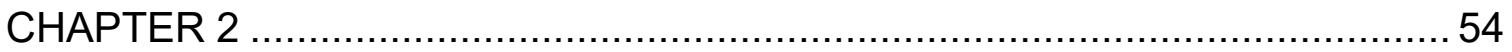

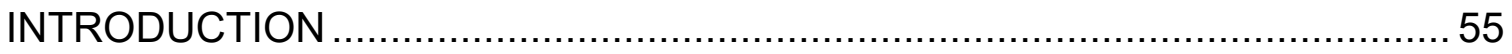

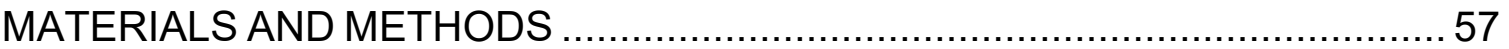

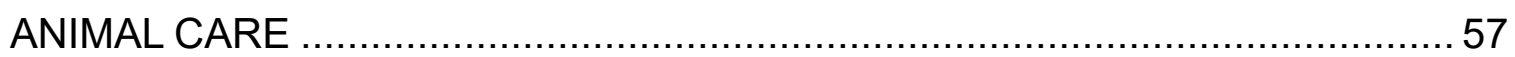

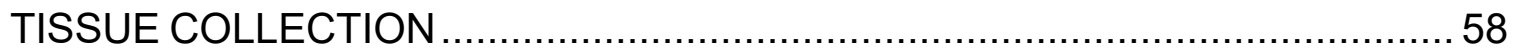

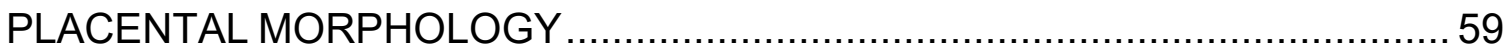

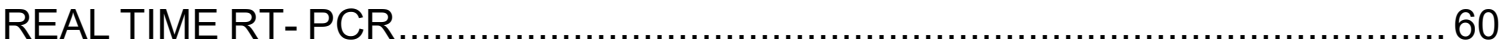

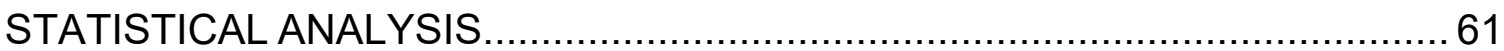

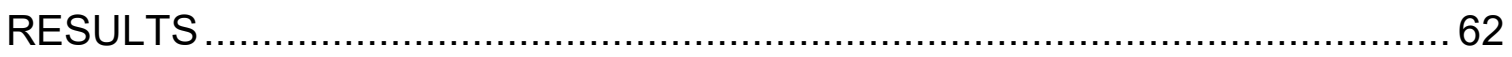

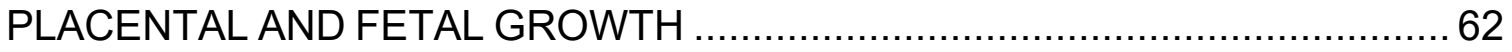

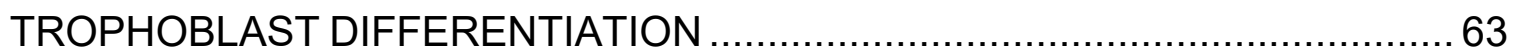

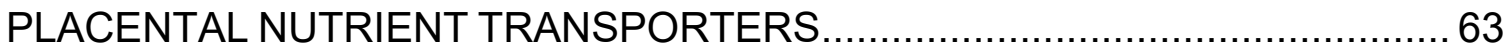

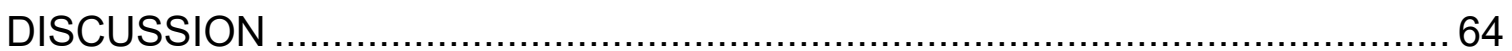

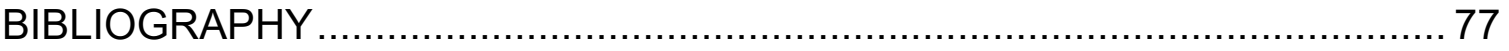

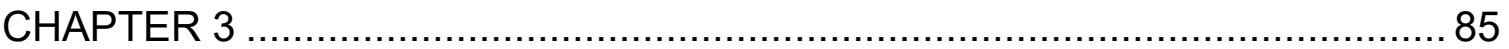

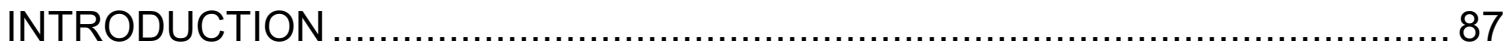

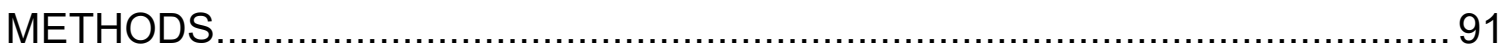

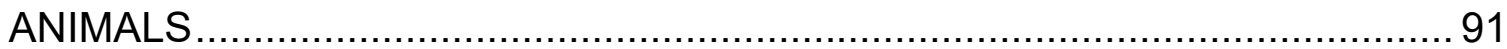

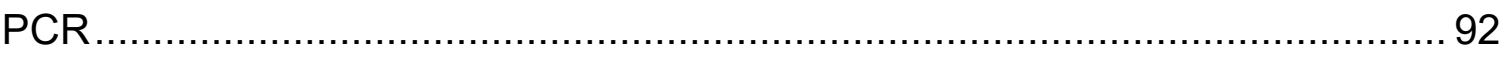


WHOLE GENOME DNA METHYLATION MICROARRAYS

IDENTIFICATION OF PATHWAYS ASSOCIATED WITH DIFFERENTIALLY

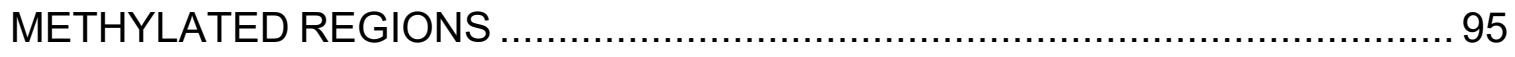

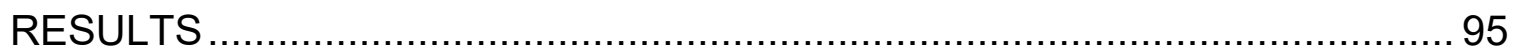

VALIDATION OF METHYLATED ISLAND RECOVERY ENRICHMENT ASSAY 95 IDENTIFICATION OF DIFFERENTIALLY METHYLATED REGIONS IN THE PLACENTAE AMONG CONTROL, RESTRICTED AND RESTRICTED + LEPTIN

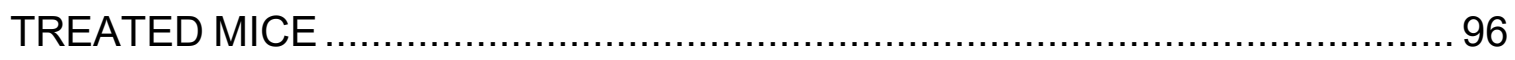
GENOMIC LOCALIZATION OF DIFFERENTIALLY METHYLATED REGIONS . 97 DIFFERENTIALLY METHYLATED PROMOTER REGIONS ….......................97 IDENTIFICATION OF PATHWAYS ASSOCIATED WITH DMRS ......................98

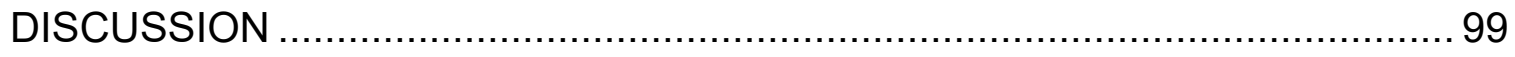

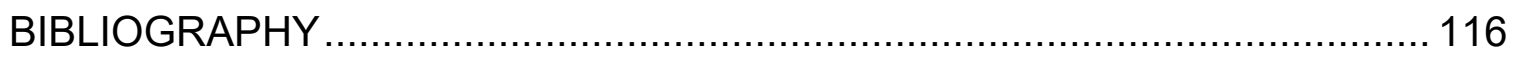

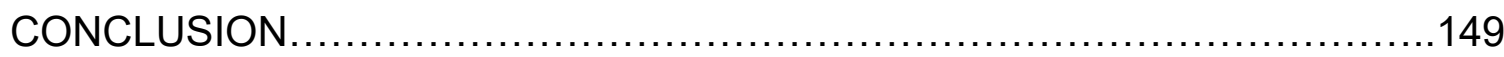

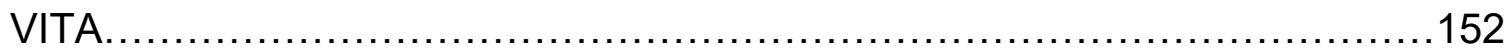




\section{LIST OF FIGURES}

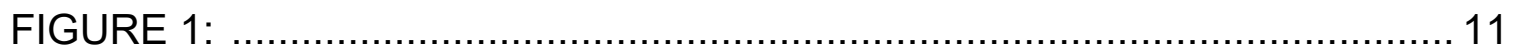

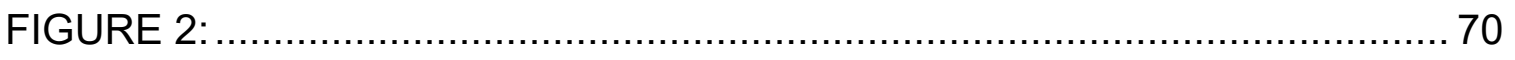

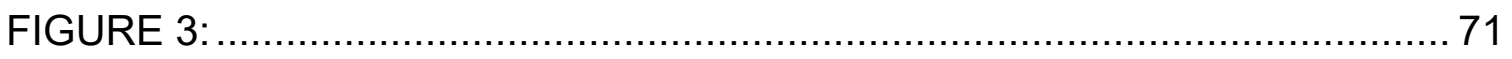

FIGURE 4:

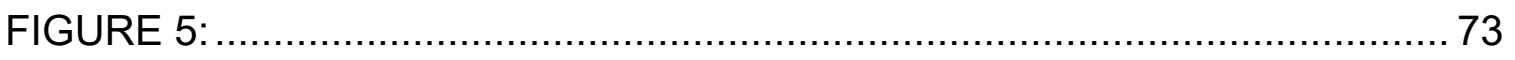

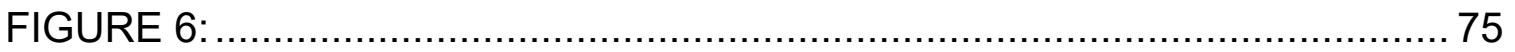

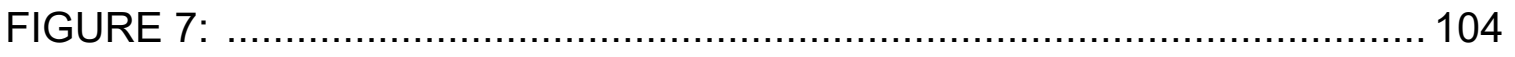

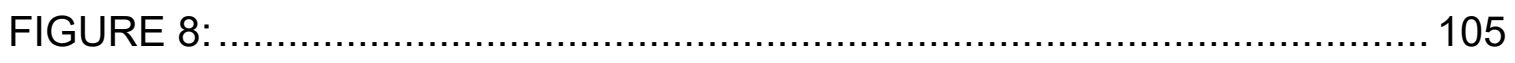

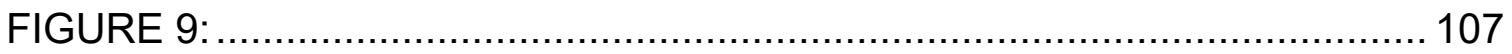

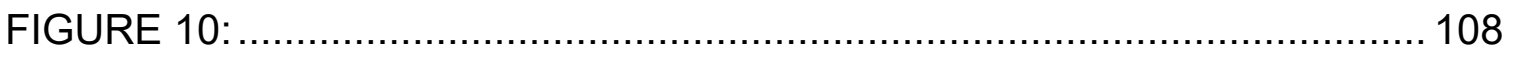

FIGURE 11:

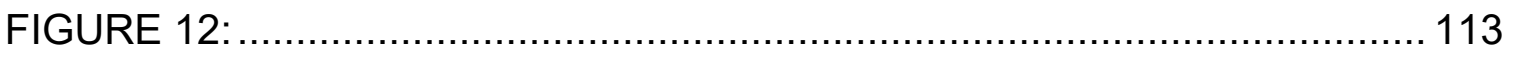

FIGURE 13:

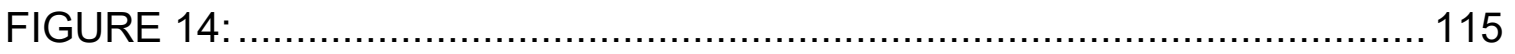




\section{LIST OF TABLES}

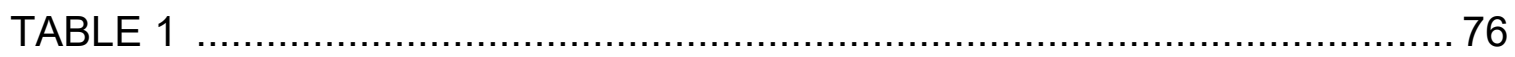

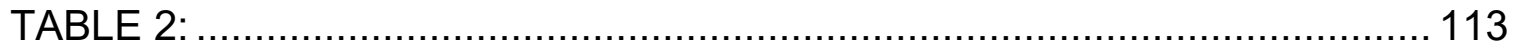

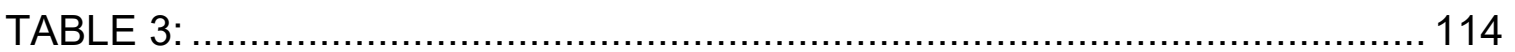

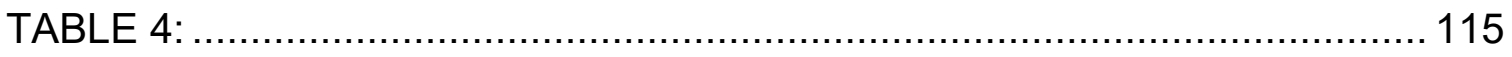




\section{ABSTRACT}

Chronic diseases such as cardiovascular disease and diabetes are on the rise among the U.S. population. Heart Disease is the leading cause of death in the US and is responsible 610,000 deaths per year. A suite of risk factors for cardiovascular disease and diabetes - obesity, elevated blood sugar, hypertension, excess cholesterol, and elevated triglycerides, referred to as Metabolic Syndrome, contributes to an increased risk of mortality. These too are increasingly prevalent. For example, according to the CDC, in 2011 more than 35 $\%$ of the U.S. population was obese, with a financial burden of US $\$ 147$ billion annually. Though improper diet, lack of exercise and socioeconomic status are associated with these adult diseases, inadequate maternal nutrition just prior to or during pregnancy is also a risk factor. The goal of my research is to identify the critical time point by which maternal under-nutrition (MUN) during early gestation permanently alters placental development, the mechanism by which this occurs, and whether leptin acts as a mediator.

The relationship between the maternal environment and long-term health of offspring is referred to as the developmental origins of health and disease $(\mathrm{DOHaD})$, or sometimes fetal programming. MUN during pregnancy may affect developing organs to alter the phenotypic outcome of the offspring to promote adult disease. The timing of the insult is also critical. During the periconceptional period and early gestation, there are major developmental processes such as embryonic organogenesis, and placenta formation. There are also two rounds of 
DNA methylation reprogramming that occur. I investigated the effects of maternal under-nutrition from three weeks prior to gestation to $\mathrm{d} 11.5$ (mid gestation in mice). I found that maternal periconceptional food restriction until mid- gestation affected formation of blood spaces within the labyrinthine placenta near term, as compared to those from control-fed dams. There was also a three-fold decrease in mRNA encoding SNAT4, an amino acid transporter, in restricted placentae. These changes in placentae from dams fed a nutrient restricted diet suggest some compensation to ensure adequate nutrients are available to the fetus for proper development.

I also examined the effects MUN undernutrition during the first half of gestation had on placental DNA methylation at late gestation and whether leptin would act as a mediator of these effects. It is not entirely understood how information about maternal nutrition is sensed by the placenta. Leptin, is a hormone that is secreted by fat tissue and plays a role in energy homeostasis, metabolism and reproduction. Therefore, it could be one potential mechanism by which maternal nutrition can influence placental function and in turn, fetal development. I found placentae from dams who experienced MUN and leptin supplementation had a greater number of differentially methylated regions compared to placentae from dams fed an adequate fed diet than did placentae of dams fed MUN only. Regions that were differentially methylated by maternal diet and/or leptin supplementation were located near genes in pathways involved in molecular transport and carbohydrate metabolism as well as postnatal growth, weight and body size, formation of new blood vessels during embryogenesis. 
These pathways suggest a link between maternal food deprivation and offspring's' growth, metabolism and formation of the cardiovascular system. 


\section{CHAPTER 1}

\section{REVIEW OF THE LITERATURE}

\section{DEVELOPMENTAL ORIGINS OF HEALTH AND ADULT DISEASE}

Chronic diseases such as cardiovascular disease and diabetes are on the rise among the U.S. population. Heart Disease is the leading cause of death in the US and is responsible for 610,000 deaths per year (CDC 2015). A suite of risk factors for cardiovascular disease and diabetes - obesity, elevated blood sugar, hypertension, excess cholesterol, and elevated triglycerides- is referred to as Metabolic Syndrome (MetS) and contributes to an increased risk of mortality and proves a burden to society. For example, according to the Center for Disease Control, in 2008 more than $30 \%$ of the U.S. population is obese, with a financial burden of US $\$ 147$ billion annually(Wolf 1998, Wolf and Colditz 1998, 2007). Though improper diet, lack of exercise and socioeconomic status(Forsdahl 1977, Barker, Forsen et al. 2001) are associated with an increased risk of these adult diseases, inadequate maternal nutrition just prior to or during pregnancy is also a risk factor(Uauy, Kain et al. 2011).

The relationship between the maternal environment and long-term health of offspring is referred to as the developmental origins of health and disease (DOHaD), or sometimes fetal programming. Barker and colleagues postulated 
that developing organs may be affected by an adverse in utero environment, such as maternal undernutrition, during pregnancy to alter the phenotypic outcome of the offspring to promote adult disease (Barker 1994). Timing of the insult is also critical (Schulz 2010). Studies show that alterations in nutrients during early pregnancy can result in offspring that are normal size at birth, with large placentae, high blood pressure and adult obesity, whereas offspring are born small if the nutritional insult occurred during late gestation(Barker, Bull et al. 1990, Barker, Godfrey et al. 1992).

Some have argued that these effects are a result of fetal adaptations to the uterine environment which prove maladaptive in the longer term. If a similar food deprivation is encountered by the offspring both pre- and postnatally, then this can be advantageous. If there is a bountiful supply of nutrients to the offspring postnatal, this predicted adaptive response may however prove deleterious to the offspring survival. (Gluckman and Hanson 2006). Others suggest the fetal response is maximized to short term survival at the expense of long term health or is simply a result of damage.

\section{EARLY MATERNAL UNDER NUTRITION PROMOTES ADULT DISEASE}

Some of the best evidence for the detrimental effects of maternal undernutrition during pregnancy, and particularly early pregnancy, on metabolic diseases later in life comes from epidemiological study of the Dutch Hunger Famine. The Dutch Hunger Famine spanned a five-month period from October 
1944 to May 1945. During this time, there was a blockage of supplies getting into the Netherlands including food. Prior to the famine, persons living there consumed on average $1800 \mathrm{kcal} /$ day. By November 1944, caloric intake had dropped to $1000 \mathrm{kcal} / \mathrm{day}$, and reached a low between $400-800 \mathrm{kcal} /$ day from December 1944 to April 1945. By June 1945, rations had returned to over 2000 kcal /day (Netherlands, Committee on et al. 1948). Though disastrous, this period provided the opportunity to study the long term deleterious effects maternal undernutrition had on offspring and adult health in a population of women who were previously well fed and only experienced famine for a short period of time. It was also5 possible to compare the effects of exposures at different stages of gestation. Offspring born between August $19^{\text {th }}$ and December $8^{\text {th }}, 1945$ were thought to be exposed to the famine in utero in early gestation, those born April $29^{\text {th }}$-August $18^{\text {th }}, 1945$ were considered exposed mid gestation and those born January $7^{\text {th }}-$ April $28^{\text {th }}, 1945$ late gestation (Ravelli, van Der Meulen et al. 1999). Maternal nutrition can influence the growth of fetal organs based on what is developing at the time of insult, which in turn can later determine adult health (Widdowson and McCance 1975).

MATERNAL NUTRITION DURING PREGNANCY AND CARDIOVASCULAR DISEASE

One class of outcome measure studied in relation to maternal undernutrition is cardiovascular disease. According to the Center for Disease 
Control, cardiovascular disease is the leading cause of death, that is, 1 in every 4 deaths that occur in the United States each year is due to heart disease(CDC 2015). The correlation between MUN during gestation and cardiovascular disease has been shown in several epidemiological studies (Barker, Osmond et al. 1989, Law, de Swiet et al. 1993, Campbell, Hall et al. 1996, Eriksson, Forsen et al. 2000, Roseboom, van der Meulen et al. 2000). One study found there was an increased risk of high blood pressure and it occurred at an earlier age in individuals born to a mother exposed to the Dutch Hunger Famine during early gestation as compared to those whose mothers were not exposed to the famine or as compared to their non-exposed, same sex siblings. Exposure during early gestation also doubled the likelihood of hypertension. (Painter, de Rooij et al. 2006). Exposure to the famine during any other period of gestation did not increase the odds of hypertension in adulthood (Roseboom, van der Meulen et al. 2000).

Animal studies also illustrated adverse in utero conditions such as a maternal restricted diet during critical periods of development increased the predisposition to disease as an adult, timing and nature of the insult are important. Rats exposed to a maternal protein restricted diet early in gestation indicated no changes in offspring development (Langley-Evans, Welham et al. 1999). A $30 \%$ total nutrient restricted diet throughout gestation, though, prompted an increased food consumption postnatally and high blood pressure in adulthood (Langley-Evans and Jackson 1995, Langley-Evans, Welham et al. 1999, Vickers, Breier et al. 2000). Likewise, a low protein diet throughout gestation followed by 
an adequate post-natal diet increased blood pressure in adulthood (Langley and Jackson 1994, Langley-Evans and Jackson 1995). On the contrary, maternal undernutrition during the latter part of gestation did not affect blood pressure in rat offspring(Holemans 1999). These data suggest an exposure to MUN increased susceptibility to the development of cardiovascular diseases with a greater effect on offspring's blood pressure if the insult occurred during early gestation.

\section{MATERNAL NUTRITION DURING PREGNANCY AND OBESITY}

Another parameter affected by maternal nutrition during pregnancy is the predisposition of offspring to obesity. It is estimated that by $2020,40 \%$ of the US population may be obese, which poses an economic burden of approximately $\$ 147-210$ billion per year on the nation (Kim and Basu 2016) and a decrease in work productivity because of absences due to illness (Trogdon, Finkelstein et al. 2008), with women being twice affected as men (Flegal, Kruszon-Moran et al. 2016). Though diet, sedentary lifestyle and genetics play a role in the increased chance of persons to obesity, an adverse maternal nutrition during pregnancy may permanently alter metabolism. Exposure to the Dutch Hunger Famine increased obesity rates in men at 19 years and women at 50 years (Ravelli, Stein et al. 1976, Ravelli, van Der Meulen et al. 1999). Exposure to MUN in early gestation predominantly affected women at age 50 . Women born to mothers exposed to a MUN diet during early gestation were more obese than women 
born to non-exposed mothers, whereas those born to women exposed during later gestational periods had normal weights (Lumey, Stein et al. 1995, Ravelli, van Der Meulen et al. 1999, Stein, Kahn et al. 2007).

Animal studies also supported the idea insults early in life influence obesity in adult offspring. Mice born to dams fed a low protein diet throughout pregnancy followed by a mismatched post-natal environment were heavier as adults versus those fed a normal diet through pregnancy(Ozanne, Lewis et al. 2004). A moderate, $70 \%$, maternal food restriction throughout pregnancy resulted in male pups lighter than controls; females were unaffected(Ozaki, Nishina et al. 2001). In like manner in our lab, alterations in maternal diet affected offspring body weight, however it was the females that were predominantly affected. Female mice born to dams who were fed a $50 \%$ total caloric restriction in the first half of pregnancy, followed by an adequate diet in the latter half of pregnancy weighed more and a high fat diet exacerbated this effect. Along with obesity and cardiovascular disease, a third outcome associated with maternal undernutrition is glucose intolerance.

\section{MATERNAL NUTRITION DURING PREGNANCY AND GLUCOSE INTOLERANCE}

In the Dutch Hunger Winter, when mothers were exposed to the famine during early gestation, the offspring displayed decreased glucose tolerance and increased insulin concentrations as adults. These impairments were especially 
apparent in offspring whose mothers were exposed to the famine during the mid and late gestation (Ravelli, van der Meulen et al. 1998, de Rooij, Painter et al. 2006, Lumey, Stein et al. 2009). In contrast to the obesity and cardiovascular effects of the Dutch Hunger Winter, offspring experienced glucose intolerance and an increased predisposition to diabetes as adults regardless of exposure period. Similar links between maternal undernutrition, reduced glucose tolerance and insulin insensitivity in adults have been seen in animal studies (Hales and Barker 1992). When offspring of rats fed an in utero nutrient restricted diet are fed an adequate or hyper caloric diet similar to the western diet postnatally, they had higher insulin levels (Vickers, Breier et al. 2000). Likewise, offspring of rats born to mothers fed a $50 \%$ food restricted diet throughout pregnancy had lowered insulin levels and were insulin resistant as compared to the their counterparts from mothers fed an adequate diet throughout pregnancy (Holemans, Verhaeghe et al. 1996). Offspring of rats born to mothers who experienced a maternal low protein diet throughout pregnancy exhibited decreased cell growth and pancreatic islet size, increased insulin levels and impaired glucose tolerance as adults (Snoeck, Remacle et al. 1990, Dahri, Snoeck et al. 1991, Iglesias-Barreira, Ahn et al. 1996). Much the same, rats born to dams fed a $30 \%$ nutrient restricted diet during pregnancy, followed by an adequate post-natal diet had increased insulin(Vickers, Breier et al. 2000). Animal studies also illustrated the programming effects whereby fetal exposure to maternal under nutrition in utero can permanently alter development to predispose the offspring to these metabolic diseases in later life (Bateson, 
Bateson et al. 1999). In rats, a 50\% maternal nutrient restricted diet during pregnancy promoted insulin insensitivity in female offspring (Holemans, Verhaeghe et al. 1996). This indicated the critical period whereby maternal environment influenced genotypic and phenotypic adaptations to result in long term consequences to adult health depended on the timing of what was being developed and the type of insult. Early gestation appeared to be the period most affected by this developmental plasticity. Another reason that insults during early pregnancy have such lasting impacts on offspring health may be that it is a period of active DNA demethylation and remethylation, a topic which will be discussed below.

\section{THE ROLE OF THE PLACENTA TO PROMOTE ADULT DISEASE}

The Placenta Adapts to Maternal Diet to Alter Fetal Growth and Promote Metabolic Disease in the Adult. While other organs are important, we focused on the placenta. The placenta is in contact with both the mother and fetus, and placental growth, which occurs mostly in early pregnancy, plays a critical role for fetal development, which occurs predominantly in later pregnancy. It acts as a site of gas exchange, nutrient delivery and hormone production, with rates of exchange based on its size, morphology, and blood supply (Myatt 2006). An unfavorable intrauterine environment has been linked to alterations in placental morphology, size, gene expression and DNA methylation to affect fetal growth 
and result in chronic adult diseases(Myatt 2006, Vambergue and Fajardy 2011, Gauster, Desoye et al. 2012).

The effects maternal nutrition has on placental development, and subsequently fetal and adult health, depends on the period during which this insult occurs. For example, exposure to the Dutch Hunger Famine in early gestation increased placental size, though with newborn size was comparable to offspring born prior to the famine. On the other hand, both placentae and newborns of women exposed to the famine in late gestation were smaller than the same sex non-exposed sibling (Lumey, Stein et al. 1995).

\section{COMPARISON BETWEEN THE MOUSE AND HUMAN PLACENTAE}

The placenta is one of the first organs to develop. Mice have short gestational periods and are relatively inexpensive making them an excellent animal model for reproductive physiological studies. Furthermore, based on similarities to the human placenta, the mouse placenta makes a suitable model to study placental development. The placentae in humans and rodents are both discoid and hemochorial with analogous cell types. The mouse placenta consists of three distinct structures: the maternal decidua, the junctional and the labyrinth zones. The maternal layer consists of uterine decidual cells and functions as a reservoir for cells, as well cells needed for invasion and attachment to the uterine wall. The decidua also serves as an immune barrier of sorts (Cross, Simmons et al. 2003) and transports blood to the implantation site. The mouse junctional 
zone layer consists of spongiotrophoblasts cells that functions for invasion into the uterine lining and attachment of the placenta to the uterus. The inner layer of the mouse placenta is the highly branched labyrinth, which is comprised of multinucleated syncytiotrophoblast cells that line the fetal blood spaces and mononuclear cells that line the maternal blood cells. It is responsible for the transfer of nutrients and exchange of gases between the mother and fetus (Rossant and Cross 2001).

One significant difference between human and rodent placentae lies in the numbers of layers separating the fetal blood from the maternal blood and as such acts as an influence on nutrient transfer and subsequently fetal growth. (Rossant and Cross 2001, Wooding and Fowden 2006). Other dramatic differences are that humans have predominantly single pregnancies whereas rodents bear litters, and humans have a considerably longer gestational period than the mice which has more postnatal development. From henceforth, the placenta will be referred to in terms of mouse placenta unless otherwise noted. 

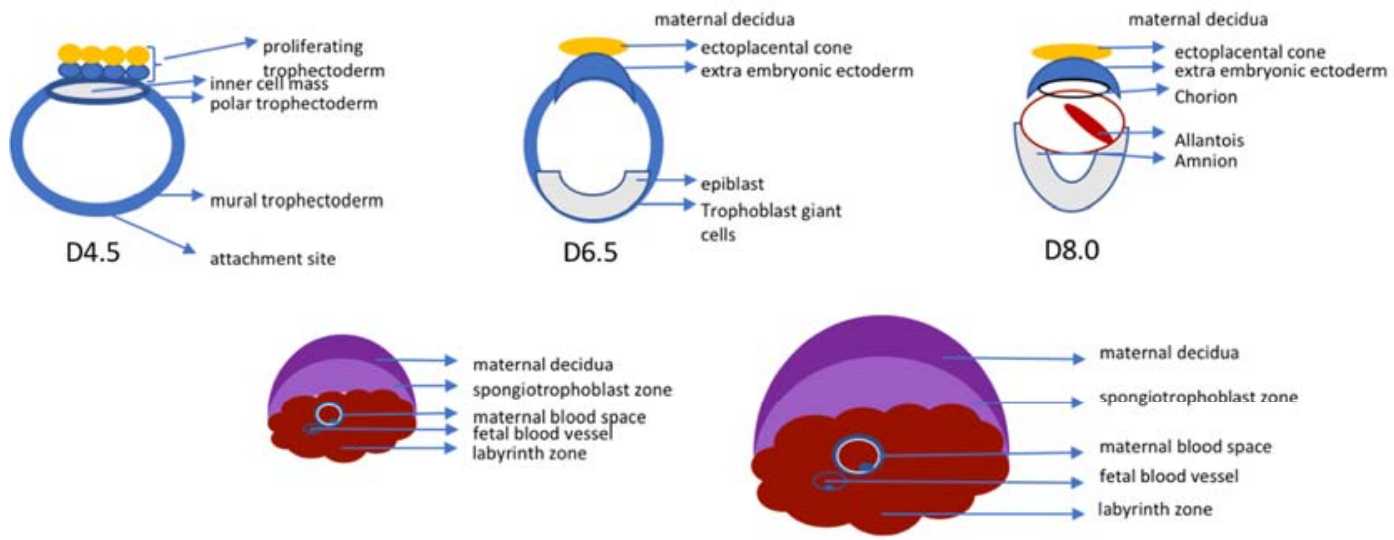

D11.5

D18.5

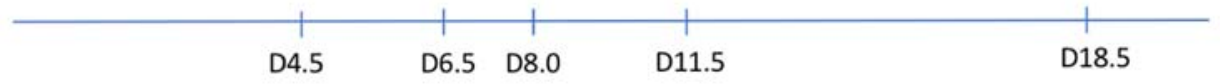

Figure 1: A Schematic of Mouse Placental Embryonic Development 
In mice, placental development begins at embryonic day (E) 3.5 with the formation of the trophectoderm and the inner cell mass which constituted of the blastocyst. Implantation begin at E4.5. Simultaneously, the mural trophectoderm (the side opposite the inner cell mass) of the blastocyst becomes primary trophoblast giant cells $(G C)$ and the polar trophectoderm (side touching the inner cell mass) give rise to (1) extraembryonic ectoderm and the (2) ectoplacental cone on d 8.0 (Copp 1979, Rossant and Cross 2001, Cross, Simmons et al. 2003). At E 8.5, the allantois, which was formed from the extraembryonic mesoderm, and the chorion combine to form the chorioallantoic attachment that is developed into a labyrinth of densely packed, interconnected, villous-like structures for the fetal exchange (E8.0-10.5). This layer becomes bigger and more villous by term (Adamson, Lu et al. 2002, Cross, Simmons et al. 2003). At E9.0, the villi within the labyrinth begins to be developed and branched. Gcm1, expressed in the distal part of the labyrinth, promotes the differentiation of chronic cells into the syncytiotrophoblast cells of the labyrinth. By E11.5, all the placental cells are present, and the placenta continues to increase in size until term.

TIMING OF THE MATERNAL NUTRTION INSULT IS IMPORTANT

While other organs adapted to changes in maternal diet during pregnant to alter fetal growth and promote metabolic disease in the adult, in this review we focused on the placenta. The placenta is in contact with both the mother and 
fetus. Placental growth which occurs mostly in early pregnancy plays a critical role for fetal development, which occurs predominantly in later pregnancy. It acts as a site of gas exchange, nutrient delivery and hormone production, with rates of exchange based on its size, morphology, and blood supply (Myatt 2006). An unfavorable intrauterine environment has been linked to alterations in placental morphology, size, gene expression and DNA methylation to affect fetal growth and result in chronic adult diseases(Myatt 2006, Vambergue and Fajardy 2011, Gauster, Desoye et al. 2012).

The effects maternal nutrition has on placental development, and subsequently fetal and adult health, depends on the period during which this insult occurs. For example, exposure to the Dutch Hunger Famine in early gestation increased placental size, though newborn size was comparable to offspring born prior to the famine. On the other hand, both placentae and newborns of women exposed to the famine in late gestation were smaller than the same sex non-exposed sibling (Lumey, Stein et al. 1995), indicating that timing of the insult is critical. Further results of placental response to the timing a maternal nutritional insult will be reviewed in detail below.

PLACENTAL SIZE

Epidemiological studies have linked an adverse maternal nutritional intake during pregnancy to the permanent adaptations the fetus made in utero which altered their metabolic status to increase their predisposition to adult disease. For 
example, offspring born to mothers exposed to a nutrient restricted diet during pregnancy have focused on the correlation between birth weight, a measure of a maternal nutrient deficient diet and offspring health outcomes as adults.

According to the Barker hypothesis, organs exposed to poor maternal nutrition during pregnancy may adapt its development to increase the offspring chances at survival(Barker 1990). Though advantageous for short term survival, these adaptations may have detrimental effects in the long term.

Studies indicated the organs affected by maternal food depravation and the long-term consequences on the offspring depends on what organ is growing during the period, the time of gestation food restriction occurred and the type of the nutrient insult. A maternal nutrient restricted diet, during the first trimester as seen in the infamous Dutch Hunger Famine, followed by an adequate fed diet in the latter half of pregnancy resulted in increased placental growth at term (Lunney 1998). Offspring of women exposed to the famine in the first trimester of pregnancy had heavier placentae at term as compared to women who experienced the famine in the mid to latter part of pregnancy or to those who were not exposed(Barker, Bull et al. 1990). On the other hand, children born to women exposed to the famine in the second or third trimester of pregnancy had decreased placental growth as compared to women who were exposed to the nutrient restricted diet in the first trimester or babies born to non-exposed women (Ravelli, van der Meulen et al. 1998). Offspring with increased placental weight at birth also had increased diastolic and systolic blood pressure as adults, suggestion they were hypertensive(Barker, Bull et al. 1990, Campbell, Hall et al. 
1996, Eriksson, Forsen et al. 2000). Smaller placentae, on the other hand, were associated with increased incidences of diabetes (Forsen, Eriksson et al. 2000). This substantiates that placenta morphology adapts to maternal diet during pregnancy to play a critical role in increasing the chances of the offspring to chronic adult disease.

Analogous to human studies, findings in animals demonstrated the placenta responded to a maternal environment which may later predispose the offspring to chronic diseases. In sheep, placental size increased at term of ewes fed a $50 \%$ nutrient restricted diet during early pregnancy (Heasman, Clarke et al. 1999). On the other hand, in rats, a maternal low protein diet reduced fetal and placental weights and labyrinth zone at term (Rutland, Latunde-Dada et al. 2007). Much the same, in mice, maternal undernutrition during pregnancy reduced placenta weight and junctional and labyrinth zones at term (Coan, Vaughan et al. 2010). Moreover, placentae from ewes feed a nutrient restricted diet during mid gestation and during late gestation were heavier at term as compared to the controls fed a maintenance diet (Faichney and White 1987, McCrabb, Egan et al. 1991). Offspring from ewes fed a restricted diet during mid gestation when there is more placental growth than fetal growth were larger. Conversely, if maternal nutrient restriction occurred during the third trimester, where there is mostly fetal growth, the fetuses were smaller (Faichney and White 1987). In rats, a maternal low protein diet throughout pregnancy increased placental weights and reduced fetal weights as well as placental efficiency(Levy and Jackson 1993). On the other hand, $70 \%$ total maternal food restriction prior 
to and during early gestation reduced placental weight, fetal exchange area, and maternal blood spaces guinea-pigs term placentae (de Rooij, Painter et al. 2006). In guinea pigs, $40 \%$ maternal nutrient restriction in the latter half of pregnancy from d25-65 resulted in a lighter placental, as well as labyrinth zone reduction at term (Dwyer, Madgwick et al. 1992). Studies across several species associate placental growth with fetal growth with a smaller placenta being less efficient at transporting nutrients to fetus (Jones 1976, Saintonge and Rosso 1981). These aberrant changes seen by the placenta indicate that not just timing of the insult, but the types of insult are important.

\section{PLACENTAL BLOOD SPACES}

Maternal nutrient restriction during pregnancy is associated with changes in metabolism which is also linked to nutrient transfer and fetal growth. This relationship between the fetus permanently adapting to an in-utero environment and adult diseases, is not influenced only by an adverse maternal diet, but maternal and fetal blood spaces, reduced placental blood flow(Garris 1983), and nutrient transfer across the placenta as well. Maternal and fetal blood spaces are important to proper placental development and nutrient transfer. Cited1 is required for placental development, and embryo growth and survival. In mutants lacking Cited1, there is a reduced labyrinth and increased maternal blood spaces which left less labyrinth surface area and resulted in a reduction in nutrient transfer. Comparably a small labyrinth exhibits a reduction in fetal blood spaces 
suggesting changes in nutrient transport. (Mercer, Hoggard et al. 1996, Rodriguez, Sparrow et al. 2004).

Maternal nutrient restricted diet during pregnancy altered placental morphology to change the function of the placenta. For example, in guinea pigs, a severe maternal nutrient restricted diet resulted in a reduction of maternal blood spaces. The total placental and fetal exchange area were also reduced, signifying a (Roberts, Sohlstrom et al. 2001). Likewise, in the mouse, extreme maternal food depravation resulted not only a reduction in maternal blood spaces, but placental weight and junctional zone indicating the placental adapts to maternal in utero environment (Coan, Vaughan et al. 2010). Similar results were seen in mice fed a maternal low protein diet. There was a reduction in maternal and fetal blood spaces, as well as placental weight, suggesting changes in placental vascular function which can play a role in developing metabolic diseases such as hypertension in later life. (Rutland, Latunde-Dada et al. 2007). This data suggests that poor maternal nutrition altered placental blood spaces which influenced the exchange area of the placenta needed for nutrient transport to alter fetal growth and result in an increased chance of the offspring developing adult disease.

\section{PLACENTAL BLOOD SUPPLY}

Nutrient transport to the fetus across the placenta in controlled by placental blood supply. Babies born small for gestational age displayed impaired 
placental blood flow(Pardi, Cetin et al. 1993) In the mouse, fetal and maternal blood flow in opposite directions to each other to increase nutrient transfer. This placental blood supply can be influenced by maternal diet to affect fetal growth and metabolism. The development of the fetal heart also is linked with placental blood flow, suggesting that changes in placental blood supply could have an adverse outcome the offspring cardiovascular system. In ewes, manipulating the placenta to limit blood supply resulted in smaller fetuses and a reduction in glucose, and amino acids, thus demonstrating the ability of the placenta blood supply to regulate nutrient availability and therefore fetal growth. Mice fed a low protein diet experienced reduction in placental blood supply, maternal blood spaces and fetal capillaries, as well as altered nutrient transport (Jansson and Powell 2007). Contrarily in the pigs, low protein diet is associated with an increase in fetal blood vessels and the efficiency of the placenta to transport nutrients to the fetus(Vonnahme and Ford 2004). This evidence suggests the morphology of the placenta is not only associated with nutrient transport, but subsequent fetal growth. In sheep, over nutrition throughout pregnancy resulted in reduced placental blood flow, and glucose and amino acids thus limiting fetal growth(Wallace, Aitken et al. 2004). These studies indicated maternal diet influenced placenta blood supply and the fetus adapted its metabolism to alter fetal growth. 


\section{PLACENTAL NUTRIENT TRANSPORTERS}

The placenta is responsible for the transport of nutrients to the fetus. Some of the nutrients is also utilized by the placenta for growth and development(Fowden, Sferruzzi-Perri et al. 2009). Most of fetal growth occurs in the latter half of gestation where the placenta becomes more vascular and increases blood flow to enhance the transport of nutrients to the fetus for proper growth (Fowden, Forhead et al. 2008). The fetal size of the placenta also adapts its morphology by increasing the number of blood spaces to facilitate transport of nutrients to the fetus. (Coan, Ferguson-Smith et al. 2004, Coan, Ferguson-Smith et al. 2005, Mayhew 2009). In mice, smaller placentae have a large labyrinth zone which increases surface area to optimize nutrient transport and maximize fetal growth(Coan, Angiolini et al. 2008). Instances of a maternal restricted diet results in the labyrinth being protected, that is, no alterations in size, however the junctional zone of the placental becomes smaller(Coan, Vaughan et al. 2010). Taken together this indicates alterations in the placenta alters nutrient transport to influence offspring growth and development.

Fetal growth depends on this supply of nutrients such as glucose, amino acids and lipids which are obtained from the maternal diet. In times of food depravation, the fetus alters its metabolism. Maternal food depravation in the sheep during pregnancy resulted in amino acid synthesis instead of glucose metabolism(Tsoulos, Colwill et al. 1971). Thaler et al. determined in rats, low maternal food intake during pregnancy correlated with increased lipid metabolism 
(Thaler 1972). Glucose, amino acids and lipids cross the placenta, though they are often times higher in the fetus than on the maternal side. Glucose is a major nutrient needed for fetal growth and its supply to the fetus is regulated by the placenta. Amino acids are the building blocks and have been shown to be needed for glucose synthesis lipid production and respiration in the sheep (Tsoulos, Colwill et al. 1971, Gresham, James et al. 1972). These substances rely on their transporters, located in the plasma membrane to cross the fetalplacental barrier and is regulated by maternal nutrient supply.

The placenta responds to maternal diet by altering transport of nutrients needed for fetal growth. One way in which it does this is by altering expression of glucose transporters. Two of the main glucose transporters across the placenta are glucose transporter 1 (GLUT1) /SIc2a1 and glucose transporter 3 (GLUT3)/SIc2a3 (Barros, Yudilevich et al. 1995). GLUT1 is expressed in the labyrinth and primarily the junction zones (Zhou and Bondy 1993, Boileau, Mrejen et al. 1995) with diminishing expression near term (Zhou and Bondy 1993). GLUT3, expressed in the labyrinth zone and is responsible for the transfer of glucose from the mother to the fetus. (Zhou and Bondy 1993, Boileau, Mrejen et al. 1995). For example, in ewes, maternal food depravation during early to mid-pregnancy, followed by an adequate diet for the latter half of pregnancy resulted in increased GLUT1 transport and a larger placenta and fetus. However, a maternal nutrient restricted diet fed in the latter half of pregnancy had no impact on glucose transport. This indicated alterations in maternal diet resulted in 
changes in nutrient transport which may lead to changes in fetal development and offspring growth (Dandrea, Wilson et al. 2001).

Another class of placental nutrient transporters influenced by maternal diet are the approximately 15 amino acid transporters that concentrate amino acids in the fetal circulation. Amino acid transport is regulated in part by system A (SNAT1, SNAT2 and SNAT4, and system L (LAT1 and LAT2) transporters ), which transport neutral amino acids such as glutamine, glycine, serine and alanine (Cleal and Lewis 2008). Rats given a 50\% nutrient restriction in late gestation had decreased expression of SNAT2/ Slc38a2 (Lesage, Hahn et al. 2002), whereas mice fed a severe nutrient restricted diet during most of pregnancy had increased in the amount SNAT2 in the fetus, suggesting there was an increase in placental efficiency in transporting nutrients to the fetus (Coan, Vaughan et al. 2010) but reduced SNAT4 expression (Coan, Vaughan et al. 2010, Coan, Vaughan et al. 2011). Maternal high fat diet increased amino acid transport by SNAT 2, though the SNAT3 and SNAT4 isoforms of the amino acid transporter remained unchanged, (Jones, Woollett et al. 2009). In multiple studies, a maternal low protein diet during pregnancy decreased system A amino acid transport which reduced the ability of the placenta to foster fetal growth (Coan, Vaughan et al. 2011). (Jansson, Pettersson et al. 2006, Rosario, Jansson et al. 2011), as well as system $L$ amino acid transporters LAT1 and LAT2(Rosario, Jansson et al. 2011). From this it can be concluded that based on the type and severity of maternal diet changes, amino acid transport may be altered to either promote or restrict fetal growth. 
Fatty acids, for example, docosahexanoic acid (DHA) is need for proper fetal development such as the formation of cellular membranes. Maternal food deprivation increases the amount of fatty acids transported to the fetus across the placenta from the maternal circulation(Widdowson 1974). Fatty acid transporters: fatty acid translocase (FAT/CD36), plasma membrane fatty acid binding protein (FABPpm), fatty acid transport protein (FATP) and intracellular FABPs are found in the placenta and are thought to be mainly protein mediated mechanisms. SREBP-1 is a transcription factor activated by fatty acid and control fatty acid transport and placenta functions (Campbell, Bush et al. 1998, Duttaroy 2009). There is a decrease of DHA in babies born small for gestational age, suggesting fatty acid transport is impaired leading to neural and vascular impediments in the offspring (Cetin, Giovannini et al. 2002). Maternal diet supplemented with DHA resulted in increased expression of fatty acids transporters in the placenta (Larque, Krauss-Etschmann et al. 2006). Further, placentae of women with gestational diabetes had an upsurge of DHA, suggesting an increase uptake of fatty acids, however transport across the syncytiotrophoblast to the fetus was impaired (Bitsanis, Ghebremeskel et al. 2006). These data indicate the placenta responds to the transport of fatty acids.

\section{THE ROLE OF LEPTIN IN THE DEVELOPMENT OF ADULT DISEASES}

It is not entirely understood how information about maternal nutrition is sensed by the placenta, resulting in the functional changes summarized above. 
Leptin, a 16KD protein, plays a role in energy homeostasis, metabolism and reproduction. It is secreted by white adipose tissue(Cinti, Frederich et al. 1997, Margetic, Gazzola et al. 2002), in direct proportion to the amount of fat mass (Maffei, Halaas et al. 1995, Considine, Sinha et al. 1996, Klein, Coppack et al. 1996). Leptin deficient mice are obese (Tritos and Mantzoros 1997),diabetic, have reduced metabolic activity and are infertile. Supplementation of exogenous leptin reduced body weight, glucose levels, and triglyceride levels, increased metabolic activity and lipid oxidation (Pelleymounter, Cullen et al. 1995, Kolaczynski, Considine et al. 1996) (Shimabukuro, Koyama et al. 1997)and restores reproduction (Chehab, Lim et al. 1996). However, people who are obese are usually leptin resistant (Maffei, Halaas et al. 1995, Considine, Sinha et al. 1996), leading to a positive correlation between obesity, insulin and leptin levels (Havel, Kasim-Karakas et al. 1996).

Leptin may act as a mediator by which maternal nutrition signals the offspring to alter metabolic phenotype. Leptin levels fall during a nutrient restricted diet (Ahima, Prabakaran et al. 1996, Chan, Heist et al. 2003) whereas, over-nutrition increase leptin levels (Kolaczynski, Considine et al. 1996, Kolaczynski, Ohannesian et al. 1996, Flier 1997). Rats born to dams fed a 30\% nutrient restricted diet during pregnancy, followed by an adequate post-natal diet had increased leptin, suggesting maternal nutrition and leptin play a key role in the adaptions of the fetus to the intrauterine environment. Moreover, these rats exhibited hypertension and insulin resistance, which linked the effects of 
maternal diet to have long lasting consequences of offspring metabolic health and suggested leptin acts as a regulator.

These studies proposed a role for leptin to regulate body weight by decreasing food satiety and energy expenditure (Halaas, Gajiwala et al. 1995). The hormone leptin exerts its action via neuropeptide $Y$ (NPY) in the hypothalamus to decrease satiety, insulin and metabolism (Stephens, Basinski et al. 1995). Leptin is regulated primarily by the hypothalamus(Lee, Proenca et al. 1996, Mercer, Hoggard et al. 1996) and signals predominately through the long form, LepRb via the JAK-STAT (Baumann, Morella et al. 1996, Ghilardi, Ziegler et al. 1996, Rosenblum, Tota et al. 1996, Vaisse, Halaas et al. 1996), PI3 Kinase (mTOR) (Maroni, Bendinelli et al. 2005) and Erk1/2 pathways. Due to alternative splicing, the leptin receptor has six isoforms, LepRa-LepRf (Peelman, Zabeau et al. 2014). While the short forms of the isoforms, regulate transport (Lee, Proenca et al. 1996, Bjorbaek, Elmquist et al. 1998).

Leptin's action is also exerted on the placenta. In humans, leptin is produced by the placenta (Masuzaki, Ogawa et al. 1997). Leptin receptors are also found in the placenta (humans: (Castellucci, De Matteis et al. 2000, Challier, Galtier et al. 2003). During pregnancy leptin levels increased (Henson, Swan et al. 1998, Sivan, Whittaker et al. 1998), in humans and peaked in late second/early third trimester then plateaued until gestation (Stock, Sande et al. 1999). In mice, there was a positive correlation between leptin level and fetal weight, which indicated a role in fetal growth. On the other hand, maternal leptin level had an inverse relationship to placental weight which signified a role for 
leptin to regulate placental weight(Schubring, Kiess et al. 1997). Because of its elevated concentration during pregnancy, its role as an indicator of energy homeostasis, and its actions in the placenta, leptin is one mechanism by which maternal nutrition can influence placental function and in turn, fetal development.

\section{MATERNAL NUTRITION AND DNA METHYLATION}

Human and animal studies indicated early pregnancy is a critical period by which maternal nutrition influenced fetal growth and adult development. During this period, major developmental processes such as embryonic organogenesis, placenta formation and two rounds of DNA methylation occur. During embryonic stages of development, the fetus can make permanent adaptations to an adverse in utero environment by a phenomenon known as developmental programming or the Barker's Hypothesis (Barker, Eriksson et al. 2002, Gillman 2005, Gluckman, Hanson et al. 2009), and this may be influenced by epigenetics (Holliday and Pugh 1975). Epigenetics literally means "above genetics" and today is most commonly defined as heritable changes that occur without changing DNA nucleotide sequence and are thus reversible in the mammalian genome (Goldberg, Allis et al. 2007, Zhu 2009).

DNA methylation is one of the most studied epigenetic mechanisms. It is regulated by enzymes called DNA methyltransferases (DNMTs) (Herman and Baylin 2003, Seki, Williams et al. 2012). DNMT1 maintained methylation by adding a methyl group to a hemi methylated strand during replication( $\mathrm{Li}$, Bestor 
et al. 1992). DNMT3A and DNMT3B are responsible for de novo methylation; that is, they add methylation to places where there are no methyl marks (Okano, Xie et al. 1998). The DNMTs transfer a methyl group from S-adenosylmethionine to the $5^{\text {th }}$ carbon of a cytosine ring in the DNA. The methyl group in Sadenosylmethionine is obtained from diet. (Smith and Meissner 2013). CpG islands are located within gene regulatory regions such as promoters and are typically unmethylated.(Deaton and Bird 2011). Typically, increased methylation in promoter $\mathrm{CpG}$ islands is associated with gene repression, whereas decreased methylation is associated with gene expression (Bird 1986, Reik and Dean 2001). CpGs outside of the promoter region, such as those in exons, intergenic DNA, coding regions and repeat elements are usually methylated and these CpGs are thought to aid in maintaining the genome

During the life cycle, there are dramatic shifts in DNA methylation. There are two cycles of genome wide reprogramming of DNA methylation: genome wide erasure of DNA methylation occurs in primordial germ cells, which is then re-established in a sex-specific way (Smith and Meissner 2013). Secondly, within eight hours of embryo formation there is active global demethylation of the paternal genome (Mayer, Niveleau et al. 2000), with the paternal genome also undergoing histone modification (Morgan, Santos et al. 2005), (Li 2002). (Mayer, Niveleau et al. 2000, Santos, Hendrich et al. 2002). On the other hand, Demethylation of the maternal genome occurs passively over the first few rounds of cell cleavage (Wolf, Jolly et al. 1984). Imprinted genes escape these demethylation events. Prior to implantation, a second major DNA methylation 
event occurs. New / de novo methylation occurs after implantation by DNA methyltransferase (DNMT) 3a/3b and DNMT3L (Sasaki and Matsui 2008). This new methylation is important for fetal development, is maintained throughout adult life in the new organism and affects the health of the adult (Okano, Bell et al. 1999).

This demethylation and remethylation processes provides a window during which DNA methylation levels can be influenced by maternal nutrition. Alterations in epigenetic regulation during this critical period of development may affect fetal development and later the health of the adult (Dolinoy, Das et al. 2007). For example, maternal diet during pregnancy altered DNMT expression and DNA methylation status which correlated with change in offspring phenotype(Lillycrop, Slater-Jefferies et al. 2007). Several studies have linked maternal nutrition during pregnancy to altered tissue specific DNA methylation which affected offspring phenotype (Rees, Hay et al. 2000, Cooney, Dave et al. 2002, Waterland and Jirtle 2003, Lillycrop, Phillips et al. 2005, Waterland, Dolinoy et al. 2006, Burdge, Slater-Jefferies et al. 2007, Lillycrop, Phillips et al. 2008). Epidemiology studies of children born to mothers who experienced the1945 Dutch Hunger famine during their first 10 weeks of pregnancy indicated DNA hypomethylation of insulin growth factor 2 (IGF2) gene (Heijmans, Tobi et al. 2008) and an increase susceptibility to cardiovascular disease and obesity as compared to their same sex siblings who were not exposed to the famine. On the other hand, exposure to the famine during late gestation was not associated with alteration of the IGF2 gene, indicating timing of exposure is critical and that early 
gestation is the crucial period by which DNA methylation may be prone to reprogramming (Heijmans, Tobi et al. 2008). Likewise, animal studies illustrate DNA methylation can influenced by maternal diet to increase the chances of offspring developing metabolic diseases (Waterland and Jirtle 2003, Sinclair, Allegrucci et al. 2007).

DNA methylation is also important for proper placental development passive DNA demethylation, resulted in reduced giant cells, placental weight and labyrinth zone area, cell proliferation and invasion (Vlahovic, Bulic-Jakus et al. 1999, Rahnama, Shafiei et al. 2006, Serman, Vlahovic et al. 2007). Homozygous deletion of DNMT3L in mice altered junctional and labyrinth zone formation and led to chorionallontoic fusion defects (Arima, Hata et al. 2006). Globally, there is more DNA methylation in the embryo as compared to the placenta (Santos, Hendrich et al. 2002). This includes specific genes known to function in placental growth, like IGF2, which is hypomethylated in the placenta compared to adult tissues, whereas it is normally methylated in neonatal blood (Guo, Choufani et al. 2008). Thus, DNA methylation plays key roles in placental structural development and gene expression.

Though previous studies have examined the effects of maternal caloric restriction on DNA methylation on offspring, few have studied the effects on placental DNA methylation. Banister et al found a correlation between changes in placental DNA methylation and babies who were small for gestational age, signifying that placental DNA methylation could alter fetal development (Banister, Koestler et al. 2011). No studies have examined whether maternal undernutrition 
limited to early gestation, when there is massive DNA reprogramming, and organogenesis occurring, affected placental DNA methylation through the remainder of pregnancy.

These evidences illustrated maternal food restriction during early pregnancy, followed by adequate nutrients later in gestation predisposed the offspring to metabolic diseases as adults and DNA methylation may be the possible mechanism by which this occurred.

\section{RESEARCH GOALS}

It is imperative to elucidate the mechanism by which an adverse intrauterine environment influenced offspring health to have long lasting consequences such as diabetes, obesity and cardiovascular diseases as adults. Human epidemiological studies demonstrated maternal food deprivation as a key contributing factor to development of metabolic diseases in adults. Evidence also indicated that maternal diet altered placental epigenetics, which in turn may have led to adaptations in placental size, morphology, gene expression, and nutrient transfer to influence fetal growth and subsequently adult health of offspring, thereby predisposing them to metabolic diseases.

Further elucidation is needed in understanding the mechanism by which changes in the maternal diet and in utero environment could have on placental development and consequently long-lasting effects on adult health. Studies are needed to determine the specific CpG loci which responded to maternal food 
restriction to alter placental DNA methylation and structural development. Understanding the mechanism by which maternal nutrition alter placental development would aid scientists in possibly using the placental as a tissue to identify key biomarkers to predict adult disease. The goal of my research is to identify the critical time point by which maternal under-nutrition (MUN) during early gestation permanently alters placental development, the mechanism by which this occurs, and whether leptin acts as a mediator. The aim of my first study is to investigate the effects of maternal under-nutrition from three weeks prior to gestation to d 11.5 (mid gestation in mice). Studies show, maternal diet prior to pregnancy altered offspring health outcome and epigenetic mechanism to increase their likelihood to develop adult diseases and altered the epigenetic mechanism (Sinclair, Allegrucci et al. 2007). The aim of my second study is to examine the effects MUN undernutrition during the first half of gestation had on placental DNA methylation at late gestation and whether leptin would act as a mediator of these effects. It is not entirely understood how information about maternal nutrition is sensed by the placenta. Leptin, is a hormone that is secreted by fat tissue and plays a role in energy homeostasis, metabolism and reproduction. Therefore, it could be one potential mechanism by which maternal nutrition can influence placental function and in turn, fetal development. 


\section{BIBLIOGRAPHY}

(2007). The Surgeon General's Call to Action To Prevent and Reduce Underage Drinking. Rockville (MD).

Adamson, S. L., Y. Lu, K. J. Whiteley, D. Holmyard, M. Hemberger, C. Pfarrer and J. C. Cross (2002). "Interactions between trophoblast cells and the maternal and fetal circulation in the mouse placenta." Dev Biol 250(2): 358-373. Ahima, R. S., D. Prabakaran, C. Mantzoros, D. Qu, B. Lowell, E. Maratos-Flier and J. S. Flier (1996). "Role of leptin in the neuroendocrine response to fasting." Nature 382(6588): 250-252.

Arima, T., K. Hata, S. Tanaka, M. Kusumi, E. Li, K. Kato, K. Shiota, H. Sasaki and N. Wake (2006). "Loss of the maternal imprint in Dnmt3Lmat-/- mice leads to a differentiation defect in the extraembryonic tissue." Dev Biol 297(2): 361-373. Banister, C. E., D. C. Koestler, M. A. Maccani, J. F. Padbury, E. A. Houseman and C. J. Marsit (2011). "Infant growth restriction is associated with distinct patterns of DNA methylation in human placentas." Epigenetics 6(7): 920-927. Barker, D. J. (1990). "The fetal and infant origins of adult disease." BMJ 301(6761): 1111.

Barker, D. J., A. R. Bull, C. Osmond and S. J. Simmonds (1990). "Fetal and placental size and risk of hypertension in adult life." BMJ 301(6746): 259-262. Barker, D. J., J. G. Eriksson, T. Forsen and C. Osmond (2002). "Fetal origins of adult disease: strength of effects and biological basis." Int J Epidemiol 31(6): 1235-1239. 
Barker, D. J., T. Forsen, A. Uutela, C. Osmond and J. G. Eriksson (2001). "Size at birth and resilience to effects of poor living conditions in adult life: longitudinal study." BMJ 323(7324): 1273-1276.

Barker, D. J., K. M. Godfrey, C. Osmond and A. Bull (1992). "The relation of fetal length, ponderal index and head circumference to blood pressure and the risk of hypertension in adult life." Paediatr Perinat Epidemiol 6(1): 35-44.

Barker, D. J., C. Osmond and C. M. Law (1989). "The intrauterine and early postnatal origins of cardiovascular disease and chronic bronchitis." $\underline{\mathrm{J} \text { Epidemiol }}$ Community Health 43(3): 237-240.

Barker, D. J. P. (1994). "Mothers, Babies and Disease in Later Life."

Barros, L. F., D. L. Yudilevich, S. M. Jarvis, N. Beaumont and S. A. Baldwin (1995). "Quantitation and immunolocalization of glucose transporters in the human placenta." Placenta 16(7): 623-633.

Bateson, P., P. P. G. Bateson and P. R. Martin (1999). Design for a life: how behaviour develops, Jonathan Cape.

Baumann, H., K. K. Morella, D. W. White, M. Dembski, P. S. Bailon, H. Kim, C. F. Lai and L. A. Tartaglia (1996). "The full-length leptin receptor has signaling capabilities of interleukin 6-type cytokine receptors." Proc Natl Acad Sci U S A 93(16): 8374-8378.

Bell, A. W., W. W. Hay, Jr. and R. A. Ehrhardt (1999). "Placental transport of nutrients and its implications for fetal growth." J Reprod Fertil Suppl 54: 401-410. Bird, A. P. (1986). "CpG-rich islands and the function of DNA methylation." Nature 321(6067): 209-213. 
Bitsanis, D., K. Ghebremeskel, T. Moodley, M. A. Crawford and O. Djahanbakhch (2006). "Gestational diabetes mellitus enhances arachidonic and docosahexaenoic acids in placental phospholipids." Lipids 41(4): 341-346. Bjorbaek, C., J. K. Elmquist, P. Michl, R. S. Ahima, A. van Bueren, A. L. McCall and J. S. Flier (1998). "Expression of leptin receptor isoforms in rat brain microvessels." Endocrinology 139(8): 3485-3491. Boileau, P., C. Mrejen, J. Girard and S. Hauguel-de Mouzon (1995). "Overexpression of GLUT3 placental glucose transporter in diabetic rats." $\underline{\mathrm{J} \text { Clin }}$ Invest 96(1): 309-317.

Burdge, G. C., J. Slater-Jefferies, C. Torrens, E. S. Phillips, M. A. Hanson and K. A. Lillycrop (2007). "Dietary protein restriction of pregnant rats in the F0 generation induces altered methylation of hepatic gene promoters in the adult male offspring in the F1 and F2 generations." Br J Nutr 97(3): 435-439. Campbell, D. M., M. H. Hall, D. J. Barker, J. Cross, A. W. Shiell and K. M. Godfrey (1996). "Diet in pregnancy and the offspring's blood pressure 40 years later." Br J Obstet Gynaecol 103(3): 273-280.

Campbell, F. M., P. G. Bush, J. H. Veerkamp and A. K. Dutta-Roy (1998). "Detection and cellular localization of plasma membrane-associated and cytoplasmic fatty acid-binding proteins in human placenta." Placenta 19(5-6): 409-415.

Castellucci, M., R. De Matteis, A. Meisser, R. Cancello, V. Monsurro, D. Islami, R. Sarzani, D. Marzioni, S. Cinti and P. Bischof (2000). "Leptin modulates 
extracellular matrix molecules and metalloproteinases: possible implications for trophoblast invasion." Mol Hum Reprod 6(10): 951-958.

CDC, N. ( 2015). "Underlying Cause of Death 1999-2013 " CDC WONDER Online Database.

Cetin, I., N. Giovannini, G. Alvino, C. Agostoni, E. Riva, M. Giovannini and G. Pardi (2002). "Intrauterine growth restriction is associated with changes in polyunsaturated fatty acid fetal-maternal relationships." Pediatr Res 52(5): 750 755.

Challier, J., M. Galtier, T. Bintein, A. Cortez, J. Lepercq and S. Hauguel-de Mouzon (2003). "Placental leptin receptor isoforms in normal and pathological pregnancies." Placenta 24(1): 92-99.

Chan, J. L., K. Heist, A. M. DePaoli, J. D. Veldhuis and C. S. Mantzoros (2003). "The role of falling leptin levels in the neuroendocrine and metabolic adaptation

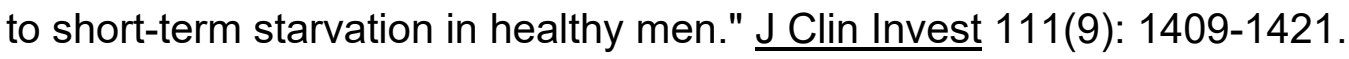
Chehab, F. F., M. E. Lim and R. Lu (1996). "Correction of the sterility defect in homozygous obese female mice by treatment with the human recombinant leptin." Nat Genet 12(3): 318-320.

Cinti, S., R. C. Frederich, M. C. Zingaretti, R. De Matteis, J. S. Flier and B. B. Lowell (1997). "Immunohistochemical localization of leptin and uncoupling protein in white and brown adipose tissue." Endocrinology 138(2): 797-804.

Cleal, J. K. and R. M. Lewis (2008). "The mechanisms and regulation of placental amino acid transport to the human foetus." J Neuroendocrinol 20(4): 419-426. 
Coan, P. M., E. Angiolini, I. Sandovici, G. J. Burton, M. Constancia and A. L. Fowden (2008). "Adaptations in placental nutrient transfer capacity to meet fetal growth demands depend on placental size in mice." J Physiol 586(18): 45674576.

Coan, P. M., A. C. Ferguson-Smith and G. J. Burton (2004). "Developmental dynamics of the definitive mouse placenta assessed by stereology." Biol Reprod 70(6): 1806-1813.

Coan, P. M., A. C. Ferguson-Smith and G. J. Burton (2005). "Ultrastructural changes in the interhaemal membrane and junctional zone of the murine chorioallantoic placenta across gestation." J Anat 207(6): 783-796. Coan, P. M., O. R. Vaughan, J. McCarthy, C. Mactier, G. J. Burton, M. Constancia and A. L. Fowden (2011). "Dietary composition programmes placental phenotype in mice." J Physiol 589(Pt 14): 3659-3670. Coan, P. M., O. R. Vaughan, Y. Sekita, S. L. Finn, G. J. Burton, M. Constancia and A. L. Fowden (2010). "Adaptations in placental phenotype support fetal growth during undernutrition of pregnant mice." J Physiol 588(Pt 3): 527-538. Considine, R. V., M. K. Sinha, M. L. Heiman, A. Kriauciunas, T. W. Stephens, M. R. Nyce, J. P. Ohannesian, C. C. Marco, L. J. McKee, T. L. Bauer and et al. (1996). "Serum immunoreactive-leptin concentrations in normal-weight and obese humans." N Engl J Med 334(5): 292-295.

Cooney, C. A., A. A. Dave and G. L. Wolff (2002). "Maternal methyl supplements in mice affect epigenetic variation and DNA methylation of offspring." $\underline{\mathrm{J} \text { Nutr }}$ 132(8 Suppl): 2393S-2400S. 
Copp, A. J. (1979). "Interaction between inner cell mass and trophectoderm of the mouse blastocyst. II. The fate of the polar trophectoderm." J Embryol Exp Morphol 51: 109-120.

Cross, J. C., D. G. Simmons and E. D. Watson (2003). "Chorioallantoic morphogenesis and formation of the placental villous tree." Ann N Y Acad Sci 995: 84-93.

Dahri, S., A. Snoeck, B. Reusens-Billen, C. Remacle and J. J. Hoet (1991). "Islet function in offspring of mothers on low-protein diet during gestation." Diabetes 40 Suppl 2: 115-120.

Dandrea, J., V. Wilson, G. Gopalakrishnan, L. Heasman, H. Budge, T. Stephenson and M. E. Symonds (2001). "Maternal nutritional manipulation of placental growth and glucose transporter 1 (GLUT-1) abundance in sheep." Reproduction 122(5): 793-800.

de Rooij, S. R., R. C. Painter, T. J. Roseboom, D. I. Phillips, C. Osmond, D. J. Barker, M. W. Tanck, R. P. Michels, P. M. Bossuyt and O. P. Bleker (2006). "Glucose tolerance at age 58 and the decline of glucose tolerance in comparison with age 50 in people prenatally exposed to the Dutch famine." Diabetologia 49(4): 637-643.

Deaton, A. M. and A. Bird (2011). "CpG islands and the regulation of transcription." Genes Dev 25(10): 1010-1022.

Dolinoy, D. C., R. Das, J. R. Weidman and R. L. Jirtle (2007). "Metastable epialleles, imprinting, and the fetal origins of adult diseases." Pediatr Res 61 (5 Pt 2): $30 R-37 R$. 
Duttaroy, A. K. (2009). "Transport of fatty acids across the human placenta: a review." Prog Lipid Res 48(1): 52-61.

Dwyer, C. M., A. J. Madgwick, A. R. Crook and N. C. Stickland (1992). "The effect of maternal undernutrition on the growth and development of the guinea pig placenta." J Dev Physiol 18(6): 295-302.

Eriksson, J., T. Forsen, J. Tuomilehto, C. Osmond and D. Barker (2000). "Fetal and childhood growth and hypertension in adult life." Hypertension 36(5): $790-$ 794.

Faichney, G. J. and G. A. White (1987). "Effects of maternal nutritional status on fetal and placental growth and on fetal urea synthesis in sheep." Aust J Biol Sci 40(4): 365-377.

Flegal, K. M., D. Kruszon-Moran, M. D. Carroll, C. D. Fryar and C. L. Ogden (2016). "Trends in Obesity Among Adults in the United States, 2005 to 2014." JAMA 315(21): 2284-2291.

Flier, J. S. (1997). "Leptin expression and action: new experimental paradigms." Proc Natl Acad Sci U S A 94(9): 4242-4245.

Forsdahl, A. (1977). "Are poor living conditions in childhood and adolescence an important risk factor for arteriosclerotic heart disease?" Br J Prev Soc Med 31(2): 91-95.

Forsen, T., J. Eriksson, J. Tuomilehto, A. Reunanen, C. Osmond and D. Barker (2000). "The fetal and childhood growth of persons who develop type 2 diabetes." Ann Intern Med 133(3): 176-182. 
Fowden, A. L., A. J. Forhead, P. M. Coan and G. J. Burton (2008). "The placenta and intrauterine programming." $\mathrm{J}$ Neuroendocrinol 20(4): 439-450.

Fowden, A. L., A. N. Sferruzzi-Perri, P. M. Coan, M. Constancia and G. J. Burton (2009). "Placental efficiency and adaptation: endocrine regulation." J Physiol 587(Pt 14): 3459-3472.

Garris, D. R. (1983). "Regional variations in guinea pig uterine blood flow during pregnancy: relationship to intrauterine growth of the fetal-placental unit."

Teratology 27(1): 101-107.

Gauster, M., G. Desoye, M. Totsch and U. Hiden (2012). "The placenta and gestational diabetes mellitus." Curr Diab Rep 12(1): 16-23.

Ghilardi, N., S. Ziegler, A. Wiestner, R. Stoffel, M. H. Heim and R. C. Skoda (1996). "Defective STAT signaling by the leptin receptor in diabetic mice." Proc Natl Acad Sci U S A 93(13): 6231-6235.

Gillman, M. W. (2005). "Developmental origins of health and disease." N Engl J Med 353(17): 1848-1850.

Gluckman, P. D. and M. A. Hanson (2006). "The Consequences of Being Born Small - An Adaptive Perspective." Hormone Research in Paediatrics 65(suppl 3)(Suppl. 3): 5-14.

Gluckman, P. D., M. A. Hanson, T. Buklijas, F. M. Low and A. S. Beedle (2009). "Epigenetic mechanisms that underpin metabolic and cardiovascular diseases." Nat Rev Endocrinol 5(7): 401-408. 
Gresham, E. L., E. J. James, J. R. Raye, F. C. Battaglia, E. L. Makowski and G. Meschia (1972). "Production and excretion of urea by the fetal lamb." Pediatrics 50(3): 372-379.

Guo, L., S. Choufani, J. Ferreira, A. Smith, D. Chitayat, C. Shuman, R. Uxa, S. Keating, J. Kingdom and R. Weksberg (2008). "Altered gene expression and methylation of the human chromosome 11 imprinted region in small for gestational age (SGA) placentae." Dev Biol 320(1): 79-91.

Halaas, J. L., K. S. Gajiwala, M. Maffei, S. L. Cohen, B. T. Chait, D. Rabinowitz, R. L. Lallone, S. K. Burley and J. M. Friedman (1995). "Weight-reducing effects of the plasma protein encoded by the obese gene." Science 269(5223): 543-546. Hales, C. N. and D. J. Barker (1992). "Type 2 (non-insulin-dependent) diabetes mellitus: the thrifty phenotype hypothesis." Diabetologia 35(7): 595-601. Havel, P. J., S. Kasim-Karakas, W. Mueller, P. R. Johnson, R. L. Gingerich and J. S. Stern (1996). "Relationship of plasma leptin to plasma insulin and adiposity in normal weight and overweight women: effects of dietary fat content and sustained weight loss." J Clin Endocrinol Metab 81(12): 4406-4413. Heasman, L., L. Clarke, T. J. Stephenson and M. E. Symonds (1999). "The influence of maternal nutrient restriction in early to mid-pregnancy on placental and fetal development in sheep." Proc Nutr Soc 58(2): 283-288.

Heijmans, B. T., E. W. Tobi, A. D. Stein, H. Putter, G. J. Blauw, E. S. Susser, P. E. Slagboom and L. H. Lumey (2008). "Persistent epigenetic differences associated with prenatal exposure to famine in humans." Proc Natl Acad Sci U S A 105(44): 17046-17049. 
Henson, M. C., K. F. Swan and J. S. O'Neil (1998). "Expression of placental leptin and leptin receptor transcripts in early pregnancy and at term." Obstet Gynecol 92(6): 1020-1028.

Herman, J. G. and S. B. Baylin (2003). "Gene silencing in cancer in association with promoter hypermethylation." $\mathrm{N}$ Engl J Med 349(21): 2042-2054.

Holemans, K. (1999). "Maternal food restriction in the second half of pregnancy affects vascular function but not blood pressure of rat female offspring." British Journal of Nutrition: 73-79.

Holemans, K., J. Verhaeghe, J. Dequeker and F. A. Van Assche (1996). "Insulin sensitivity in adult female rats subjected to malnutrition during the perinatal period." J Soc Gynecol Investig 3(2): 71-77.

Holliday, R. and J. E. Pugh (1975). "DNA modification mechanisms and gene activity during development." Science 187(4173): 226-232.

Iglesias-Barreira, V., M. T. Ahn, B. Reusens, S. Dahri, J. J. Hoet and C. Remacle (1996). "Pre- and postnatal low protein diet affect pancreatic islet blood flow and insulin release in adult rats." Endocrinology 137(9): 3797-3801.

Jansson, N., J. Pettersson, A. Haafiz, A. Ericsson, I. Palmberg, M. Tranberg, V. Ganapathy, T. L. Powell and T. Jansson (2006). "Down-regulation of placental transport of amino acids precedes the development of intrauterine growth restriction in rats fed a low protein diet." J Physiol 576(Pt 3): 935-946. 
Jansson, T. and T. L. Powell (2007). "Role of the placenta in fetal programming: underlying mechanisms and potential interventional approaches." Clin Sci (Lond) 113(1): 1-13.

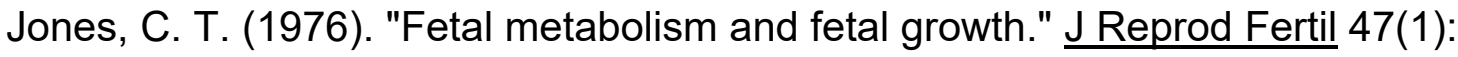
189-201.

Jones, H. N., L. A. Woollett, N. Barbour, P. D. Prasad, T. L. Powell and T. Jansson (2009). "High-fat diet before and during pregnancy causes marked upregulation of placental nutrient transport and fetal overgrowth in C57/BL6 mice." FASEB J 23(1): 271-278.

Kim, D. D. and A. Basu (2016). "Estimating the Medical Care Costs of Obesity in the United States: Systematic Review, Meta-Analysis, and Empirical Analysis." Value Health 19(5): 602-613.

Klein, S., S. W. Coppack, V. Mohamed-Ali and M. Landt (1996). "Adipose tissue leptin production and plasma leptin kinetics in humans." Diabetes 45(7): 984-987. Kolaczynski, J. W., R. V. Considine, J. Ohannesian, C. Marco, I. Opentanova, M. R. Nyce, M. Myint and J. F. Caro (1996). "Responses of leptin to short-term fasting and refeeding in humans: a link with ketogenesis but not ketones themselves." Diabetes 45(11): 1511-1515. Kolaczynski, J. W., J. P. Ohannesian, R. V. Considine, C. C. Marco and J. F. Caro (1996). "Response of leptin to short-term and prolonged overfeeding in humans." J Clin Endocrinol Metab 81(11): 4162-4165. 
Langley, S. C. and A. A. Jackson (1994). "Increased systolic blood pressure in adult rats induced by fetal exposure to maternal low protein diets." $\underline{\text { Clin Sci }}$ (Lond) 86(2): 217-222; discussion 121.

Langley-Evans, S. C. and A. A. Jackson (1995). "Captopril normalises systolic blood pressure in rats with hypertension induced by fetal exposure to maternal low protein diets." Comp Biochem Physiol A Physiol 110(3): 223-228.

Langley-Evans, S. C., S. J. Welham and A. A. Jackson (1999). "Fetal exposure to a maternal low protein diet impairs nephrogenesis and promotes hypertension in the rat." Life Sci 64(11): 965-974.

Larque, E., S. Krauss-Etschmann, C. Campoy, D. Hartl, J. Linde, M. Klingler, H. Demmelmair, A. Cano, A. Gil, B. Bondy and B. Koletzko (2006).

"Docosahexaenoic acid supply in pregnancy affects placental expression of fatty acid transport proteins." Am J Clin Nutr 84(4): 853-861.

Law, C. M., M. de Swiet, C. Osmond, P. M. Fayers, D. J. Barker, A. M. Cruddas and C. H. Fall (1993). "Initiation of hypertension in utero and its amplification throughout life." BMJ 306(6869): 24-27.

Lee, G. H., R. Proenca, J. M. Montez, K. M. Carroll, J. G. Darvishzadeh, J. I. Lee and J. M. Friedman (1996). "Abnormal splicing of the leptin receptor in diabetic mice." Nature 379(6566): 632-635.

Lesage, J., D. Hahn, M. Leonhardt, B. Blondeau, B. Breant and J. P. Dupouy (2002). "Maternal undernutrition during late gestation-induced intrauterine growth restriction in the rat is associated with impaired placental GLUT3 expression, but 
does not correlate with endogenous corticosterone levels." J Endocrinol 174(1): $37-43$.

Levy, L. and A. A. Jackson (1993). "Modest restriction of dietary protein during

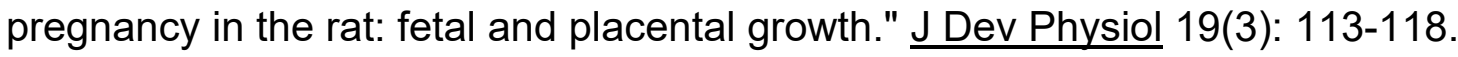

Li, E. (2002). "Chromatin modification and epigenetic reprogramming in mammalian development." Nat Rev Genet 3(9): 662-673.

Lillycrop, K. A., E. S. Phillips, A. A. Jackson, M. A. Hanson and G. C. Burdge (2005). "Dietary protein restriction of pregnant rats induces and folic acid supplementation prevents epigenetic modification of hepatic gene expression in the offspring." J Nutr 135(6): 1382-1386.

Lillycrop, K. A., E. S. Phillips, C. Torrens, M. A. Hanson, A. A. Jackson and G. C. Burdge (2008). "Feeding pregnant rats a protein-restricted diet persistently alters the methylation of specific cytosines in the hepatic PPAR alpha promoter of the offspring." Br J Nutr 100(2): 278-282.

Lillycrop, K. A., J. L. Slater-Jefferies, M. A. Hanson, K. M. Godfrey, A. A. Jackson and G. C. Burdge (2007). "Induction of altered epigenetic regulation of the hepatic glucocorticoid receptor in the offspring of rats fed a protein-restricted diet during pregnancy suggests that reduced DNA methyltransferase-1 expression is involved in impaired DNA methylation and changes in histone modifications." $\underline{\mathrm{Br} \mathrm{J}}$ Nutr 97(6): 1064-1073.

Lumey, L. H., A. D. Stein and H. Kahn (2009). Food restriction during gestation and impaired fasting glucose or glucose tolerance and type 2 diabetes mellitus in adulthood: Evidence from the DutchHunger Winter Families Study. 
Lumey, L. H., A. D. Stein and A. C. Ravelli (1995). "Timing of prenatal starvation in women and birth weight in their first and second born offspring: the Dutch Famine Birth Cohort study." Eur J Obstet Gynecol Reprod Biol 61(1): 23-30. Lunney, L. H. (1998). "Compensatory placental growth after restricted maternal nutrition in early pregnancy." Placenta 19(1): 105-111.

Maffei, M., J. Halaas, E. Ravussin, R. E. Pratley, G. H. Lee, Y. Zhang, H. Fei, S. Kim, R. Lallone, S. Ranganathan and et al. (1995). "Leptin levels in human and rodent: measurement of plasma leptin and ob RNA in obese and weight-reduced subjects." Nat Med 1(11): 1155-1161.

Margetic, S., C. Gazzola, G. G. Pegg and R. A. Hill (2002). "Leptin: a review of its peripheral actions and interactions." Int J Obes Relat Metab Disord 26(11): 14071433.

Maroni, P., P. Bendinelli and R. Piccoletti (2005). "Intracellular signal transduction pathways induced by leptin in C2C12 cells." Cell Biol Int 29(7): 542550.

Masuzaki, H., Y. Ogawa, N. Sagawa, K. Hosoda, T. Matsumoto, H. Mise, H. Nishimura, Y. Yoshimasa, I. Tanaka, T. Mori and K. Nakao (1997). "Nonadipose tissue production of leptin: leptin as a novel placenta-derived hormone in humans." Nat Med 3(9): 1029-1033.

Mayer, W., A. Niveleau, J. Walter, R. Fundele and T. Haaf (2000).

"Demethylation of the zygotic paternal genome." Nature 403(6769): 501-502. Mayhew, T. M. (2009). "A stereological perspective on placental morphology in normal and complicated pregnancies." J Anat 215(1): 77-90. 
McCrabb, G. J., A. R. Egan and B. J. Hosking (1991). "Maternal undernutrition during mid-pregnancy in sheep. Placental size and its relationship to calcium transfer during late pregnancy." Br J Nutr 65(2): 157-168.

Mercer, J. G., N. Hoggard, L. M. Williams, C. B. Lawrence, L. T. Hannah and P. Trayhurn (1996). "Localization of leptin receptor mRNA and the long form splice variant $(\mathrm{Ob}-\mathrm{Rb})$ in mouse hypothalamus and adjacent brain regions by in situ hybridization." FEBS Lett 387(2-3): 113-116.

Morgan, H. D., F. Santos, K. Green, W. Dean and W. Reik (2005). "Epigenetic reprogramming in mammals." Hum Mol Genet 14 Spec No 1: R47-58.

Myatt, L. (2006). "Placental adaptive responses and fetal programming." $\underline{\mathrm{J}}$ Physiol 572(Pt 1): 25-30.

Netherlands, M. Committee on, G. C. E. Burger, J. C. Drummond and H. R. Sandstead (1948). Malnutrition and starvation in Western Netherlands:

September 1944 - July 1945 Pt. 1. Pt. 1. The Hague, General State Print. Office. Okano, M., D. W. Bell, D. A. Haber and E. Li (1999). "DNA methyltransferases Dnmt3a and Dnmt3b are essential for de novo methylation and mammalian development." Cell 99(3): 247-257.

Okano, M., S. Xie and E. Li (1998). "Cloning and characterization of a family of novel mammalian DNA (cytosine-5) methyltransferases." Nat Genet 19(3): 219220.

Ozaki, T., H. Nishina, M. A. Hanson and L. Poston (2001). "Dietary restriction in pregnant rats causes gender-related hypertension and vascular dysfunction in offspring." J Physiol 530(Pt 1): 141-152. 
Ozanne, S. E., R. Lewis, B. J. Jennings and C. N. Hales (2004). "Early programming of weight gain in mice prevents the induction of obesity by a highly palatable diet." Clin Sci (Lond) 106(2): 141-145.

Painter, R. C., S. R. de Rooij, P. M. Bossuyt, T. A. Simmers, C. Osmond, D. J. Barker, O. P. Bleker and T. J. Roseboom (2006). "Early onset of coronary artery disease after prenatal exposure to the Dutch famine." Am J Clin Nutr 84(2): 322327; quiz 466-327.

Pardi, G., I. Cetin, A. M. Marconi, A. Lanfranchi, P. Bozzetti, E. Ferrazzi, M. Buscaglia and F. C. Battaglia (1993). "Diagnostic value of blood sampling in

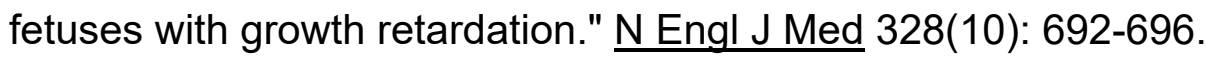

Peelman, F., L. Zabeau, K. Moharana, S. N. Savvides and J. Tavernier (2014). "20 years of leptin: insights into signaling assemblies of the leptin receptor." $\underline{\mathrm{J}}$ Endocrinol 223(1): T9-23.

Pelleymounter, M. A., M. J. Cullen, M. B. Baker, R. Hecht, D. Winters, T. Boone and F. Collins (1995). "Effects of the obese gene product on body weight regulation in ob/ob mice." Science 269(5223): 540-543.

Rahnama, F., F. Shafiei, P. D. Gluckman, M. D. Mitchell and P. E. Lobie (2006). "Epigenetic regulation of human trophoblastic cell migration and invasion." Endocrinology 147(11): 5275-5283.

Ravelli, A. C., J. H. van der Meulen, R. P. Michels, C. Osmond, D. J. Barker, C. N. Hales and O. P. Bleker (1998). "Glucose tolerance in adults after prenatal exposure to famine." Lancet 351(9097): 173-177. 
Ravelli, A. C., J. H. van Der Meulen, C. Osmond, D. J. Barker and O. P. Bleker (1999). "Obesity at the age of $50 \mathrm{y}$ in men and women exposed to famine prenatally." Am J Clin Nutr 70(5): 811-816.

Ravelli, G. P., Z. A. Stein and M. W. Susser (1976). "Obesity in young men after famine exposure in utero and early infancy." N Engl J Med 295(7): 349-353.

Rees, W. D., S. M. Hay, D. S. Brown, C. Antipatis and R. M. Palmer (2000). "Maternal protein deficiency causes hypermethylation of DNA in the livers of rat fetuses." J Nutr 130(7): 1821-1826.

Reik, W. and W. Dean (2001). "DNA methylation and mammalian epigenetics." Electrophoresis 22(14): 2838-2843.

Roberts, C. T., A. Sohlstrom, K. L. Kind, R. A. Earl, T. Y. Khong, J. S. Robinson, P. C. Owens and J. A. Owens (2001). "Maternal food restriction reduces the exchange surface area and increases the barrier thickness of the placenta in the guinea-pig." Placenta 22(2-3): 177-185.

Rodriguez, T. A., D. B. Sparrow, A. N. Scott, S. L. Withington, J. I. Preis, J. Michalicek, M. Clements, T. E. Tsang, T. Shioda, R. S. Beddington and S. L. Dunwoodie (2004). "Cited1 is required in trophoblasts for placental development and for embryo growth and survival." Mol Cell Biol 24(1): 228-244.

Rosario, F. J., N. Jansson, Y. Kanai, P. D. Prasad, T. L. Powell and T. Jansson (2011). "Maternal protein restriction in the rat inhibits placental insulin, mTOR, and STAT3 signaling and down-regulates placental amino acid transporters." Endocrinology 152(3): 1119-1129. 
Roseboom, T. J., J. H. van der Meulen, C. Osmond, D. J. Barker, A. C. Ravelli, J. M. Schroeder-Tanka, G. A. van Montfrans, R. P. Michels and O. P. Bleker (2000). "Coronary heart disease after prenatal exposure to the Dutch famine, 1944-45." Heart 84(6): 595-598.

Rosenblum, C. I., M. Tota, D. Cully, T. Smith, R. Collum, S. Qureshi, J. F. Hess, M. S. Phillips, P. J. Hey, A. Vongs, T. M. Fong, L. Xu, H. Y. Chen, R. G. Smith, C. Schindler and L. H. Van der Ploeg (1996). "Functional STAT 1 and 3 signaling by the leptin receptor (OB-R); reduced expression of the rat fatty leptin receptor in transfected cells." Endocrinology 137(11): 5178-5181.

Rossant, J. and J. C. Cross (2001). "Placental development: lessons from mouse mutants." Nat Rev Genet 2(7): 538-548.

Rutland, C. S., A. O. Latunde-Dada, A. Thorpe, R. Plant, S. Langley-Evans and L. Leach (2007). "Effect of gestational nutrition on vascular integrity in the murine placenta." Placenta 28(7): 734-742.

Saintonge, J. and P. Rosso (1981). "Placental blood flow and transfer of nutrient analogs in large, average, and small guinea pig littermates." Pediatr Res 15(2): $152-156$.

Santos, F., B. Hendrich, W. Reik and W. Dean (2002). "Dynamic reprogramming of DNA methylation in the early mouse embryo." Dev Biol 241(1): 172-182. Sasaki, H. and Y. Matsui (2008). "Epigenetic events in mammalian germ-cell development: reprogramming and beyond." Nat Rev Genet 9(2): 129-140. Schubring, C., W. Kiess, P. Englaro, W. Rascher, J. Dotsch, S. Hanitsch, A. Attanasio and W. F. Blum (1997). "Levels of leptin in maternal serum, amniotic 
fluid, and arterial and venous cord blood: relation to neonatal and placental weight." J Clin Endocrinol Metab 82(5): 1480-1483.

Schulz, L. C. (2010). "The Dutch Hunger Winter and the developmental origins of health and disease." Proc Natl Acad Sci U S A 107(39): 16757-16758.

Seki, Y., L. Williams, P. M. Vuguin and M. J. Charron (2012). "Minireview:

Epigenetic programming of diabetes and obesity: animal models." Endocrinology 153(3): 1031-1038.

Serman, L., M. Vlahovic, M. Sijan, F. Bulic-Jakus, A. Serman, N. Sincic, R. Matijevic, G. Juric-Lekic and A. Katusic (2007). "The impact of 5-azacytidine on placental weight, glycoprotein pattern and proliferating cell nuclear antigen expression in rat placenta." Placenta 28(8-9): 803-811.

Shimabukuro, M., K. Koyama, G. Chen, M. Y. Wang, F. Trieu, Y. Lee, C. B. Newgard and R. H. Unger (1997). "Direct antidiabetic effect of leptin through triglyceride depletion of tissues." Proc Natl Acad Sci U S A 94(9): 4637-4641. Sinclair, K. D., C. Allegrucci, R. Singh, D. S. Gardner, S. Sebastian, J. Bispham, A. Thurston, J. F. Huntley, W. D. Rees, C. A. Maloney, R. G. Lea, J. Craigon, T. G. McEvoy and L. E. Young (2007). "DNA methylation, insulin resistance, and blood pressure in offspring determined by maternal periconceptional B vitamin and methionine status." Proc Natl Acad Sci U S A 104(49): 19351-19356.

Sivan, E., P. G. Whittaker, D. Sinha, C. J. Homko, M. Lin, E. A. Reece and G. Boden (1998). "Leptin in human pregnancy: the relationship with gestational hormones." Am J Obstet Gynecol 179(5): 1128-1132. 
Smith, Z. D. and A. Meissner (2013). "DNA methylation: roles in mammalian development." Nat Rev Genet 14(3): 204-220.

Snoeck, A., C. Remacle, B. Reusens and J. J. Hoet (1990). "Effect of a low protein diet during pregnancy on the fetal rat endocrine pancreas." Biol Neonate 57(2): 107-118.

Stein, A. D., H. S. Kahn, A. Rundle, P. A. Zybert, K. van der Pal-de Bruin and L. H. Lumey (2007). "Anthropometric measures in middle age after exposure to famine during gestation: evidence from the Dutch famine." Am J Clin Nutr 85(3): 869-876.

Stephens, T. W., M. Basinski, P. K. Bristow, J. M. Bue-Valleskey, S. G. Burgett, L. Craft, J. Hale, J. Hoffmann, H. M. Hsiung, A. Kriauciunas and et al. (1995). "The role of neuropeptide $Y$ in the antiobesity action of the obese gene product." Nature 377(6549): 530-532.

Stock, S. M., E. M. Sande and K. A. Bremme (1999). "Leptin levels vary significantly during the menstrual cycle, pregnancy, and in vitro fertilization treatment: possible relation to estradiol." Fertil Steril 72(4): 657-662. Thaler, M. M. (1972). "Effects of starvation on normal development of hydroxybutyrate dehydrogenase activity in foetal and newborn rat brain." Nat New Biol 236(66): 140-141.

Tritos, N. A. and C. S. Mantzoros (1997). "Leptin: its role in obesity and beyond." Diabetologia 40(12): 1371-1379. 
Trogdon, J. G., E. A. Finkelstein, T. Hylands, P. S. Dellea and S. J. Kamal-Bahl (2008). "Indirect costs of obesity: a review of the current literature." Obes Rev 9(5): 489-500.

Tsoulos, N. G., J. R. Colwill, F. C. Battaglia, E. L. Makowski and G. Meschia (1971). "Comparison of glucose, fructose, and O2 uptakes by fetuses of fed and starved ewes." Am J Physiol 221(1): 234-237.

Uauy, R., J. Kain and C. Corvalan (2011). "How can the Developmental Origins of Health and Disease $(\mathrm{DOHaD})$ hypothesis contribute to improving health in developing countries?" Am J Clin Nutr 94(6 Suppl): 1759S-1764S.

Vaisse, C., J. L. Halaas, C. M. Horvath, J. E. Darnell, Jr., M. Stoffel and J. M. Friedman (1996). "Leptin activation of Stat3 in the hypothalamus of wild-type and ob/ob mice but not db/db mice." Nat Genet 14(1): 95-97.

Vambergue, A. and I. Fajardy (2011). "Consequences of gestational and pregestational diabetes on placental function and birth weight." World J Diabetes 2(11): 196-203.

Vickers, M. H., B. H. Breier, W. S. Cutfield, P. L. Hofman and P. D. Gluckman (2000). "Fetal origins of hyperphagia, obesity, and hypertension and postnatal amplification by hypercaloric nutrition." Am J Physiol Endocrinol Metab 279(1): E83-87.

Vlahovic, M., F. Bulic-Jakus, G. Juric-Lekic, A. Fucic, S. Maric and D. Serman (1999). "Changes in the placenta and in the rat embryo caused by the demethylating agent 5-azacytidine." Int J Dev Biol 43(8): 843-846. 
Vonnahme, K. A. and S. P. Ford (2004). "Differential expression of the vascular endothelial growth factor-receptor system in the gravid uterus of yorkshire and Meishan pigs." Biol Reprod 71(1): 163-169.

Wallace, J. M., R. P. Aitken, J. S. Milne and W. W. Hay, Jr. (2004). "Nutritionally mediated placental growth restriction in the growing adolescent: consequences for the fetus." Biol Reprod 71(4): 1055-1062.

Waterland, R. A., D. C. Dolinoy, J. R. Lin, C. A. Smith, X. Shi and K. G. Tahiliani (2006). "Maternal methyl supplements increase offspring DNA methylation at Axin Fused." Genesis 44(9): 401-406.

Waterland, R. A. and R. L. Jirtle (2003). "Transposable elements: targets for early nutritional effects on epigenetic gene regulation." Mol Cell Biol 23(15): $5293-5300$.

Widdowson, E. M. (1974). "Immediate and long term consequences of being large or small at birth: a comparative approach. In size at birth:." (27): 65-76 Widdowson, E. M. and R. A. McCance (1975). "A review: new thoughts on growth." Pediatr Res 9(3): 154-156.

Wolf, A. M. (1998). "What is the economic case for treating obesity?" Obes Res 6 Suppl 1: 2S-7S.

Wolf, A. M. and G. A. Colditz (1998). "Current estimates of the economic cost of obesity in the United States." Obes Res 6(2): 97-106.

Wolf, S. F., D. J. Jolly, K. D. Lunnen, T. Friedmann and B. R. Migeon (1984). "Methylation of the hypoxanthine phosphoribosyltransferase locus on the human 
X chromosome: implications for X-chromosome inactivation." Proc Natl Acad Sci U S A 81(9): 2806-2810.

Wooding, F. B. and A. L. Fowden (2006). "Nutrient transfer across the equine placenta: correlation of structure and function." Equine Vet J 38(2): 175-183.

Zhou, J. and C. A. Bondy (1993). "Placental glucose transporter gene expression and metabolism in the rat." $\underline{\mathrm{J} \text { Clin Invest } 91(3): 845-852 .}$

Zhu, J. K. (2009). "Active DNA demethylation mediated by DNA glycosylases." Annu Rev Genet 43: 143-166. 
CHAPTER 2

THE EFFECTS OF MATERNAL UNDER NUTRITION DURING THE PERICONCEPTIONAL PERIOD ON THE MOUSE PLACENTA

Gerialisa Van Gronigen Case ${ }^{1,2}$, Lauren Parmeley ${ }^{1}$, Laura C. Schulz ${ }^{2}$

Division of Biological Sciences ${ }^{1}$, Department of Obstetrics, Gynecology and Women's Health², University of Missouri-Columbia 65211 


\section{INTRODUCTION}

Among the US population 29.1 million (9.3\%) are diabetic, more than a third of adult diabetics and $17 \%$ of child diabetics are obese(Ogden, Carroll et al. 2014). In the U.S., heart disease is the leading cause of death affecting approximately 600,000 and 1 in every 4 people in the U.S. die from this condition(Kochanek, Xu et al. 2011). Though genetics, improper diet and lack of exercise play roles in predisposing adults to these chronic diseases, several studies have associated environmental factors during pregnancy with their incidence. Specifically, nutrient restriction, protein, and micronutrient deficiencies during early pregnancy followed by adequate nutrition in later gestation predisposed offspring to metabolic diseases such as heart disease (Frankel, Elwood et al. 1996, Rich-Edwards, Stampfer et al. 1997, Barker 2004) and obesity (Curhan, Chertow et al. 1996) in adulthood in both humans and animal models.

The molecular mechanisms by which this occured however remain poorly understood. The placenta is the organ responsible for the transfer of nutrients from the mother to the fetus. It is also in direct contact with both the maternal and fetal circulations. The placenta therefore can respond to maternal environmental stimuli to in turn affect the growing fetus. Furthermore, maternal nutrition in early pregnancy may program placental 
development such that it provided differently for the fetus later in pregnancy. For example, women that were exposed to the Dutch Hunger Famine during the first trimester and received an adequate diet in later pregnancy showed increased placental weight at delivery compared to control mothers (Lumey 1998). Sons of these women had increased incidences of obesity, diabetes and cardiovascular disease as adults (Ravelli, van Der Meulen et al. 1999, Ravelli, Bleker et al. 2005). Similarly, placentas of ewes born to mothers who were undernourished during mid pregnancy were larger than normal at birth (McCrabb, Egan et al. 1991). In contrast, maternal food restriction prior to and during the first half of gestation in guinea pigs reduced placental surface area and labyrinth zone, changes in placental structure which may cause changes in fetal growth and alterations to adult health status(Roberts, Sohlstrom et al. 2001). These findings suggested that differences in the timing of caloric restriction, perhaps interacted with species differences in placental development, to determine an impact on placental development.

In our lab, we previously we compared placentae of pups whose mothers were fed a control diet to placentae from pups whose mothers were given a $50 \%$ total caloric food restriction from days $1.5-11.5$ of gestation. At d11.5, we found placentae from offspring whose mothers were fed a restricted diet were significantly lighter than their control counterparts and showed a decrease in placental area. This was due to a reduction in the junctional zone, suggesting that the labryinth zone, where 
nutrient and gaseous exchange occur, was maintained for proper growth and development of the fetus. However, when fed an adequate diet from mid-gestation to d18.5, just prior to parturition, effects of the early caloric restriction on placental morphology were reversed, suggesting the placenta was able to adapt to the adverse in utero enviroment, but not overgrow, as had been observed in sheep and humans.

It is possible that caloric restriction did not permanently alter placental morphology because of the timing of the nutritional insult. Specifically, in our lab we also hypothesized that the placenta may only be susceptible to permanent effects of caloric restriction if the restriction occurred during the periconceptional period. During this period there is oocyte selection and maturation as well as two rounds of DNA methylation reprogramming that can be influenced by maternal nutrition. To test this hypothesis, mice were subjected to $50 \%$ caloric restriction from days 3 weeks prior to mating to 11.5 of gestation, then returned to an adequate fed chow diet for the latter half of gestation. Placentas were then collected and examined at gestation d18.5.

MATERIALS AND METHODS

ANIMAL CARE

All animal procedures were approved by University of Missouri Institutional Animal Care and Use Committee. Swiss Webster mice 6-8 weeks old and $\geq 25 \mathrm{~g}$ were obtained from Envigo (Indianapolis, IN). They were individually housed in a 
12hr dark, $12 \mathrm{hr}$ light cycle and fed an AIN-93G chow ad libitum for one week to acclimatize them to their surroundings. Specialized feeding containers were used so that daily food consumption could be recorded(Townsend, Lorenzi et al. 2008). Beginning three weeks prior to mating, female mice were randomly separated into two groups: a control group fed ad libitum $(n=5)$ and a restricted group (fed $50 \%$ previous daily food consumption, customized to each dam) $(\mathrm{n}=6)$. Mice were fed at $2 \mathrm{pm}$ and mated at $8 \mathrm{pm}$. Females on a nutrient restricted diet finished their chow diet shortly after feeding, thus by mating nutrient restricted females had consumed their entire food allotment. Males who were fed an ad libitum diet were housed in the females cages overnight for mating. The day copulatory plug was observed was called d0.5. Dietary treatment continued until d11.5, and then both treatment groups were fed ad libitum from d11.5 to d18.5. Females and males in the control fed group were allowed ad libitum rations overnight. All animals were allowed free access to water. At d18.5, mice were sacrificed, and placentae collected to examine placental morphology and gene expression.

\section{TISSUE COLLECTION}

At d18.5, pregnant females were euthanized using $\mathrm{CO}_{2}$ asphyxiation and cervical dislocation, and fetuses were euthanized by decapitation. Placentae were collected, and placental and fetal weights were recorded. One half of each placenta was fixed in 4\% paraformaldehyde/PBS overnight for histological 
analysis. The second half of each placenta was divided into two pieces, one for gene expression analysis and the second for DNA analysis. All tissue was snap frozen in liquid nitrogen and stored at $-80^{\circ} \mathrm{C}$ until needed for analysis.

\section{PLACENTAL MORPHOLOGY}

Fixed placentae were dehydrated and embedded in paraffin. Placentae were cut into 6 serial mid- sagittal sections, 5um thick, 50um apart, mounted on glass slides and stained with hematoxylin and eosin (H\&E) (IDEXX Bioresearch, Columbia, MO). The largest cross-section on each slide was chosen for morphological analysis.

For analysis of total area and major zones, overlapping images were photographed with a $4 x$ objective lens on a Zeiss Axiovert 200M microscope, and arranged into a single, high-resolution image of the entire placental crosssection. Junctional zone and labyrinth zone areas were measured by manual outlining using the freehand selection tool in Image J software $(\mathrm{NIH})$ by an operator blinded to treatment groups. Cross sectional measurements were averaged from three placentas per dam.

To identify fetal blood vessels in the labyrinth zone, cross sections were immunohistochemically stained for CD31 by using VECTASTAIN Elite ABC HRP Kit (Peroxidase, Rabbit lgG). Briefly, sections were rehydrated, and antigen retrieval was performed by boiling in sodium citrate buffer $(10 \mathrm{mM} \mathrm{Na}$ Citrate, $0.05 \%$ Tween $20, \mathrm{pH} 6.0$ ) for 3 minutes, and then incubated in 1\% BSA and $10 \%$ 
normal goal serum (Fisher Scientific) to block non-specific binding. Placentae sections were then incubated with anti-CD 31. Secondary antibody and color development were carried out according to Vectastain instructions, and counterstained with hematoxylin. Five representative images were photographed per placenta with a $40 x$ objective. The total cross-sectional areas of maternal blood sinuses and fetal blood vessels were determined by using the freehand selection tool within ImageJ software. Measurements from 3 placentas were analyzed per dam to obtain $n=1$.

REAL TIME RT- PCR

Placental tissue was homogenized in Trizol Reagent (Sigma Aldrich) with an Omni GLH Homogenizer. After phase separation, RNA was further purified using Qiagen RNeasy kit (QIAGEN, Valencia, CA) according to manufacturer's protocol. RNA concentration was determined. Two $\mu \mathrm{g}$ of total RNA was reversed transcribed with SuperScript III First-Strand Synthesis System (Invitrogen/Life Technologies, Grand Island, NY), using random hexamer primers, according to manufacturer's protocol.

Real-time RT-PCR was used to measure relative transcript levels of genes specific to the major trophoblast lineages: heart and neural crest derivative 1 (Hand1) was selected as a marker for giant cells (El-Hashash, Warburton et al. 2010); trophoblast specific protein alpha (Tpbpa) for spongiotrophoblast and glycogen cells (Cowden Dahl, Fryer et al. 2005, Natale, Starovic et al. 2006), 
extraembryonic spermatogenesis homeobox 1 homolog (Esx1) for synctiotrophoblast cells(Plant and Zeleznik 2014). CD36 predominately marks the syncytiotrophoblast (Diaz, Harris et al. 2015, Lager, Ramirez et al. 2016), sterol regulatory element binding transcription factor 1 (srebp1), prl3b1 for giant cells and pecam1 for endothelial cells.

Primers were synthesized by Integrated DNA Technologies (Coralville, IA). The specificity and efficiency of each reaction was validated by using serial dilutions of placental cDNA. PCR was conducted in triplicate using $\mathrm{RT}^{2} \mathrm{SYBR}$ Green ROX qPCR master mix (Qiagen) in a final volume of $12 \mu$ on Biorad CFX Connect Thermocycler (Bio-Rad,CA) .Cycling conditions were as follows: $95^{\circ} \mathrm{C}$ for 10 minutes, 40 cycles of $95^{\circ} \mathrm{C}$ for 15 secs, $60^{\circ} \mathrm{C}$ for 1 minute No-template and no reverse transcriptase controls were performed. Data was normalized to housekeeping genes hypoxanthine phosphoribosyltransferase 1 (HPRT) and Glyceraldehyde-3-Phosphate Dehydrogenase (GAPDH). A sample Fold change differences in gene expression, and error bars were calculated using the $\Delta \Delta \mathrm{Ct}$ method (Livak and Schmittgen 2001)

\section{STATISTICAL ANALYSIS}

q-PCR data were expressed as SEM. Dams were considered the experimental unit. One-way ANOVA using GraphPad prism, tukey posthoc test was used to analyze for treatment effects. Data was termed statistical significant if $p \leq 0.05$. 


\section{RESULTS}

\section{PLACENTAL AND FETAL GROWTH}

As compared to the placentae of dams fed an adequate diet throughout pregnancy (Fig 2A), the overall size of the placenta near term, measured either by weight or cross-sectional area, was not affected by maternal food restriction during the peri-conceptional period (Fig 2B). Similarly, there were no significant differences in the areas of the junctional (figure $3 \mathrm{~A}$ ) and labyrinth zones (figure $3 \mathrm{~B}$ ) of the placenta, the ratio of junctional: labyrinth zones (figure $3 \mathrm{C}$ ), total area (figure 3D), placental weights (figure 3E), nor were fetal weights (figure 3F) and placental efficiency [the ratio of fetal/placental weight] (figure 3G) different between dietary groups.

Periconceptional maternal food restriction affected the formation of blood spaces within the labyrinthine placenta near term. Although, there were no significant differences in fetal blood vessel areas (Figure 4A), there was a significant increase in maternal blood space area in placentae from dams fed a restricted diet during the perioconceptional period as compared to those from control-fed dams (Figure 4B). 


\section{TROPHOBLAST DIFFERENTIATION}

In order to further characterize the permanent impacts of periconceptional food restriction on placental development, semi quantitative real-time PCR was used to compare steady state mRNA levels of transcription factors that are specifically expressed at each of the major trophoblast sublineages within the placenta (Table 1). There were no significant differences in relative mRNA levels of placental lineage markers Esx1 (synctiotrophoblast), Tpbpa (spongiotrophoblast), Hand1(trophoblast stem cells) or Prl3b1 in parietal, cytotrophoblasts and spongiotrophblast giant cells (Simmons, Rawn et al. 2008). Additionally, Ctsq, which is expressed by trophoblast giant cells that line the sinusoids of the labyrinth(Outhwaite, McGuire et al. 2015) and Pecam1, which is found in the fetal endothelial cells(Shafiee, Patel et al. 2018). (Figure 5).

\section{PLACENTAL NUTRIENT TRANSPORTERS}

Real-time PCR was also used to compare expression of key placental nutrient transporters at d18.5 following periconceptional food restriction. There was a three-fold decrease in mRNA encoding slc38A4, an amino acid transporter which transport neutral amino acids such as glutamine, glycine, serine and alanine (Cleal and Lewis 2008) in restricted placentae. However, there were no differences in mRNA levels for the other amino acid transporters slc38A1 and slc38A2 and the amino acid transporters Lat 1 and Lat 2. Levels of mRNA for 
fatty acid transporter Cd36 andSrebp1c, a transcription factor that regulates genes involved in sterol biosynthesis were not changed, nor were there differences in expression of glucose transporters slc2A1 and slc2A3 between control and restricted $(\mathrm{N}=6)$ placentae (Figure 5).

\section{DISCUSSION}

The goal of this study was to determine whether, in mice, the periconceptional period is a critical time in which maternal total caloric restriction can permanently alter placental development and function. Both human and animal data suggest that changes in the maternal environment during early gestation can alter fetal development with an increased risk of the offspring developing chronic adult diseases such as obesity, hypertension and diabetes (Kwong, Wild et al. 2000, Bertram and Hanson 2001, Gluckman and Hanson 2004). Additionally, both human and sheep studies have shown that total caloric nutrient restriction early in gestation results in placental overgrowth at term. This suggests one mechanism by which nutrient restriction in early gestation can continue to exert effects on fetal development through the remainder of pregnancy.

In contrast, we previously found that while placentae from mouse dams fed a $50 \%$ total caloric diet during days $1.5-11.5$ of pregnancy were altered at mid gestation, there were no differences in placental morphology or gene expression 
when an ad libitium diet was fed to the food restricted dams for the latter half of pregnancy(Harper, Caesar et al. 2015).

We reasoned that the differing outcome might be due to small differences in timing. Specifically, we hypothesized that the critical period during which maternal nutrient restriction permanently alters placental development might occur prior to d1.5, during late oocyte and early zygotic development. The results of this study are generally consistent with this hypothesis; unlike $50 \%$ food restriction from days $1.5-11.5$, restriction from 21 days before mating through day 11.5 altered placental morphology and gene expression at day 18 .

Alternatively, it may be the difference in the total length of food restriction between these two studies, 32 vs. 10 days, rather than the importance of days 21 through 1.5, that produced a more lasting effect on the placenta. This periconceptional period was chosen as in mice there is oocyte selection and two rounds of DNA methylation reprogramming occurring, period We used the periconceptional period as this period was critical to embryonic development and two rounds of DNA methylation as well as oocyte selection occur here. Three weeks prior to conception until mid-gestation was chosen as there is two rounds of DNA methylation reprogramming that occur and well as oocyte selection, all events which can be influenced by factors such as maternal nutrition.

There were no changes in areas of the placental junctional or labyrinth zones, placental weights, or efficiency (placenta/fetal weight) on d18.5 following food restriction from -21 to d111.5. This is unlike the sheep, in which nutrient restriction either from days -45 through $d 7$ or days 30 through 125 results in 
larger placentas later in pregnancy (Heasman, Clarke et al. 1999, MacLaughlin, Walker et al. 2005, Fowden, Ward et al. 2006). Similarly, in humans' early pregnancy food restriction leads to increased placental weight at term, though this study did not differentiate between periconceptional and later first trimester restriction. The species difference is unlikely to be due to an inability of the mouse placenta to change morphology after d11.5. Under normal feeding conditions, mouse placental weight and area increase steadily through d16.5, and the relative proportion of the labyrinth zone continues to increase through d18.5 (Mu, Slevin et al. 2008\{Coan, $2004 \# 2023)\}$. Ongoing maternal food restriction continues to affect placental weight and relative proportions of the junctional and labyrinth zones through d18.5 (Coan, Vaughan et al. 2010). This growth pattern is intermediate between that of sheep, in which placental weight peaks at day 90 of 152 and humans, in which placental weight continues to increase throughout gestation (Reynolds, Borowicz et al. 2005). We conclude that the inability of maternal food restriction to permanently change placental weight and area in the mouse holds regardless of whether the food restriction occurred in the period immediately surrounding conception or in during the period surrounding implantation and placental establishment.

However, there was a significant increase in maternal blood space area in placentae of food-restricted dams at $\mathrm{d} 18.5$ following restriction from days -21 to d11.5. In contrast, previously, when food was restricted only from d1.5-11.5, there was no effect on maternal blood spaces at d18.5 (Harper, Caesar et al. 2015). This suggested that food restriction during days -21 to 1.5 leads to long- 
lasting compensatory increases in the placental exchange area in order to maintain fetal development. Somewhat similarly, food restriction during early pregnancy leads to increased vascularity in the caruncle, the maternal portion of the bovine placenta, near term. (Vonnahme, Zhu et al. 2007). However, this was observed after food restriction from d30-125 of gestation, not at the time of conception. Thus, there appeared to be a conserved effect of maternal nutrition on placental maternal blood exchange areas, but the timing of the critical period may differ.

The placenta also acts as a nutrient sensing organ by altering transport of nutrients to the fetus to balance adequate fetal growth with maternal nutrient needs (Jansson and Powell 2007). Among those nutrients is glucose, which is primarily transported across the placenta by solute carrier family 2 member 1 (slc2A1), solute carrier family 2 member 3 (slc2A3) Solute Carrier Family 2 Member 1(Boileau, Mrejen et al. 1995, Sciullo, Cardellini et al. 1997, Bell, Hay et al. 1999, Jansson, Wennergren et al. 1999, Das, He et al. 2000, Dandrea, Wilson et al. 2001, Wooding, Fowden et al. 2005). slc2A1 was shown to be increased in late gestation following maternal undernutrition in sheep during early gestation, (Dandrea, Wilson et al. 2001). On the other hand, maternal under nutrition in late gestation resulted in an increase in GLUT3 in the sheep (Bell, Hay et al. 1999) but a decrease in the rat (Lesage, Hahn et al. 2002). We found no significant differences in late gestation gene expression of either glucose transporter in placentae from mothers that were fed malnourished during the first half of pregnancy. 
Amino acid transport is also regulated by maternal nutritional status during pregnancy (McGivan and Pastor-Anglada 1994). We demonstrated a three-fold decrease in gene expression for slc38A4, an isoform of the system A amino acid transporter in near term mouse placenta. Similarly, in rats, a maternal low protein diet throughout gestation reduced three system A amino acid transporter isoforms, solute carrier family 38 member 1 (slc38A1), solute carrier family 38 member 2 (slc38A2) and solute carrier family 38 member 4 (slc38A4) in the placenta (Malandro, Beveridge et al. 1996, Desforges, Lacey et al. 2006). In the baboon, ongoing nutrient restriction leads to reduced slc38A expression in midpregnancy (Kavitha, 2014).

Slc38A4 is a major contributor to fetal growth(Jansson and Powell 2007), and thus, the decrease in slc38A4 would most likely act to limit fetal growth. However, the increase in maternal blood space area following maternal food restriction would be expected to maximize fetal growth. These two alterations may have offset each other so that placental efficiency and fetal sizes were normal at term.

Offspring exposed to an adverse maternal environment in early pregnancy during the Dutch Hunger Famine exhibited a predisposition to metabolic disease as adults, though there were no differences in their birth weights as compared to their non-exposed counterparts. Animal studies also show that maternal diet has long term consequences on adult health and varies depending on the timing during gestation by which the insult occur and the organ developing at the time. Our data supports the idea that maternal food deprivation during the 
periconceptional period and preimplantation may have long term consequences for placental development (Edwards and McMillen 2002, Fleming, Kwong et al. 2004, Gardner, Pearce et al. 2004). These observed adaptations in the placenta may later have long term consequences, serving as a potential mechanism by which insults in the in-utero environment affect adult health. Secondly, placental alterations such as those identified here may serve as an indicator of increased risk of diseases in later life, though this remains to be tested. 


\section{FIGURES}

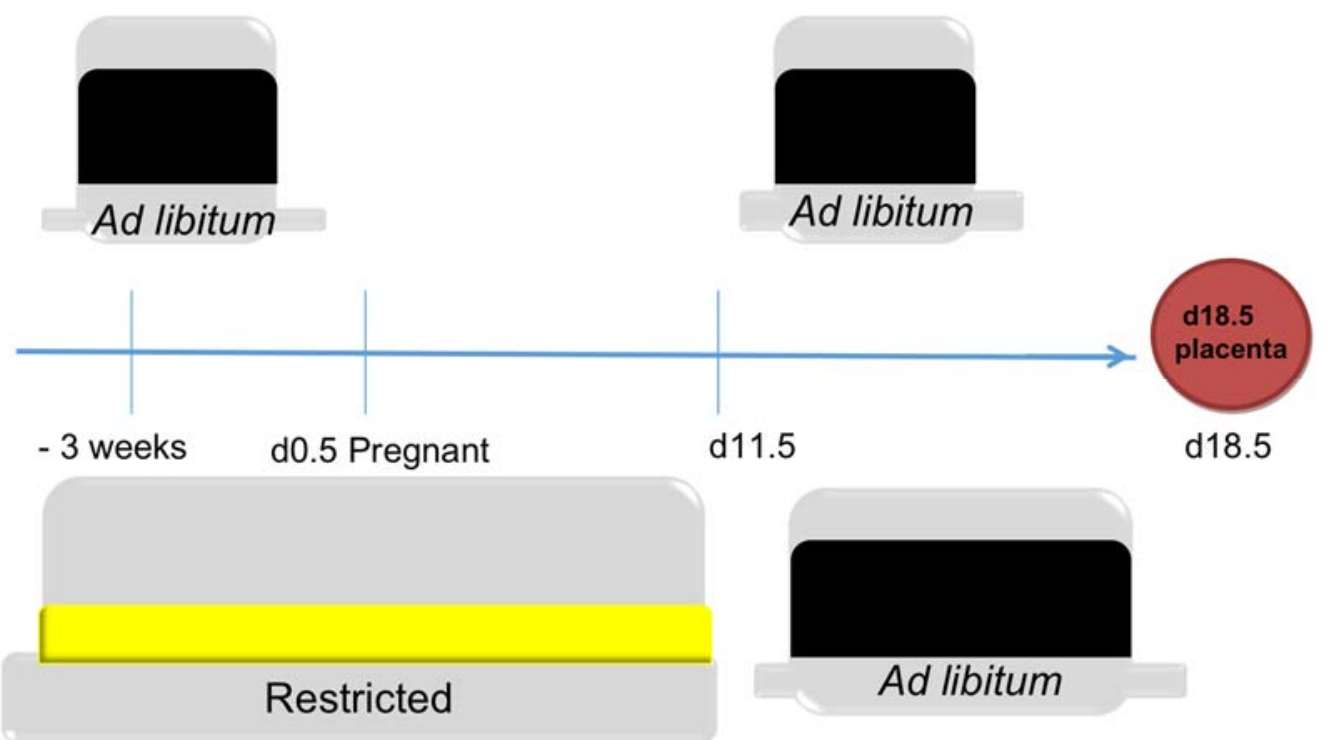

Figure 2:

Animal Study Experimental Design: 6-8 weeks old Swiss Webster mice were obtained from Harlan Tek and acclimatized to their surroundings. Dam's food consumption was measured for one week. Beginning three weeks prior to mating, mice were separated into a control fed group and a restricted group (fed $50 \%$ previous food consumption). After three weeks on their respective diets, mice were mated, and the day of plug positive was termed d0.5. At d 11.5 (mid gestation) ALL mice were placed on an ad libitum diet. At d18.5 (late gestation), mothers were sacrificed, and placentae were collected for analysis. Placental gene expression and morphology were then examined. 


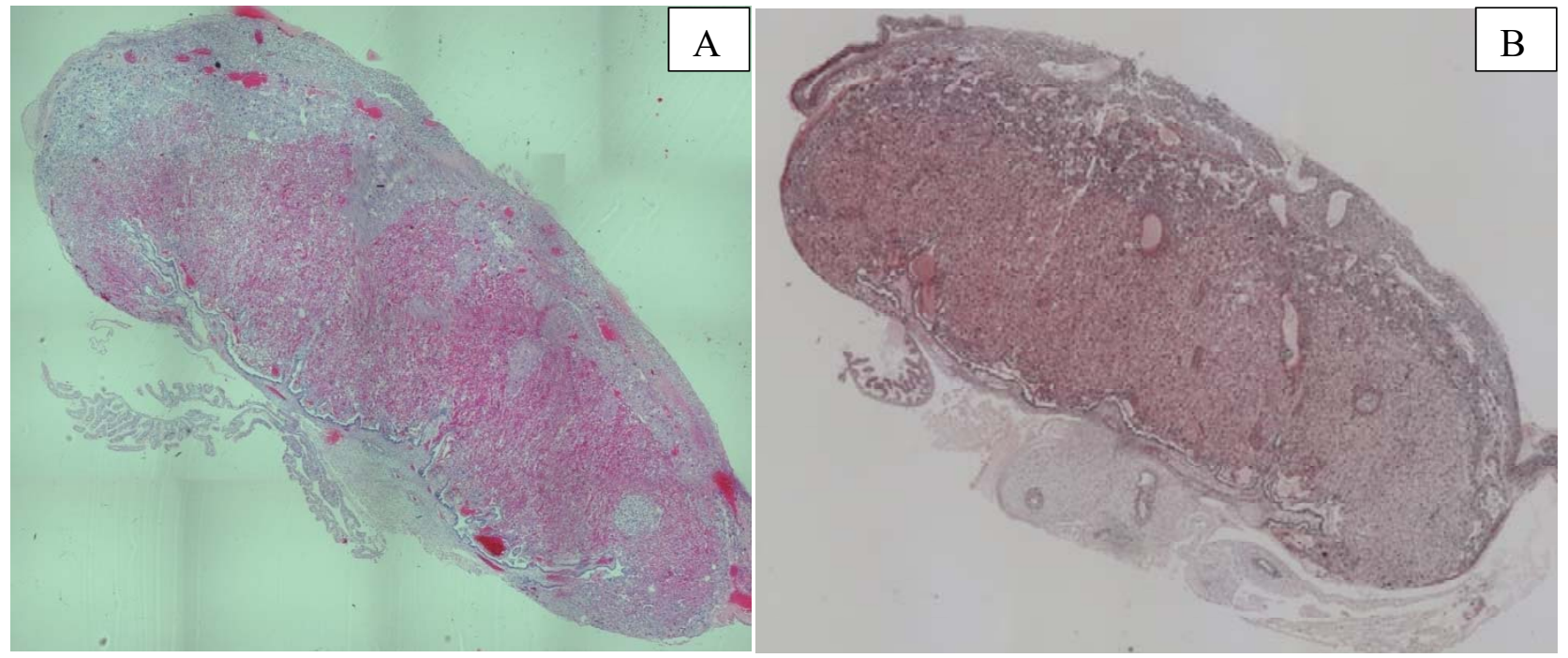

Figure 3:

d18.5 representative placental cross sections taken with a $4 \mathrm{X}$ objective and stained with hematoxylin and eosin. (A) Ad libitum (B) $50 \%$ food restriction There were no visual significant differences in the morphology. 

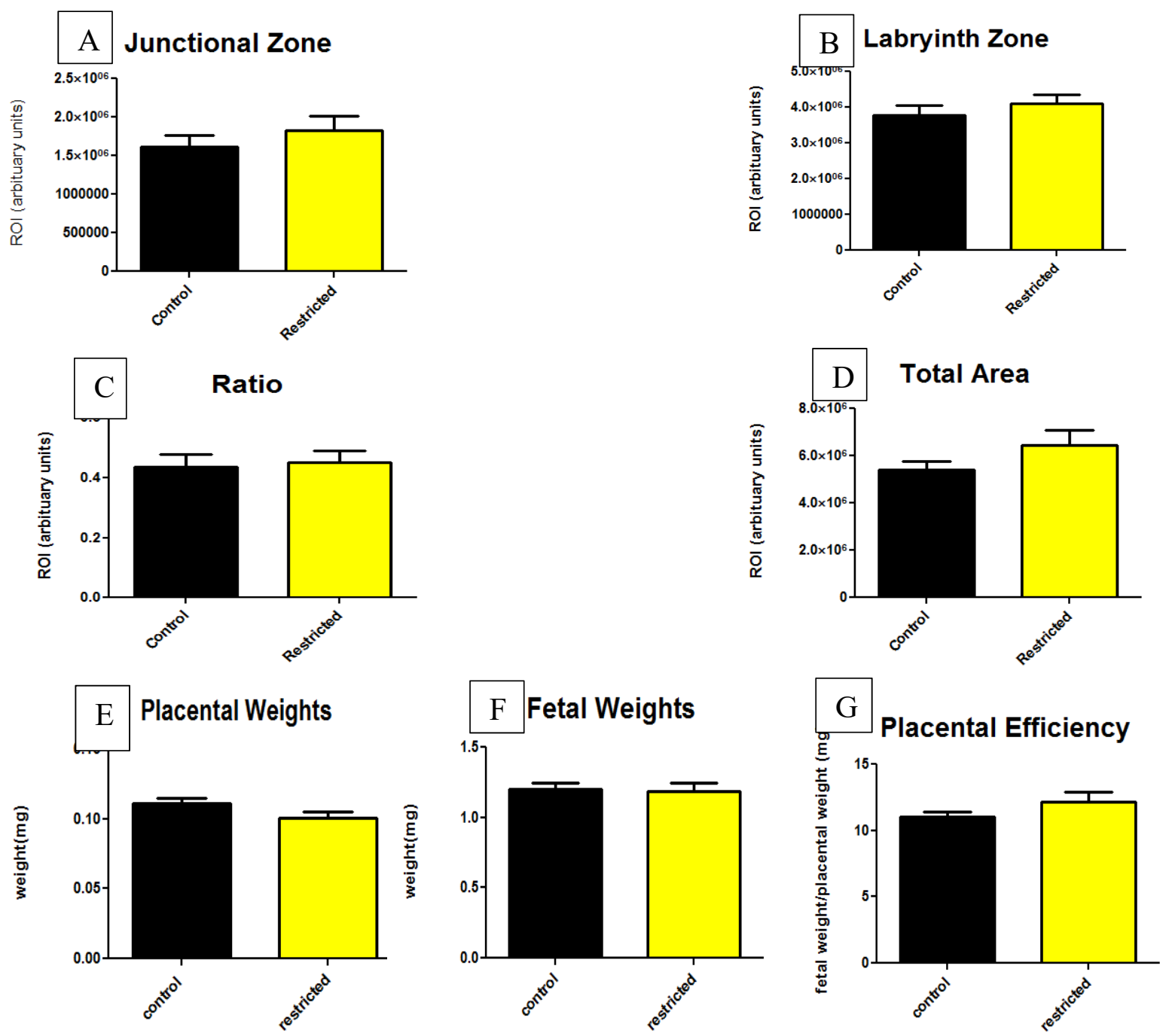

Figure 4:

Placental MorphologyMean cross-sectional areas of $(A)$ Junctional $[p=0.43]$ and (B) labyrinth [ $p=0.45]$ zone areas, $(C)$ ratio [ $p=0.80]$, (D) placental size/ total area [ $p=0.22]$. Students' $t$-test was used to compare control placentae to their food restricted counterparts. (E) Placental weights $[p=0.11]$, $(F)$ fetal weights $[p=0.85]$ and $(G)$ placental efficiency $[P=0.27]$. Results were averaged from all placentas within each dam, such that dams were considered as a single replicate [control $n=5$, restricted $n=6]$. 

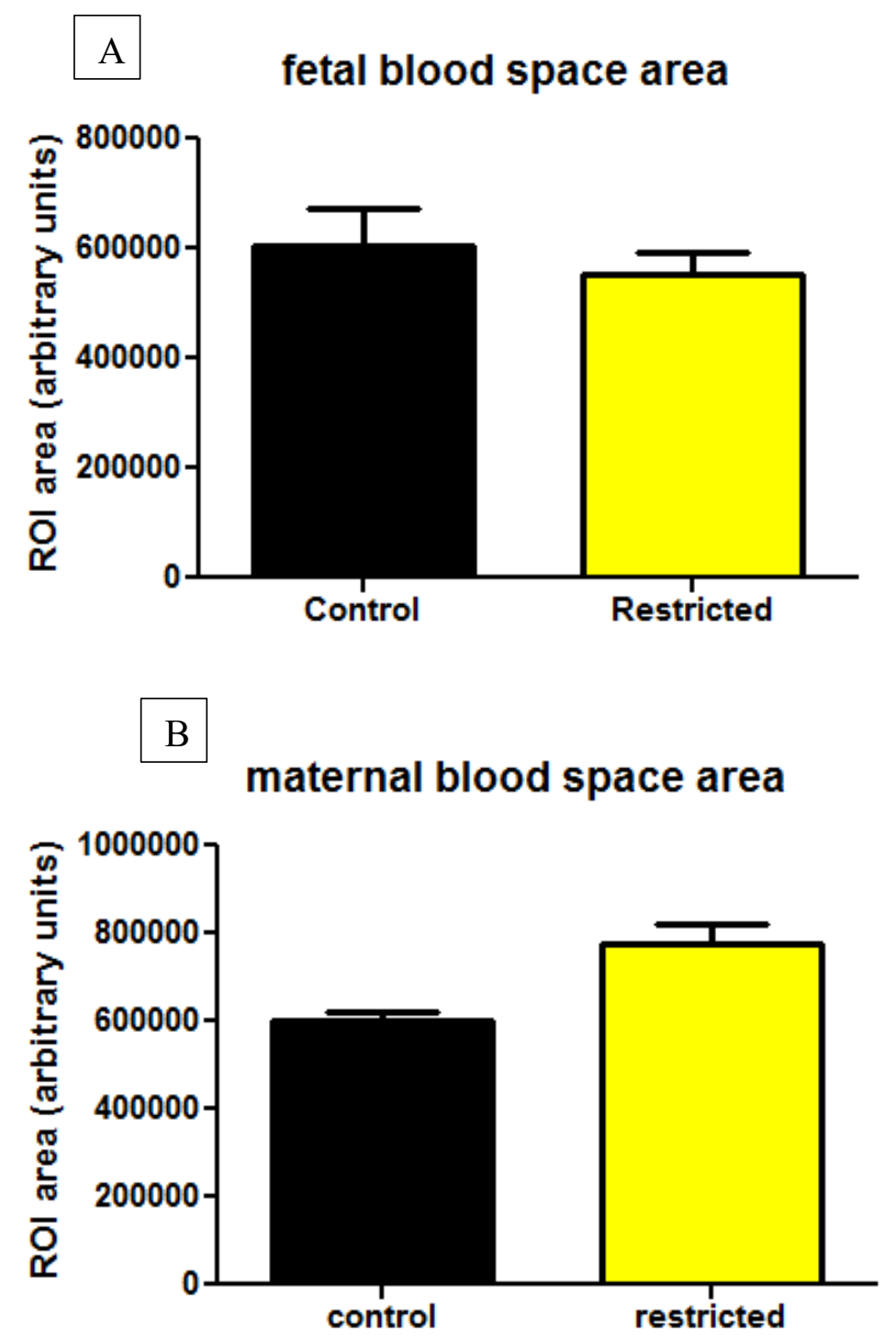

Figure 5: 
Mean cross-sectional areas of the maternal blood sinuses and the fetal blood vessels within the labyrinth zone. (A) fetal blood space areas (B) maternal blood space area. 


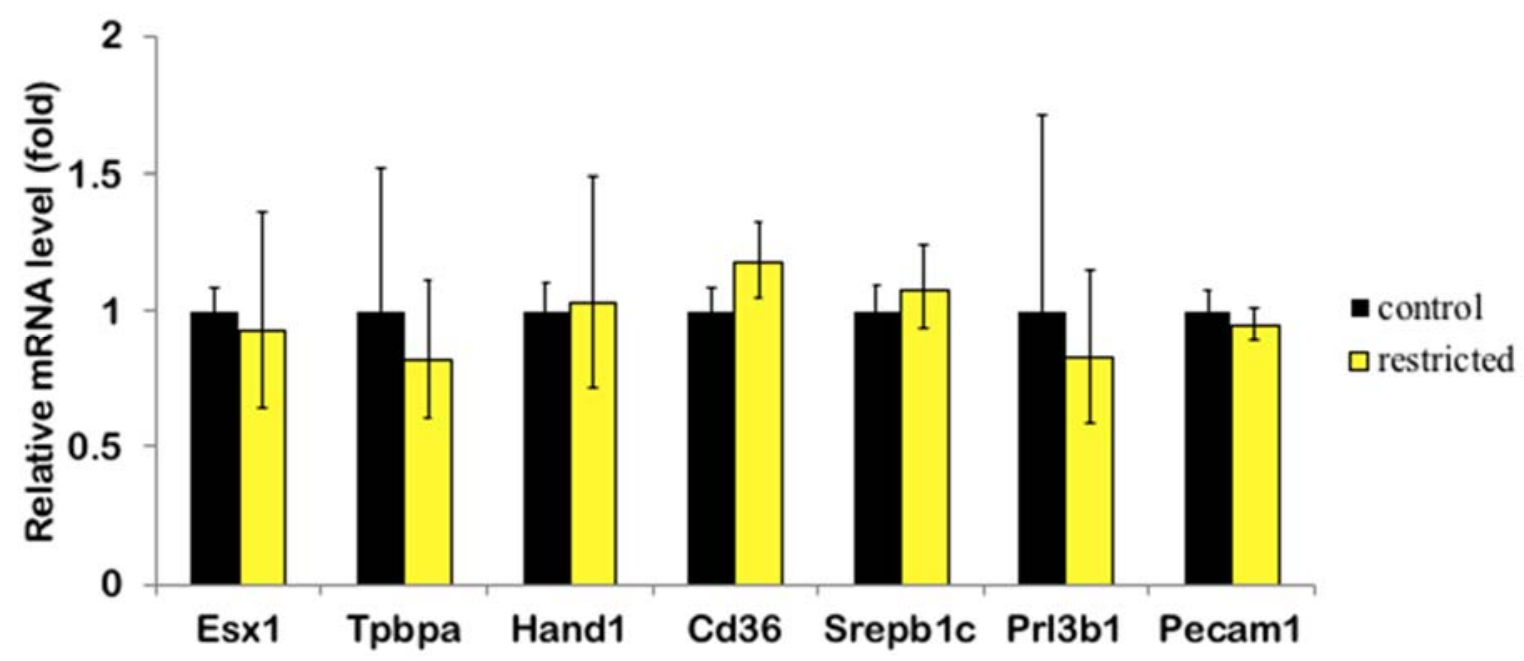

Figure 6:

Semi Quantitative Real Time PCR of d18.5 placentae of ad libitium (control) and $50 \%$ total caloric restriction (restricted) dams.

Mean control group levels are set to 1 for each transcript. Error bars are potential fold change based on standard error of CT values. slc38A4 CTSQ Esx1, Tpbpa, Hand1, CD36, Srebp1c, Prl3b1, Pecam1, linker for activation of T cells family member 1 (Lat1), linker for activation of T cells family member 2 (Lat2), slc38A1, slc2A1, slc2A3 control $(\mathrm{N}=5)$ and restricted $(\mathrm{N}=6)$ placentae 


\begin{tabular}{|c|c|c|c|}
\hline Symbol & Name & Lineage & Function \\
\hline Esxl & $\begin{array}{c}\text { Extraembryonic } \\
\text { spermatogenesis homeobox } 1 \\
\text { homolog }\end{array}$ & Syncytiotrophoblast & $\begin{array}{l}\text { Homeobox transcription factor, } \\
\text { regulates mouse embryogenesis }\end{array}$ \\
\hline Tpbpa & $\begin{array}{l}\text { Trophoblast specific } \\
\text { Protein alpha }\end{array}$ & Spongiotrophoblast & $\begin{array}{c}\text { Transcription factor essential for } \\
\text { development of } \\
\text { spongiotrophoblast }\end{array}$ \\
\hline Handl & $\begin{array}{l}\text { Heart \& neural crest } \\
\text { derivative } 1\end{array}$ & Giant Cells & $\begin{array}{l}\text { bHLH transcription factor } \\
\text { involved in tissue specific gene } \\
\text { expression, cell lineage } \\
\text { specification and differentiation }\end{array}$ \\
\hline$C d 36$ & $\begin{array}{l}\text { Cd36 antigen/ Fatty acid } \\
\text { transporter (FAT) }\end{array}$ & Predominately syncytiotrophoblast & $\begin{array}{c}\text { Transport of long chain fatty } \\
\text { acids }\end{array}$ \\
\hline Srebpl & $\begin{array}{c}\text { Sterol regulatory element } \\
\text { binding transcription factor } 1\end{array}$ & ----- & $\begin{array}{l}\text { Transcription factor, regulates } \\
\text { glucose and lipid metabolism }\end{array}$ \\
\hline $\operatorname{Prl} 3 b 1$ & $\begin{array}{l}\text { Prolactin family } 3 \text {, subfamily } \\
\text { b, member } 1 / \text { mouse placental } \\
\text { lactogen } 2\end{array}$ & Giant Cells & $\begin{array}{l}\text { Member of mouse placental } \\
\text { lactogen family }\end{array}$ \\
\hline Pecaml & $\begin{array}{l}\text { Platelet and endothelial cell } \\
\text { adhesion molecule } 1\end{array}$ & Endothelial cells & $\begin{array}{l}\text { Cell surface adhesion molecule } \\
\text { found on endothelium and WBC }\end{array}$ \\
\hline
\end{tabular}

Table 1 Location and function of placental genes examined by PCR 


\section{BIBLIOGRAPHY}

Barker, D. J. (2004). "The developmental origins of chronic adult disease." Acta Paediatr Suppl 93(446): 26-33.

Bell, A. W., W. W. Hay, Jr. and R. A. Ehrhardt (1999). "Placental transport of nutrients and its implications for fetal growth." J Reprod Fertil Suppl 54: 401-410. Bertram, C. E. and M. A. Hanson (2001). "Animal models and programming of the metabolic syndrome." Br Med Bull 60: 103-121.

Boileau, P., C. Mrejen, J. Girard and S. Hauguel-de Mouzon (1995).

"Overexpression of GLUT3 placental glucose transporter in diabetic rats." $\underline{\mathrm{J} \text { Clin }}$ Invest 96(1): 309-317.

Cleal, J. K. and R. M. Lewis (2008). "The mechanisms and regulation of placental amino acid transport to the human foetus." J Neuroendocrinol 20(4): 419-426. Coan, P. M., O. R. Vaughan, Y. Sekita, S. L. Finn, G. J. Burton, M. Constancia and A. L. Fowden (2010). "Adaptations in placental phenotype support fetal growth during undernutrition of pregnant mice." J Physiol 588(Pt 3): 527-538.

Cowden Dahl, K. D., B. H. Fryer, F. A. Mack, V. Compernolle, E. Maltepe, D. M. Adelman, P. Carmeliet and M. C. Simon (2005). "Hypoxia-inducible factors 1alpha and 2alpha regulate trophoblast differentiation." Mol Cell Biol 25(23): 10479-10491.

Curhan, G. C., G. M. Chertow, W. C. Willett, D. Spiegelman, G. A. Colditz, J. E. Manson, F. E. Speizer and M. J. Stampfer (1996). "Birth weight and adult hypertension and obesity in women." Circulation 94(6): 1310-1315. 
Dandrea, J., V. Wilson, G. Gopalakrishnan, L. Heasman, H. Budge, T. Stephenson and M. E. Symonds (2001). "Maternal nutritional manipulation of placental growth and glucose transporter 1 (GLUT-1) abundance in sheep." Reproduction 122(5): 793-800.

Das, U. G., J. He, R. A. Ehrhardt, W. W. Hay, Jr. and S. U. Devaskar (2000). "Time-dependent physiological regulation of ovine placental GLUT-3 glucose transporter protein." Am J Physiol Regul Integr Comp Physiol 279(6): R22522261.

Desforges, M., H. A. Lacey, J. D. Glazier, S. L. Greenwood, K. J. Mynett, P. F. Speake and C. P. Sibley (2006). "SNAT4 isoform of system A amino acid transporter is expressed in human placenta." Am J Physiol Cell Physiol 290(1): C305-312.

Diaz, P., J. Harris, F. J. Rosario, T. L. Powell and T. Jansson (2015). "Increased placental fatty acid transporter 6 and binding protein 3 expression and fetal liver lipid accumulation in a mouse model of obesity in pregnancy." Am J Physiol Regul Integr Comp Physiol 309(12): R1569-1577.

Edwards, L. J. and I. C. McMillen (2002). "Periconceptional nutrition programs development of the cardiovascular system in the fetal sheep." Am J Physiol Regul Integr Comp Physiol 283(3): R669-679.

El-Hashash, A. H., D. Warburton and S. J. Kimber (2010). "Genes and signals regulating murine trophoblast cell development." Mech Dev 127(1-2): 1-20. 
Fleming, T. P., W. Y. Kwong, R. Porter, E. Ursell, I. Fesenko, A. Wilkins, D. J. Miller, A. J. Watkins and J. J. Eckert (2004). "The embryo and its future." Biol Reprod 71(4): 1046-1054.

Fowden, A. L., J. W. Ward, F. P. Wooding, A. J. Forhead and M. Constancia (2006). "Programming placental nutrient transport capacity." J Physiol 572(Pt 1): 5-15.

Frankel, S., P. Elwood, P. Sweetnam, J. Yarnell and G. D. Smith (1996). "Birthweight, body-mass index in middle age, and incident coronary heart disease." Lancet 348(9040): 1478-1480.

Gardner, D. S., S. Pearce, J. Dandrea, R. Walker, M. M. Ramsay, T. Stephenson and M. E. Symonds (2004). "Peri-implantation undernutrition programs blunted angiotensin II evoked baroreflex responses in young adult sheep." $\underline{\text { Hypertension }}$ 43(6): $1290-1296$.

Gluckman, P. D. and M. A. Hanson (2004). "The developmental origins of the metabolic syndrome." Trends Endocrinol Metab 15(4): 183-187.

Harper, J. L., G. A. Caesar, K. A. Pennington, J. W. Davis and L. C. Schulz (2015). "Placental changes caused by food restriction during early pregnancy in mice are reversible." Reproduction. Harper, J. L., G. A. Caesar, K. A. Pennington, J. W. Davis and L. C. Schulz (2015). "Placental changes caused by food restriction during early pregnancy in mice are reversible." Reproduction 150(3): 165-172. 
Heasman, L., L. Clarke, T. J. Stephenson and M. E. Symonds (1999). "The influence of maternal nutrient restriction in early to mid-pregnancy on placental and fetal development in sheep." Proc Nutr Soc 58(2): 283-288.

Jansson, T. and T. L. Powell (2007). "Role of the placenta in fetal programming: underlying mechanisms and potential interventional approaches." Clin Sci (Lond) 113(1): 1-13.

Jansson, T., M. Wennergren and T. L. Powell (1999). "Placental glucose transport and GLUT 1 expression in insulin-dependent diabetes." Am J Obstet Gynecol 180(1 Pt 1): 163-168.

Kochanek, K. D., J. Xu, S. L. Murphy, A. M. Minino and H. C. Kung (2011).

"Deaths: final data for 2009." Natl Vital Stat Rep 60(3): 1-116.

Kwong, W. Y., A. E. Wild, P. Roberts, A. C. Willis and T. P. Fleming (2000). "Maternal undernutrition during the preimplantation period of rat development causes blastocyst abnormalities and programming of postnatal hypertension." Development 127(19): 4195-4202.

Lager, S., V. I. Ramirez, F. Gaccioli, B. Jang, T. Jansson and T. L. Powell (2016). "Protein expression of fatty acid transporter 2 is polarized to the trophoblast basal plasma membrane and increased in placentas from overweight/obese women." Placenta 40: 60-66.

Lesage, J., D. Hahn, M. Leonhardt, B. Blondeau, B. Breant and J. P. Dupouy (2002). "Maternal undernutrition during late gestation-induced intrauterine growth restriction in the rat is associated with impaired placental GLUT3 expression, but 
does not correlate with endogenous corticosterone levels." J Endocrinol 174(1): $37-43$.

Lumey, L. H. (1998). "Compensatory placental growth after restricted maternal nutrition in early pregnancy." Placenta 19(1): 105-111.

MacLaughlin, S. M., S. K. Walker, C. T. Roberts, D. O. Kleemann and I. C. McMillen (2005). "Periconceptional nutrition and the relationship between maternal body weight changes in the periconceptional period and feto-placental growth in the sheep." J Physiol 565(Pt 1): 111-124.

Malandro, M. S., M. J. Beveridge, M. S. Kilberg and D. A. Novak (1996). "Effect of low-protein diet-induced intrauterine growth retardation on rat placental amino acid transport." Am J Physiol 271(1 Pt 1): C295-303.

McCrabb, G. J., A. R. Egan and B. J. Hosking (1991). "Maternal undernutrition during mid-pregnancy in sheep. Placental size and its relationship to calcium transfer during late pregnancy." Br J Nutr 65(2): 157-168.

McGivan, J. D. and M. Pastor-Anglada (1994). "Regulatory and molecular aspects of mammalian amino acid transport." Biochem J 299 (Pt 2): 321-334. Mu, J., J. C. Slevin, D. Qu, S. McCormick and S. L. Adamson (2008). "In vivo quantification of embryonic and placental growth during gestation in mice using micro-ultrasound." Reprod Biol Endocrinol 6: 34.

Natale, D. R., M. Starovic and J. C. Cross (2006). "Phenotypic analysis of the mouse placenta." Methods Mol Med 121: 275-293. 
Ogden, C. L., M. D. Carroll, B. K. Kit and K. M. Flegal (2014). "Prevalence of childhood and adult obesity in the United States, 2011-2012." JAMA 311(8): 806814.

Outhwaite, J. E., V. McGuire and D. G. Simmons (2015). "Genetic ablation of placental sinusoidal trophoblast giant cells causes fetal growth restriction and embryonic lethality." Placenta 36(8): 951-955.

Plant, T. M. and A. J. Zeleznik (2014). Knobil and Neill's Physiology of Reproduction, Elsevier Science.

Ravelli, A. C., O. P. Bleker, T. J. Roseboom, G. A. van Montfrans, C. Osmond and D. J. Barker (2005). "Cardiovascular disease in survivors of the Dutch famine." Nestle Nutr Workshop Ser Pediatr Program 55: 183-191; discussion 191-185.

Ravelli, A. C., J. H. van Der Meulen, C. Osmond, D. J. Barker and O. P. Bleker (1999). "Obesity at the age of $50 \mathrm{y}$ in men and women exposed to famine prenatally." Am J Clin Nutr 70(5): 811-816.

Reynolds, L. P., P. P. Borowicz, K. A. Vonnahme, M. L. Johnson, A. T. GrazulBilska, J. M. Wallace, J. S. Caton and D. A. Redmer (2005). "Animal models of placental angiogenesis." Placenta 26(10): 689-708.

Rich-Edwards, J. W., M. J. Stampfer, J. E. Manson, B. Rosner, S. E. Hankinson, G. A. Colditz, W. C. Willett and C. H. Hennekens (1997). "Birth weight and risk of cardiovascular disease in a cohort of women followed up since 1976." BMJ 315(7105): 396-400. 
Roberts, C. T., A. Sohlstrom, K. L. Kind, R. A. Earl, T. Y. Khong, J. S. Robinson, P. C. Owens and J. A. Owens (2001). "Maternal food restriction reduces the exchange surface area and increases the barrier thickness of the placenta in the guinea-pig." Placenta 22(2-3): 177-185.

Sciullo, E., G. Cardellini, M. Baroni, P. Torresi, F. Mazziotti, P. Pozzilli and F. Fallucca (1997). "Glucose transporters (GLUT 1, GLUT 3) mRNA in human placenta of diabetic and non-diabetic pregnancies." Ann Ist Super Sanita 33(3): 361-365.

Shafiee, A., J. Patel, D. W. Hutmacher, N. M. Fisk and K. Khosrotehrani (2018). "Meso-Endothelial Bipotent Progenitors from Human Placenta Display Distinct Molecular and Cellular Identity." Stem Cell Reports 10(3): 890-904.

Simmons, D. G., S. Rawn, A. Davies, M. Hughes and J. C. Cross (2008). "Spatial and temporal expression of the 23 murine Prolactin/Placental Lactogen-related genes is not associated with their position in the locus." BMC Genomics 9: 352. Townsend, K. L., M. M. Lorenzi and E. P. Widmaier (2008). "High-fat dietinduced changes in body mass and hypothalamic gene expression in wild-type and leptin-deficient mice." Endocrine 33(2): 176-188.

Vonnahme, K. A., M. J. Zhu, P. P. Borowicz, T. W. Geary, B. W. Hess, L. P. Reynolds, J. S. Caton, W. J. Means and S. P. Ford (2007). "Effect of early gestational undernutrition on angiogenic factor expression and vascularity in the bovine placentome." J Anim Sci 85(10): 2464-2472.

Wooding, F. B., A. L. Fowden, A. W. Bell, R. A. Ehrhardt, S. W. Limesand and W. W. Hay (2005). "Localisation of glucose transport in the ruminant placenta: 
implications for sequential use of transporter isoforms." Placenta 26(8-9): 626640. 
CHAPTER 3

THE ROLE OF MATERNAL UNDER-NUTRITION AND LEPTIN IN EARLY GESTATION TO ALTER PLACENTAL PROGRAMMING IN LATE GESTATION

Gerialisa Van Gronigen Case ${ }^{1,2}$, Alexei Stuckel ${ }^{3}$, Sadia Akter ${ }^{4}$, Trupti Joshi ${ }^{5}$, Laura C. Schulz ${ }^{2}$

1 Division of Biological Sciences, University of Missouri, Columbia, MO, 2 Department of Obstetrics, Gynecology and Women's Health, University of Missouri, Columbia, MO, 3 Department of Pathology and Anatomical Sciences, Columbia, MO, 4 Informatics Institute, University of Missouri, Columbia, MO, 5 
Department of Health Management and Informatics, School of Medicine; MU Informatics Institute; University of Missouri-Columbia 


\section{INTRODUCTION}

Chronic diseases such as diabetes, obesity and hypertension affect not only the US, but are a major concern worldwide. Among the US population 29.1 million (9.3\%) are diabetic, of which more than one third (35.7\%) of the adults and $17 \%$ of the children are considered obese. Among this group, heart disease is the leading cause of death affecting approximately 600,000 and 1 in every 4 persons dies from this condition. Though factors such as genetics, improper diet and lack of exercise play roles in predisposing individuals to adult disease, maternal nutrition during pregnancy leads to an increased chance of offspring developing chronic diseases such as obesity, diabetes and hypertension as adults(Gluckman, Hanson et al. 2008), (Barker 2004), (Curhan, Chertow et al. 1996),(Frankel, Elwood et al. 1996),(Rich-Edwards, Stampfer et al. 1997) (Heijmans, Tobi et al. 2008). Barker and colleagues referred to this as a phenomenon known as programming in which they linked the permanent adaptation of the fetus in response to an adverse in utero environment which may be unsuitable for an environment of adequate nutrition thus contributing to an increased risk of individuals developing metabolic diseases later in life.

Studies show changes in the epigenome are important to embryonic development and may be the link between events that occur in utero and metabolic phenotype of the offspring in later life. Epigenetics means above genetics and refers to heritable changes in gene expression that occur without 
changes in the DNA sequence (Waddington 2012). Epigenetic modifications include DNA methylation and histone modifications. DNA methylation involves the transfer of a methyl group to the $5^{\text {th }}$ carbon of a cytosine ring and occurs at cytosine phosphodiesterly bonded to a guanine (CpG) context. $\mathrm{CpG}$ islands are predominantly located within promoter regions which are typically unmethylated (Gardiner-Garden and Frommer 1987),(Takai and Jones 2002), (Takai and Jones 2002), (Bird, Taggart et al. 1987). DNA methylation within the promoter region mostly suppresses gene expression by blocking transcription the binding of transcription factors while promoting the binding of repressive proteins. DNA methylation is important in regulating development and disease and be impacted by maternal nutrition thus acting as link between how adverse maternal environment alters offspring metabolism to predispose them to chronic diseases. Several studies show maternal diet before and during conception impacts both offspring and adult health. For example, epidemiology studies of children born to mothers who experienced the 1945 Dutch Hunger famine during their first 10 weeks of pregnancy indicated DNA hypomethylation of insulin growth factor 2 (IGF2) gene (Heijmans, Tobi et al. 2008) and an increase susceptibility to cardiovascular disease and obesity as compared to their same sex siblings who were not exposed to the famine (Heijmans, Tobi et al. 2008, Tobi, Lumey et al. 2009). This illustrates how maternal food restriction during early pregnancy, followed by adequate nutrients later in gestation predisposes the offspring to metabolic diseases as adults. Evidences shows changes in promoter methylation of the genes for glucocorticoid receptor which could act as an activator of growth 
hormone to control body growth to predispose offspring to obesity, changes offspring insulin response. There was also changes in the promoter region of the gene for peroxisome proliferator activated receptor $\alpha$, which is associated with fatty liver disease(McMillen and Robinson 2005). These changes in the methylation of genes associated with chronic diseases suggests that DNA methylation could be the link by which maternal under nutrition alters offspring metabolic phenotype to predispose them to chronic diseases. Other evidence demonstrates, treatment of obese offspring with leptin treatment reverses obesity, thus suggesting that leptin may play a role in protecting offspring for these adverse metabolic phenotypes (Gluckman, Lillycrop et al. 2007). Replacing methyl in the diet was another way to reverse the changes a maternal malnourished diet had on offspring phenotypic outcomes (KD SINCLAIR). Taken together, these studies demonstrated a link between maternal nutrition and epigenetic modifications to predispose offspring to metabolic diseases.

The placenta can act as a nutrient sensing organ to regulate the amount of maternal nutrients transported to the fetus (Nam, Greenwald et al. 2017). Since the placenta is in direct contact with the maternal environment, it is possible that placental functions, as well as expression and methylation levels, may respond to environmental stimuli predisposing the offspring to adult disease.(Fowden, Coan et al. 2011), (Sood, Zehnder et al. 2006), (Guo, Choufani et al. 2008). Data from our lab indicate at d11.5, total maternal caloric restriction in mice during the first half of pregnancy resulted in placental labyrinth sparing 
and altered gene expression (Schulz, Schlitt et al. 2012); however by d18.5, after all animals were returned to an ad libitum diet, there were no differences in placental development(Harper, Caesar et al. 2015). Maternal nutrition also alters placental morphology and DNA methylation, suggesting methylation of the placental may be a link between changes in maternal nutrition and adverse offspring phenotype. This suggests placental adaptations in order to maintain the transfer of nutrients to the fetus thus preserving fetal growth and that the placenta may be susceptible to programming. Mouse placenta is biologically similar in comparison to a human. In humans and mice, trophoblast cells of the placenta invade and attach to the uterine lining and the syncytiotrophoblast region serve as an area of exchange between the mother and the fetus. As such, the mouse serves as a good animal model for human studies.

Leptin is a $16 \mathrm{kDa}$ hormone that is secreted in direct proportion to the amount of white adipose tissue. Leptin is involved in energy homeostasis and plays a role in reproduction. In rats, maternal undernutrition during pregnancy programs the offspring to obesity which is exacerbated when a post-natal high fat diet. Leptin treatment prevented obesity in females but had no effect on the male offspring born to mothers exposed to food deprivation(Seckl 2004, Vickers, Gluckman et al. 2005, Gluckman, Lillycrop et al. 2007). Leptin is also involved in the regulation of insulin signaling which can be altered by maternal nutrition to change offspring phenotype. These responses demonstrate leptin has a role in fetal programming. We hypothesized leptin would acts a mediator by which maternal nutrition would be associated with fetal programming. Previously in our 
lab we found, $50 \%$ food restriction and leptin supplementation in early gestation, followed by an adequate diet in late gestation predisposed the female offspring to obesity and insulin resistance (Pennington, Harper et al. 2012). Our goal is to determine the molecular mechanism by which maternal under nutrition (MUN) early in gestation alters the placenta in late gestation to predispose offspring to adult diseases. We hypothesize maternal nutrient restricted diet with leptin supplementation from day $0.5-\mathrm{d} 11.5$ of pregnancy followed by an adequate fed diet from d11.8-d18.5 of pregnancy alters placental development via changes in DNA methylation to cause changes in offspring phenotype.

METHODS

ANIMALS

All animal procedures were approved by University of Missouri Institutional Animal Care and Use Committee. Swiss Webster mice 6-8 weeks old and $\geq 25 \mathrm{~g}$ were obtained from Harlan Tek (Harlan, Indianapolis, IN), individually housed in a $12 \mathrm{hr}$ dark, $12 \mathrm{hr}$ light cycle and fed an AIN-93G chow ad libitum for one week to acclimatize to their surroundings. Specialized feeding containers were used so that daily food consumption could be recorded (Townsend, Lorenzi et al. 2008). Three placentae were chosen from three different dams in each treatment group. An overview of the experimental design is presented in Figure 1A. Females were mated with control fed males and plug positive was termed d0.5. At d1.5 after a copulatory plug was observed, females were separated into three treatment 
groups: control fed ad libitum and given a saline injection, restricted: fed $50 \%$ of their previous average daily intake and given a saline injection, and leptin: fed $50 \%$ of average daily intake and given a leptin injection. At d11.5, all mice were fed ad libitum until tissue collection. At d18.5, mice were euthanized using $\mathrm{CO}_{2}$ asphyxiation and cervical dislocation. Placentae were collected and stored at$80^{\circ} \mathrm{C}$ until further analysis.

PCR

Total RNA was extracted as previously described. Briefly, placental tissue was homogenized in Trizol Reagent (Sigma Aldrich) with an Omni GLH Homogenizer. After phase separation, RNA was further purified using kit (Clonetech) according to manufacturer's protocol. Two $\mu \mathrm{g}$ of total RNA was reversed transcribed with SuperScript III First-Strand Synthesis System (Invitrogen/Life Technologies, Grand Island, NY), using random hexamer primers, according to manufacturer's protocol. TSH2 $\beta$ (Diagenode) and GAPDH (Diagenode) primers specific to their respective $\mathrm{CpG}$ regions in mouse were used to test the binding capacity of MBD2/MBD3L protein complex in MiRA.

\section{WHOLE GENOME DNA METHYLATION MICROARRAYS}

Genomic DNA was extracted from the placenta by using DNeasy Blood and Tissue Kit (Qiagen). Ten $\mu$ g DNA was sonicated on ice for 30 secs intervals on high for 12 minutes using a Diagenode Bioruptor (Diagenode). The 
fragmented DNA was separated on 1.2\% Superfine Agarose gel stained with Sybr green (Lonza). Bands at 500bp were excised from the gel and purified using Qiagen MinElute PCR purification kit (Qiagen) according to manufacturer's protocol. Methylated Island Recovery Assay (MiRa) (Active Motif North America) was used to obtain a fraction enriched with methylated DNA according to manufacturer's protocol (Fraga, Ballestar et al. 2003). The methylated DNAenriched fraction and unenriched input control were subjected to whole genome amplification using GenomePles Compler Whole Genome Amplification (Sigma). Input samples were labeled with Cy3 and methyl enriched samples were labeled with Cy5 using NimbleGen Dual Color DNA Labeling kits and then hybridized to a NimbleGen mouse 3x720K CpG Island/promoter tiling microarray by MoGene LC (St Louis.) The signal intensities were extracted by using DEVA software. Identification of Differentially Methylated Regions

NimbleScan v2.5 and NimbleGen Software (NimbleGen, Roche, Madison, WI, USA) were used to identify methylated peaks. The Cy3 and Cy5 signals were normalized using segMNT algorithm and the $\log _{2}$ ratios were scaled to center the ratio data near zero by subtracting the bi-weight mean for the log2 ratio values for all features on the array from each log2 ratio value.

Methylated regions were identified by a non-parametric, one sided KS test and a modified ACME algorithm using normalized $\log _{2}$ ratio. For the KS test, a pvalue was assigned to each region by comparing the average $\log _{2}$ ratio across 4 or more probes within a 500 bp sliding window to the mean log2 ratio across the array(Scacheri, Davis et al. 2006). A region with KS score above $2(-\log 10$ (p- 
value)) was considered methylated. NimbleGen's SignalMap software was used to visualize methylation levels from each individual region.

Bedtools was used to identify DNA regions that were methylated in all three biological replicates in one treatment group, but none of the biological replicates in another group. Such regions were considered to be differentially methylated in each pairwise comparison of treatment groups. For each sample BED file, DNA methylation peaks were numerically sorted based on chromosome number and start-end position, using the unix sort command: sort $-\mathrm{k} 1,1-\mathrm{k} 2,2 \mathrm{n}$ input_file.BED > sorted_file.BED. Sorted peak coordinates of individual biological replicates from each group $(n=3)$ that overlapped were merged as a single peak by bedtools merge tool: mergeBed -i input_file.BED > merged_file.BED. This defined methylated regions common to all replicates within each treatment group. The merged BED files from each group were then used in a series of comparisons: [Restricted ${ }^{A}$ vs. Leptin $\left.{ }^{B}\right]$, [Restricted ${ }^{A}$ vs. Control $^{B}$ ], [Leptin ${ }^{A}$ vs. Restricted ${ }^{B}$ ], $\left[\right.$ Leptin $^{A}$ vs. Control ${ }^{B}$ ], [Control ${ }^{A}$ vs. Restricted $\left.^{\mathrm{B}}\right]$, [Control ${ }^{\mathrm{A}}$ vs. Leptin $\left.{ }^{\mathrm{B}}\right]$. Using the (-v) option from bedtools intersect function: intersectBed -a Group ${ }^{A}-b G \operatorname{Group}^{B}>$ unique_peaks_in_Group ${ }^{A}$, peaks exclusively present in Group ${ }^{A}$ were identified, resulting in 6 unique methylation peak files. The genomic coordinates contained within each peak file were annotated using HOMERv4.3 (Hypergeometric Optimization of Motif EnRichment) with default settings for mouse assembly build $\mathrm{mm} 9$.

Log2 ratios and KS scores were computed for each differentially methylated region for each of the nine samples by averaging data from all of the 
probes contained within that region using the $\mathrm{R}$ software platform. These average values were used to construct heat maps and compare methylation levels across samples for each region.

IDENTIFICATION OF PATHWAYS ASSOCIATED WITH DIFFERENTIALLY METHYLATED REGIONS

Ingenuity Pathway Analysis (IPA, QIAGEN Redwood City, CA www.qiagen.com/ingenuity), a bioinformatics tool, was used to identify pathways and functions overrepresented among the genes associated with regions differentially methylated by maternal food restriction and/or leptin treatment. The analysis was run using all defaults setting for the selection of dataset, 2-fold change cutoff, FDR $=0.001$ and $p$-value $=0.001$.

\section{RESULTS}

\section{VALIDATION OF METHYLATED ISLAND RECOVERY ENRICHMENT ASSAY}

Sonication produced 500bp fragments of genomic DNA (Fig 2A). Positive and negative controls indicated enrichment of methylated DNA by the MiRA procedure (Fig $2 \mathrm{~B}$ ). A region of $\mathrm{TSH} 2 \beta$ that is highly methylated within somatic cells, was enriched approximately 10 -fold in the pulled down fraction, whereas an unmethylated region of the GAPDH promoter was not. 


\section{IDENTIFICATION OF DIFFERENTIALLY METHYLATED REGIONS IN THE PLACENTAE AMONG CONTROL, RESTRICTED AND RESTRICTED + LEPTIN TREATED MICE}

Overall, at d18.5, there were 95 DMRs from placentae of the dams fed ad libitum (control) versus placentae from dams fed a $50 \%$ food restricted diet (restricted) from days 1.5-11.5 of gestation. There were 169 DMRs between control dams and dams fed a $50 \%$ food restricted diet with leptin supplementation (leptin) and 105 regions differentially methylated between placentae of the restricted and leptin groups. This indicated there were more differences in placental DNA methylation when food restricted dams were given leptin supplementation than when they were only $50 \%$ food restricted (Fig 3 ). Similarly, clustering analysis showed the highest number of DMRs were in the ad lib diet fed dams and dams fed a 50\% food restricted diet with leptin supplementation as compared to placentae from the other treatment groups pairwise comparisons. (Figs 3B-E). These evidences suggest, maternal undernutrition in early pregnancy followed by adequate nutrition during the latter half of gestation altered the number of DMRs in near term placenta and leptin supplementation exacerbated these effects. 


\section{GENOMIC LOCALIZATION OF DIFFERENTIALLY METHYLATED REGIONS}

Regions that were differentially methylated in the restricted and leptin groups relative to the control group were most commonly located within intergenic regions, with $52.8 \%$ of the DMRs within intergenic regions in the control versus $50 \%$ food restriction and leptin supplementation comparison (Fig $4 \mathrm{~A}$ ) and $48.4 \%$ of the DMRs in the control versus restricted comparison (Fig 4B). On the other hand, $25 \%$ of the DMRs were located within exons in the restriction and leptin supplementation versus restricted placentae (Fig 4C). DMRs were also found within the promoter-transcription start site (TSS), 5' and 3' UTR, and transcription termination site (TTS). Although all murine RefSeq promoters are represented on the array $(20,404$ total), only 49 promoter regions were differentially methylated among the three treatment groups.

\section{DIFFERENTIALLY METHYLATED PROMOTER REGIONS}

To identify the promoter DMRs with the greatest differences in methylation, peak scores, and Cy5/Cy3 ratios were averaged across each DMR and fold-changes calculated.

Genes associated with the most DMRs found on both our dendogram as well as on signal map intensity along with having functional regulation in the placentae are discussed here. In the placentae from dams fed ad libitum versus the $50 \%$ food restriction, leptin supplementation pairwise comparison AKT3 DMR 
was -74366 base pairs from the transcription start site and located on an intergenic region on chromosome 1 between base pairs 179253140-179253388 with a fold increase of 1.7 fold in peak $p$ value score in the control group. When Histone 3 is methylated on the Lysine 4 , this configuration is suggestive of an enhancer present. Data from the encode project indicated that this region is bound to $\mathrm{H} 3 \mathrm{~K} 4 \mathrm{me} 1$ in the placenta, suggesting it is an enhancer region (Fig $5 \mathrm{~A}$ ). Between the ad libitum fed dams and $50 \%$ food restriction group, Sh2d7 DMR was -2480 base pairs from the transcription start site and located on a MIR/SINE on chromosome 9 between base pairs 54383832-54384791, with fold difference in methylation score of 5.4 in the control group. There was no enhancer present. (Fig 5B). In the $50 \%$ food restriction and leptin supplementation versus $50 \%$ restricted, the most differentially methylated region was associated with EMI1 gene which was -18238 base pairs from the transcription start site and located on an exon region on chromosome 12 between base pairs 109590805-109591446, with fold increase in methylation scores of 5.6 in the placentae from mothers fed a nutrient restricted diet during early pregnancy followed by an adequate diet in the latter half of gestation. Data from the encode project indicated that this region is bound to $\mathrm{H} 3 \mathrm{~K} 4 \mathrm{me} 1$ in the placenta, suggesting it is an enhancer region. (Fig 5C). Representative images of these DMRs are in Figs 5A-C.

\section{IDENTIFICATION OF PATHWAYS ASSOCIATED WITH DMRS}

IPA core analysis was used to find functional pathways overrepresented among genes associated with the differentially methylated regions, to better 
understand their functional significance (Tables 1-3). The most significant molecular and cellular functional pathways associated with DMRs in placentae exposed to maternal undernutrition in early gestation were cellular function and maintenance, cell death and survival, cell compromise, molecular transport and cell cycle; in the leptin versus restricted pairwise comparison, lipid metabolism, small molecule biochemistry, carbohydrate metabolism, cell cycle and cell death and survival ; and in control versus leptin pairwise comparison, they were cell to cell signaling and interaction, carbohydrate metabolism, cell cycle, cell death and survival and cell morphology

\section{DISCUSSION}

Alterations in DNA methylation are associated with functional and phenotypic changes (waterland and jirtle, K.D Sinclair) in multiple tissues. Aberrant DNA methylation during development also can play a role in promoting adult disease. For example, IGF2 hypomethylation and obesity of offspring, agouti mouse. It has additionally been shown that maternal food restriction in late gestation altered placental DNA methylation at term in a sex specific manner with males being more affected than females (Chen, Ganguly et al. 2013). Our study is the first to demonstrate that a maternal nutrient-restricted diet in early gestation could alter DNA methylation in the placenta in late gestation. MIRA (methylatedCpG island recovery assay) combined with $\mathrm{CpG}$ island promoter microarrays was used to identify differentially methylated regions and genes associated with 
these regions that had aberrant methylation changes in placental tissue due to changes in maternal diet. We chose a conservative approach to identifying DMRs.

Further examination of the functions of genes associated with DMRs with the highest fold changed difference in DNA methylation levels and with a peak $p$ value score greater than 2 supports out hypothesis maternal nutrition during early gestation alters DNA methylation in a manner that changes metabolic phenotype of offspring which may increase their chances of chronic diseases later in life. Biological replicates from each treatment ground tended to cluster together. the pairwise treatments predominantly clustered together. Genes associated with DMRs with the highest fold change difference in the ad libitum fed versus $50 \%$ food restricted and leptin supplementation group included Pleckstrin and Sec7 Domain Containing 3 (Psd3) and AKT3 which had a relatively moderate difference in methylation levels.

AKT kinases are regulators of cell signaling in response to insulin and growth factors and are involved biological processes such as cell proliferation, differentiation as well as glycogen synthesis and glucose uptake (Ramachandran and Saravanan 2015). Phenotypes associated with AKT3 mutations include abnormal cardiovascular system phenotype, which can be seen by changes in the morphological and physiological characteristics of the heart, blood vessels, and circulatory system, as well as abnormal growth, and size(Pinheiro, TanusSantos et al. 2017). In the placenta, Akt3 plays a role in cell migration. Trophoblast from spongiotrophoblasts migrates into the uterine lining for 
attachment and invasion and remodeling spiral artery to ensure adequate transfer of nutrients from the mother to the fetus. Changes in methylation of AKT3 may affect expression and function to subsequently alter the process of nutrient transfer from the mother to the fetus in either a negative or positive way thus changing an offspring's projective growth curve to possibly increasing their odds of chronic disease as adults. Future studies are needed to address this hypothesis. AKTs is also important as it is linked to defects in insulin stimulation which is associated with preeclampsia. Preeclampsia is a disease associated with the placenta and is due to improper invasion and remodeling of the spiral artery and usually leads to fetal and maternal mortality (Orcy, Schroeder et al. 2008, Ferreira, Orcy et al. 2011).

In the ad libitum versus $50 \%$ food restricted group genes associated with the region with the highest fold change differences in methylation according to both our heatmap analysis and quantitative visualization of the levels of methylation was $\mathrm{SH} 2$ Domain Containing 7 (Sh2d7), whose function is unknown, though it appeared to be expressed in the placenta and is highly expressed in the adipocytes. In adipose tissue from monozygotic twins where only one of the pair has type 2 diabetes, sh2d7 was differentially methylated. It could be inferred that this differential methylation in the placenta could be transferred to the offspring, thus suggesting a role for this gene in promoting chronic disease(Nilsson, Jansson et al. 2014).

In the pairwise comparison between the $50 \%$ food restricted group and the $50 \%$ food restricted, leptin supplementation groups, Echinoderm Microtubule 
Associated Protein Like 1 (Eml1) had the highest fold change difference which correlated well in both our heat map and methylation level analysis in signal map. Eml1 has altered expression in placentae of offspring with intrauterine growth restriction(Wen, Chen et al. 2017).

In our IPA core analysis, we saw genes associated with DMRs mapped to biological networks involved in carbohydrate and lipid metabolism and molecular transport. This supported the idea that either maternal diet during early gestation and/or leptin supplementation may change the way these molecules are used by the placenta or the amount of nutrients that will be transported across the placenta to the fetus for growth, thus altering metabolism or growth of the offspring to possibly increased their chances of chronic diseases later in life. Deviations in these pathways may be a plausible explanation by which changes in placental DNA methylation may be linked to maternal nutrition and altered offspring phenotype.

Previously, we demonstrated that $50 \%$ maternal nutrient restriction in mice from gestation days 1.5-11.5 altered placental morphology and gene expression at d11.5 (Schulz, Schlitt et al. 2012), but that if dams were returned to ad libitum feeding at d11.5, placentae completely recovered by d18.5 (Harper, Caesar et al. 2015), and offspring were not significantly affected in adulthood (Pennington, Harper et al. 2012). Here we found a maternal nutrient restricted diet of 50 percent total caloric intake increased the number of differentially methylated region regions in the placentae as compared to placentae from dams fed an adequate diet. Food restriction causes leptin levels to fall which is associated 
with predisposing offspring to chronic disease later in life. We hypothesized returning leptin levels to normal would protect offspring from the deleterious effects of an adverse maternal environment. Hyperleptenima, however further promoted these offspring to chronic diseases by aberrant methylation levels in promoter regions of genes involved in promoting abnormal body growth and phenotype to possibly predispose offspring to hypertension, obesity and diabetes. This is in line with our studies of the largest number of DMRs being in placentae of offspring fed an adequate diet as compared to offspring born to dams who were fed a nutrient restricted diet and treated with leptin. This correlates with offspring of dams that were only food restricted, offspring of dams that were supplemented with leptin during food restriction were more obese at 6 months of age (Pennington, Harper et al. 2012)

The use of MiRA assay followed by CpG island promoter microarray proved to be an effective way to identify DNA regions that were epigenetically altered by diet in placental tissue. More differential methylation was detected in the food restriction and leptin supplementation group than in the restriction group alone, consistent with the observation of greater metabolic disturbances in the offspring born to the leptin supplemented pregnancies. These suggest that DNA methylation in placenta may provide possible molecular markers to identify individuals who are more predisposed to metabolic diseases due to maternal diet during gestation and to develop interventions to alleviate these adverse outcomes. 


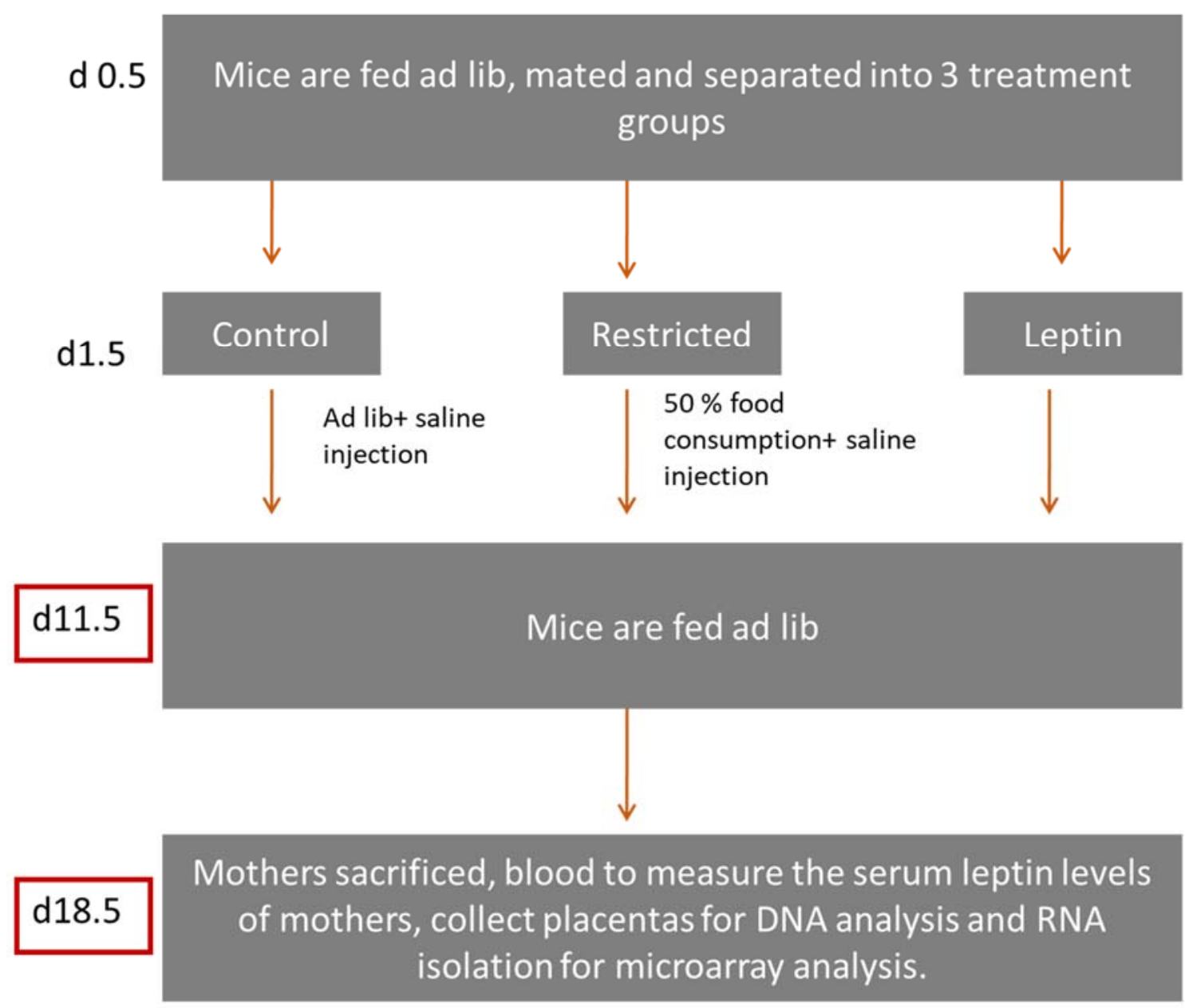

Figure 7: Experimental design 


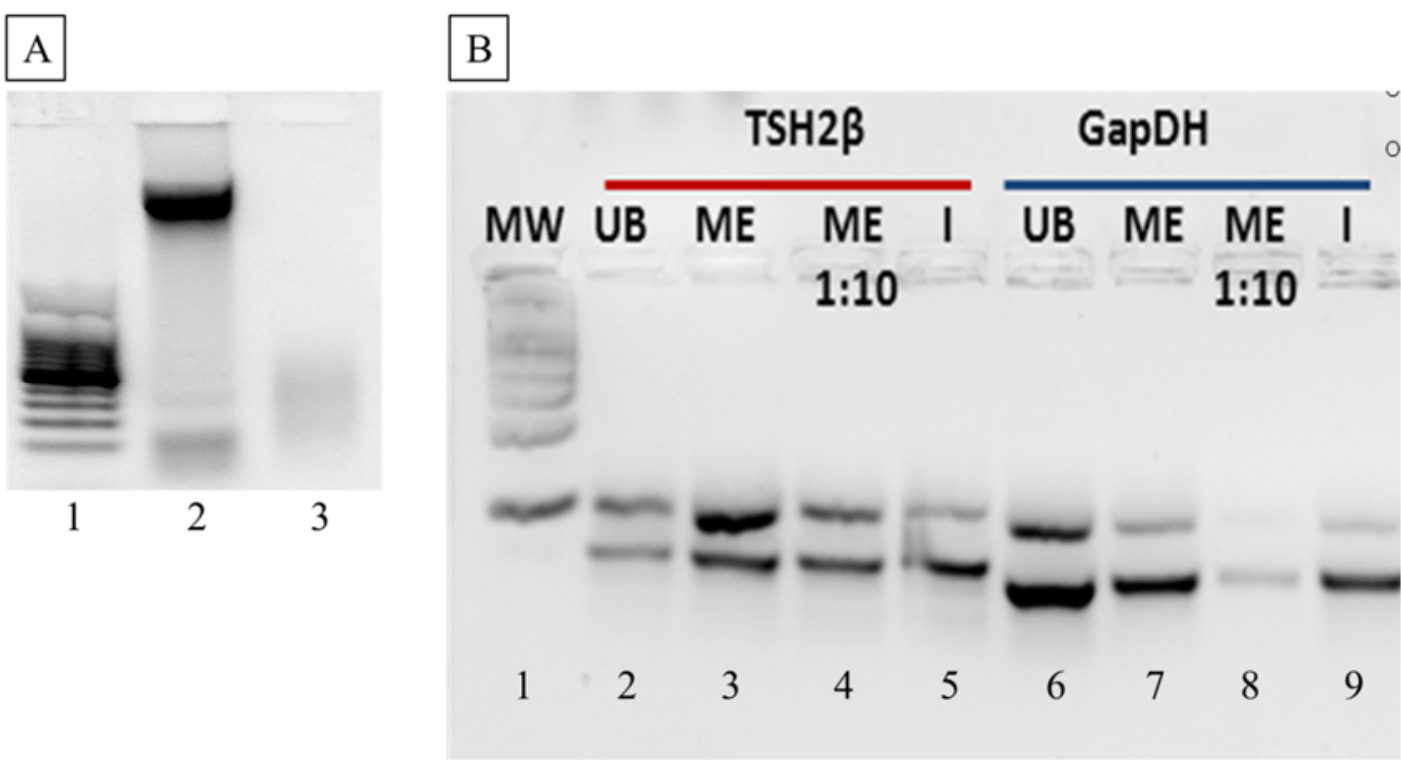

Figure 8:

Validation of Methylated Island Recovery Enrichment Assay(A)Fragmentation of DNA. Lane 1: NEB 100 bp molecular weight marker. Lane 2: unfragmented DNA. Lane 3: fragmented DNA (B)The PCR product amplified with mouse TSH2B primer pair (cat \# pp-1042-050, -500) as described in Figure 1 was analyzed by electrophoresis ( $2 \%$ agarose gel stained with SYBR Safe). A $51 \mathrm{bp}$ product was obtained in MiRA unbound and input DNA fractions with GAPDH. Lane 1: NEB $1 \mathrm{~kb}$ molecular weight marker. Lane 2: unbound fraction. Lane 3: pull-down fraction was enriched for methylated DNA as indicated by the thicker, darker bands at $101 \mathrm{bp}$ of TSH2 $\beta$ in the methyl enriched (ME). Lane 4: The 1: $10 \mathrm{ME}$ dilution, lane 4 of TSH2b (methylated DNA) indicated a band of much lighter intensity corresponding to a 10 percent dilution as compared to the darker band in lane 3. Lane 5: in the control fraction containing both methylated and unmethylated DNA. Lanes 6-9 are 51bp amplicons of primers specific to an unmethylated promoter region within the GAPDH gene of the mouse. Lane 6 is 
an unbound fraction of MiRa. Lane 7 is the methyl enriched fraction. Lane 8 is the 1:10 dilution. Lane 9 is the control fraction contain both methylated and unmethylated DNA. 


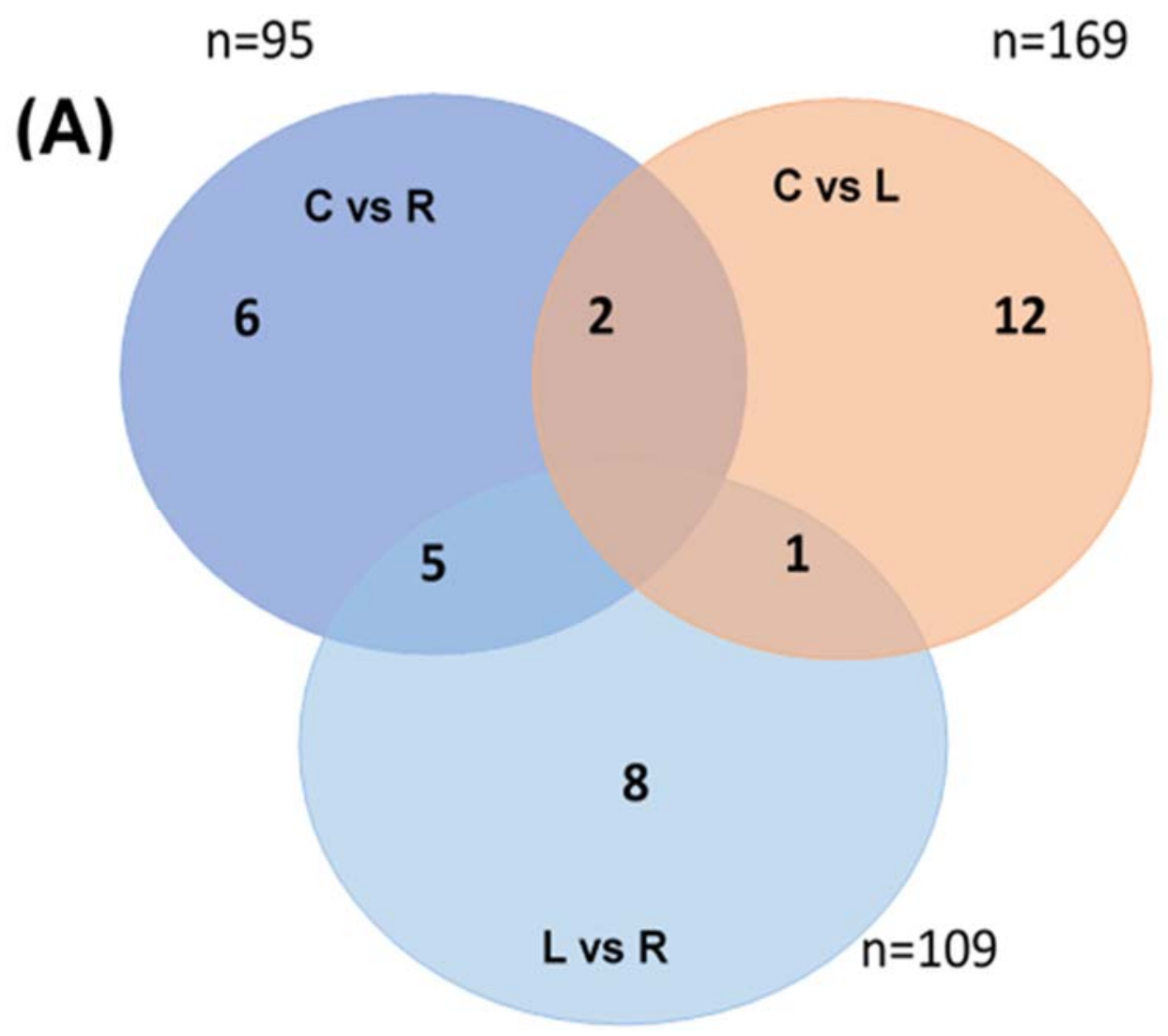

Figure 9:

Identification of Differentially Methylated Regions in the Placentae among Control, Restricted and Restricted + Leptin treated mice 

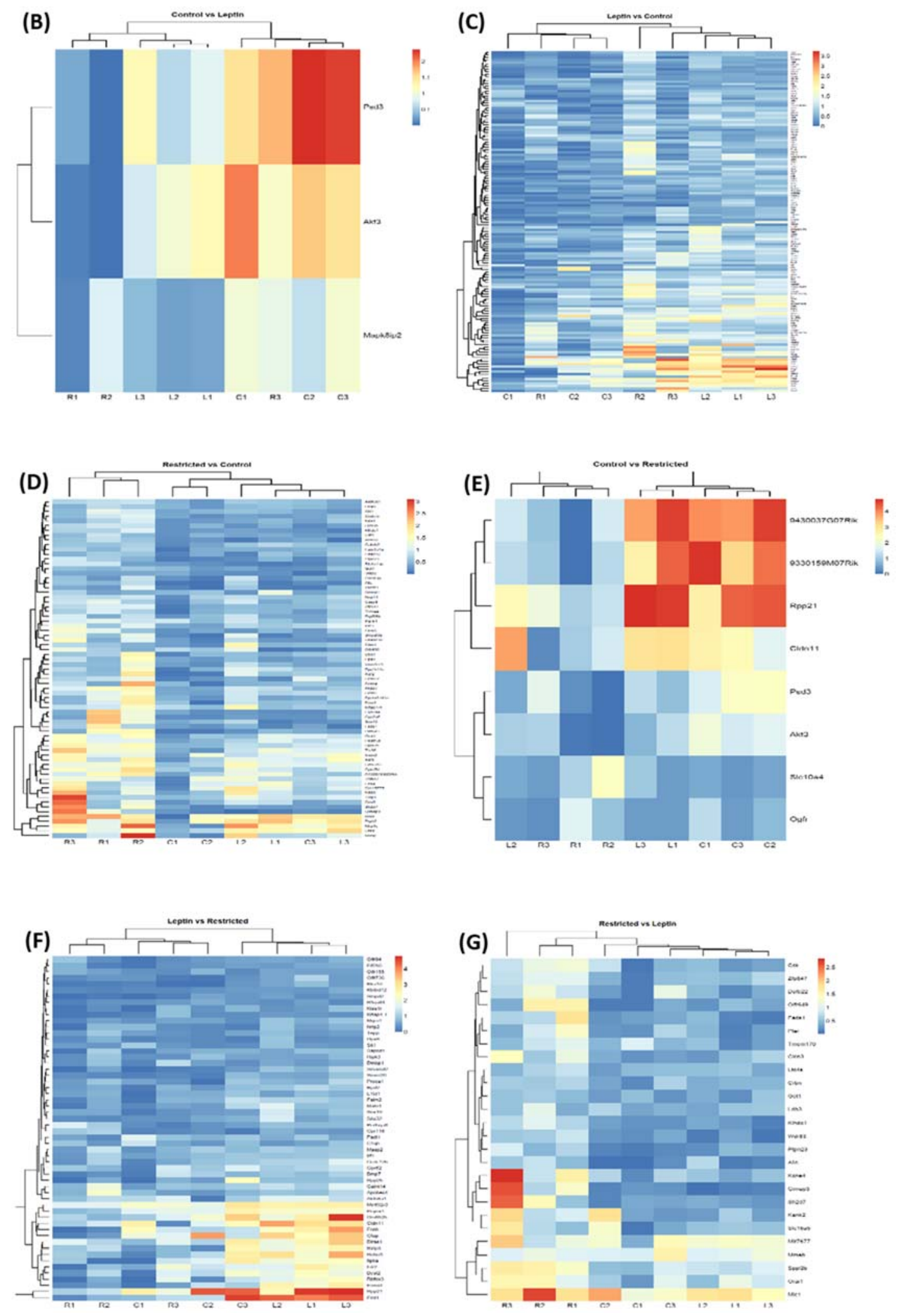

Figure 10: 
Nimblegen mouse DNA methylation 3x720K CpG Island Plus Refseq Promoter array by MoGene, LC in order to identify methylated regions among the three maternal treatment groups ( $\mathrm{C}$, control; $\mathrm{R}$, restricted; $\mathrm{L}$, restricted + leptin). Data was analyzed with Bedtools to identify differentially methylated regions (DMRs). (A) Venn Diagram summarizing the location of differentially methylated regions indicates numbers of differentially methylated regions in each pairwise comparison. There were 95 DMRs identified in the control versus restricted, 169 in control versus leptin, and 109 in leptin versus restricted groups. (B and C) Heatmap of DMRs regulated by maternal nutrient restricted diet and leptin supplementation (leptin) as compared to placentae from offspring whose mothers were fed an adequate diet (control). ( $D$ and $E$ ) placentae from dams fed $50 \%$ total caloric nutrient restricted diet (restricted) versus their control parts and ( $F$ and G) placentae from offspring whose mothers were fed a leptin and restricted diet. Red are peak $p$ value scores of DMRs that were highly methylated, white had some methylation and blue low levels of methylation. Each column represents a treatment group and each row is a gene associated with a DMRs. 

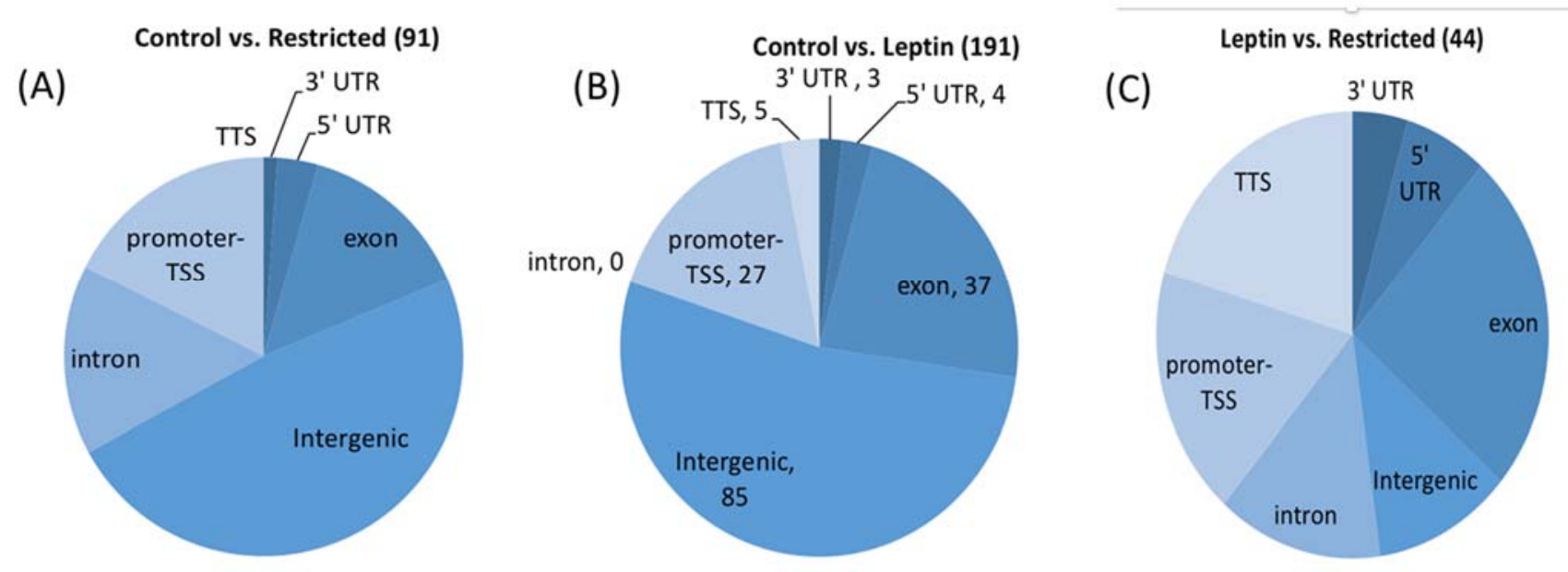

Figure 11:

Pie chart indicating number and location of DMRs: $(A-C)$ In the control versus restricted and control versus leptin with $52.8 \%$ and $48.4 \%$ respectively of the DMRs were most commonly located within the intergenic regions, with $25 \%$ located within exons in the leptin versus restricted placentae 
(A) AKT3 (Control vs. Leptin)

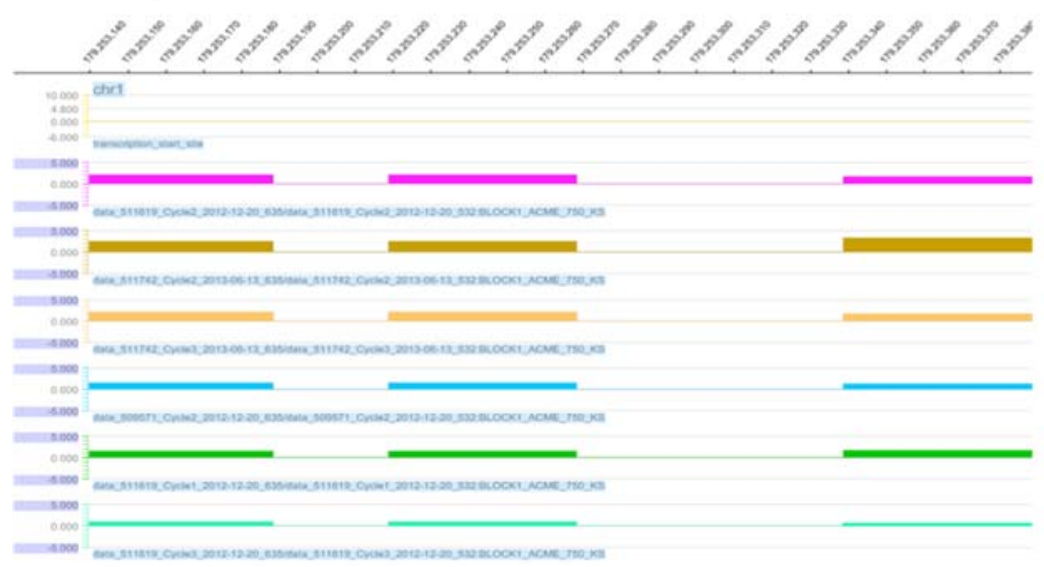

(B) Sh2d7 (Restricted vs. Control)

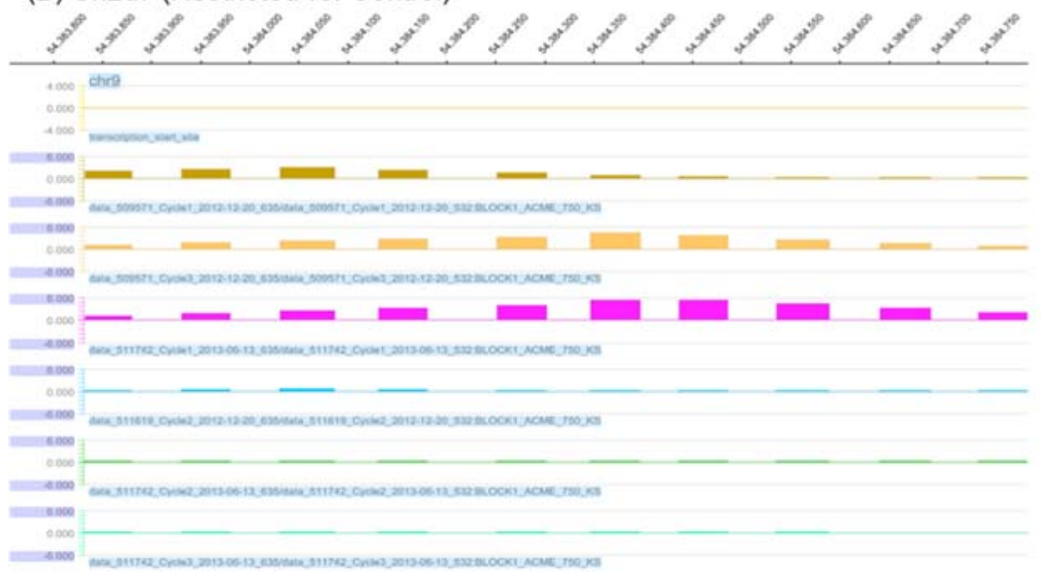

(C) EMI1 (Leptin vs. Restricted)

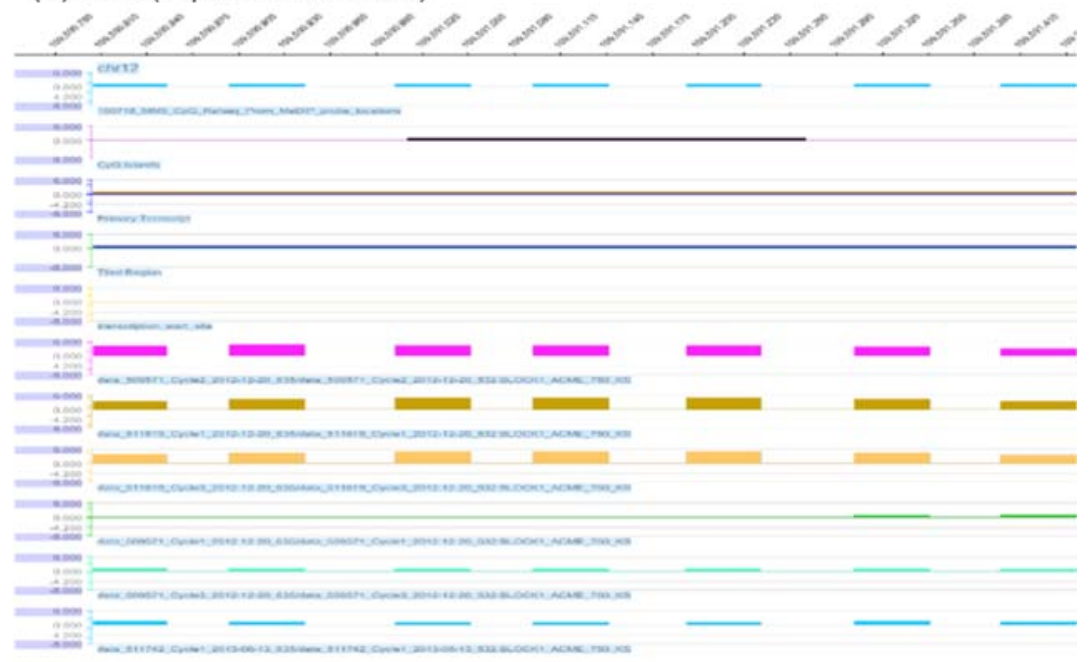

Figure 12 
NimbleGen SignalMap displays Most DMRs methylation levels in each pairwise comparison. Methylation levels are shown on the $x$ axis, with peak $p$ value score on the y axis. (A) Control vs leptin, AKT3: Intergenic, -74366 (location, and distance to TSS), with a fold increase of 1.7-fold in peak p value score (B) Restricted vs. Control Sh2d7: (MIR/SINE, -2480) was associated with the most differentially methylated region, with fold difference in methylation score of 5.4 (C) Restricted vs Leptin: EMl1 (exon, -18238), Robo3 (exon, 3516), with fold increases in methylation scores of 5.6 and 3.4 , respectively 


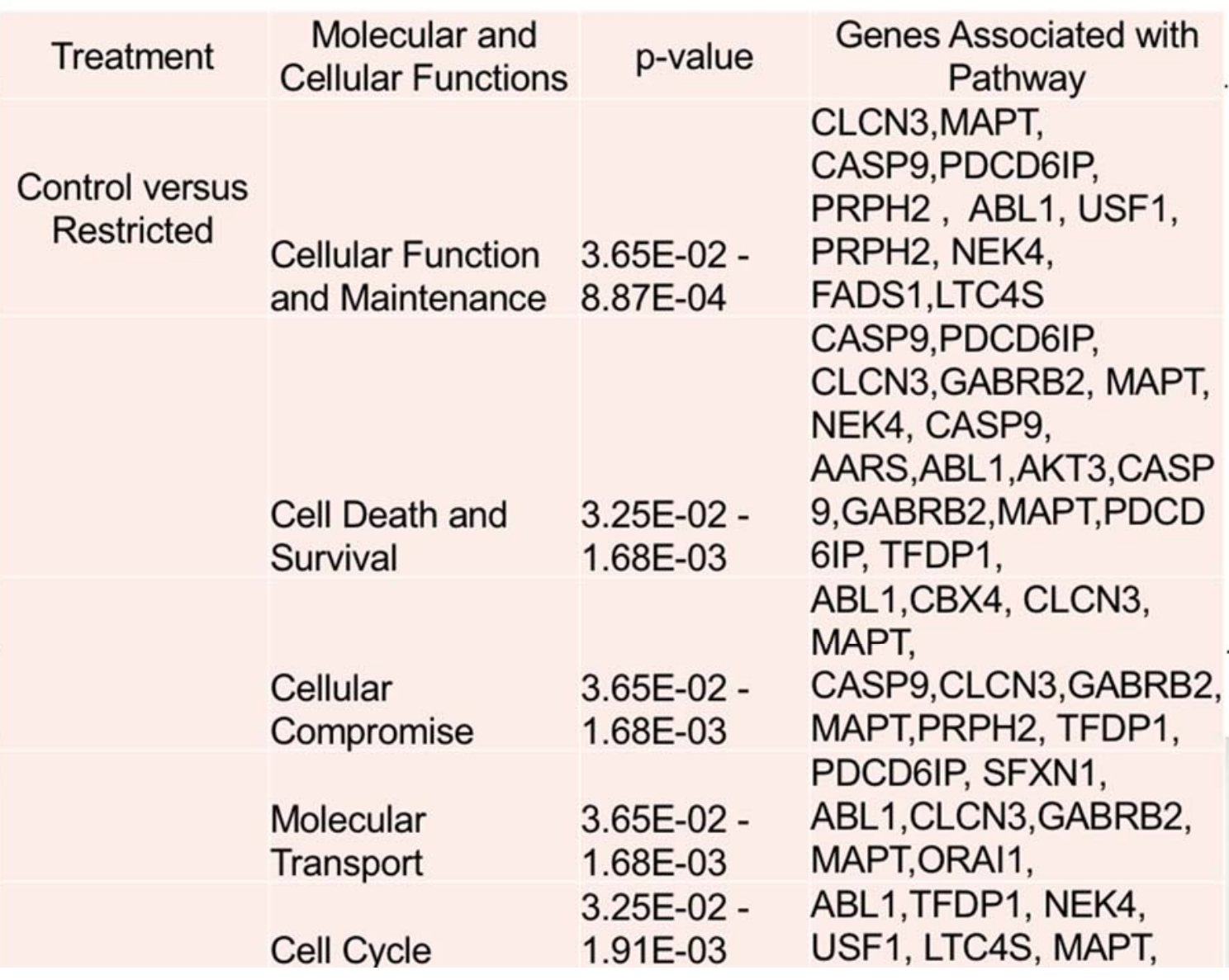

Table 2:

Top 5 molecular and cellular functions discovered by Ingenuity Pathway Analysis core analysis of genes associated with differentially methylated regions significantly changed by $\mathrm{CpG}$ island and promoter methylation in the placentas. The degree of enrichment of the IPA analysis was performed by the Fisher's exact test $(p \leq 0.05)$. The most significant molecular and cellular functional pathways associated with DMRs in placentae exposed to maternal undernutrition in early gestation were cellular function and maintenance, cell death and survival, cell compromise, molecular transport and cell cycle in the ad libitum $50 \%$ food restricted treatment groups 
Leptin versus

Restricted

\section{Lipid Metabolism}

Small Molecule

Biochemistry

Carbohydrate

Metabolism

Cell Cycle

Cell Death and Survival
4.98E-02 - FADS1,LTC4S, SMPD2,

$3.83 \mathrm{E}-03$

4.98E-02 -

3.83E-03

2.93E-02 -

4.24E-03

4.57E-02 -

4.24E-03

4.70E-02 -

4.24E-03
B3GALT4, BMP7, GOT1, GOT1,PCYOX1, LTC4S, CCK, SMPD2, FADS1, B3GALT4, BMP7, GOT1,

BMP7, CCK, GOT1, BMP7, LTC4S, CCK, IRF1, KIra7, PCYOX1, BMP7, GFAP, IRF1,SMPD2, KIra7, CLCN3, CCK, RIPK3, CRBN,

CXCR2, AKAP7, BMP7, CTSZ,SERPINE1,

\section{Table 3:}

In the $50 \%$ food restriction, leptin treated placentae versus restricted pairwise comparison, lipid metabolism, small molecule biochemistry, carbohydrate metabolism, cell cycle and cell death and survival were the biological pathways represented. 


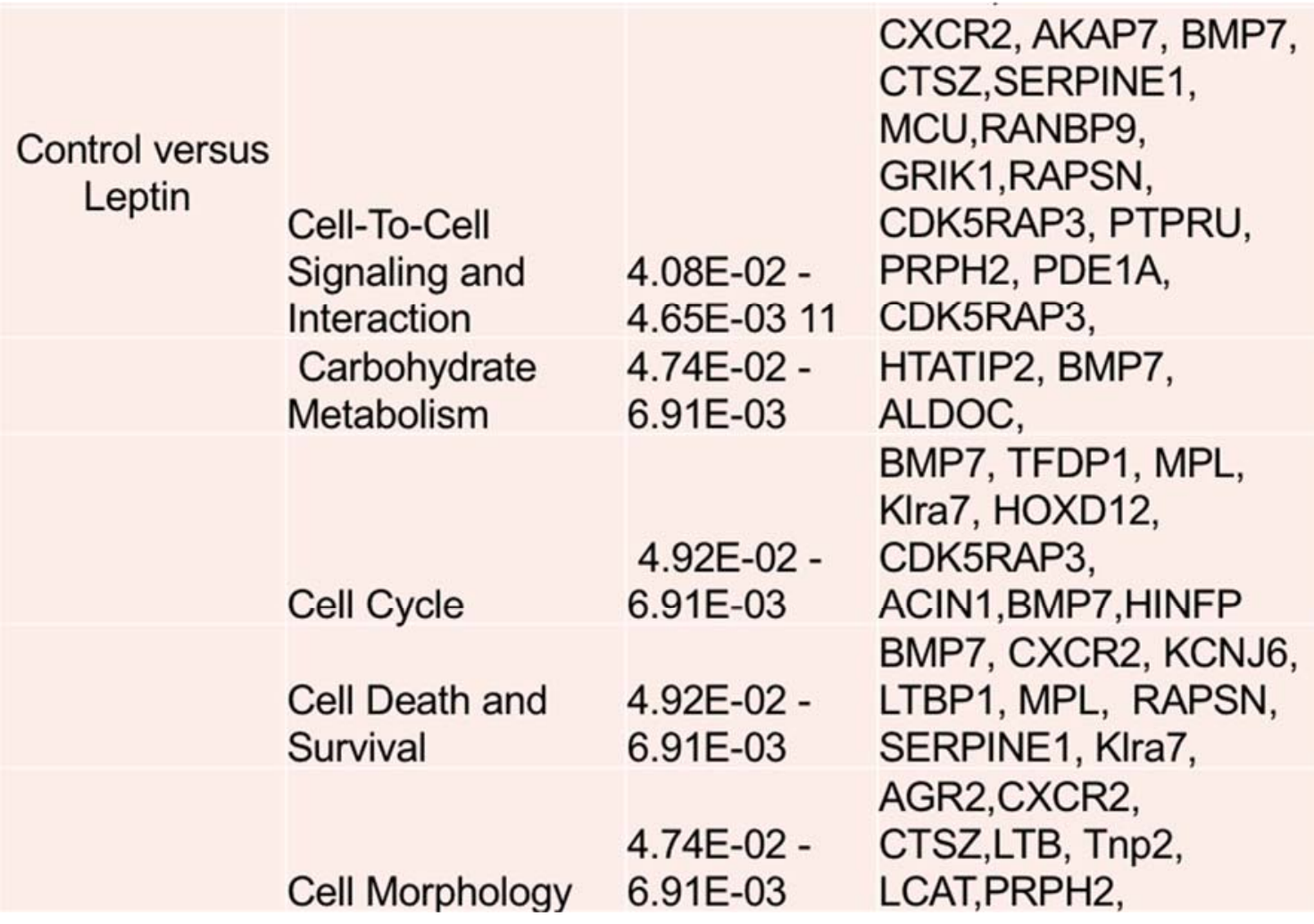

\section{Table 4:}

In control versus leptin pairwise comparison, they were cell to cell signaling and interaction, carbohydrate metabolism, cell cycle, cell death and survival and cell morphology biological pathways represented 


\section{BIBLIOGRAPHY}

(2007). The Surgeon General's Call to Action To Prevent and Reduce Underage Drinking. Rockville (MD).

Adamson, S. L., Y. Lu, K. J. Whiteley, D. Holmyard, M. Hemberger, C. Pfarrer and J. C. Cross (2002). "Interactions between trophoblast cells and the maternal and fetal circulation in the mouse placenta." Dev Biol 250(2): 358-373.

Ahima, R. S., D. Prabakaran, C. Mantzoros, D. Qu, B. Lowell, E. Maratos-Flier and J. S. Flier (1996). "Role of leptin in the neuroendocrine response to fasting." Nature 382(6588): 250-252.

Arima, T., K. Hata, S. Tanaka, M. Kusumi, E. Li, K. Kato, K. Shiota, H. Sasaki and N. Wake (2006). "Loss of the maternal imprint in Dnmt3Lmat-/- mice leads to a differentiation defect in the extraembryonic tissue." Dev Biol 297(2): 361-373.

Banister, C. E., D. C. Koestler, M. A. Maccani, J. F. Padbury, E. A. Houseman and C. J. Marsit (2011). "Infant growth restriction is associated with distinct patterns of DNA methylation in human placentas." Epigenetics 6(7): 920-927. Barker, D. J. (1990). "The fetal and infant origins of adult disease." BMJ 301(6761): 1111.

Barker, D. J. (2004). "The developmental origins of chronic adult disease." Acta Paediatr Suppl 93(446): 26-33.

Barker, D. J., A. R. Bull, C. Osmond and S. J. Simmonds (1990). "Fetal and placental size and risk of hypertension in adult life." BMJ 301(6746): 259-262. 
Barker, D. J., J. G. Eriksson, T. Forsen and C. Osmond (2002). "Fetal origins of adult disease: strength of effects and biological basis." Int J Epidemiol 31(6): 1235-1239.

Barker, D. J., T. Forsen, A. Uutela, C. Osmond and J. G. Eriksson (2001). "Size at birth and resilience to effects of poor living conditions in adult life: longitudinal study." BMJ 323(7324): 1273-1276.

Barker, D. J., K. M. Godfrey, C. Osmond and A. Bull (1992). "The relation of fetal length, ponderal index and head circumference to blood pressure and the risk of hypertension in adult life." Paediatr Perinat Epidemiol 6(1): 35-44.

Barker, D. J., C. Osmond and C. M. Law (1989). "The intrauterine and early postnatal origins of cardiovascular disease and chronic bronchitis." Community Health 43(3): 237-240.

Barker, D. J. P. (1994). "Mothers, Babies and Disease in Later Life." Barros, L. F., D. L. Yudilevich, S. M. Jarvis, N. Beaumont and S. A. Baldwin (1995). "Quantitation and immunolocalization of glucose transporters in the human placenta." Placenta 16(7): 623-633.

Bateson, P., P. P. G. Bateson and P. R. Martin (1999). Design for a life: how behaviour develops, Jonathan Cape.

Baumann, H., K. K. Morella, D. W. White, M. Dembski, P. S. Bailon, H. Kim, C. F. Lai and L. A. Tartaglia (1996). "The full-length leptin receptor has signaling capabilities of interleukin 6-type cytokine receptors." Proc Natl Acad Sci U S A 93(16): 8374-8378. 
Bell, A. W., W. W. Hay, Jr. and R. A. Ehrhardt (1999). "Placental transport of nutrients and its implications for fetal growth." J Reprod Fertil Suppl 54: 401-410. Bertram, C. E. and M. A. Hanson (2001). "Animal models and programming of the metabolic syndrome." Br Med Bull 60: 103-121.

Bird, A. P. (1986). "CpG-rich islands and the function of DNA methylation." Nature 321(6067): 209-213.

Bird, A. P., M. H. Taggart, R. D. Nicholls and D. R. Higgs (1987). "Nonmethylated CpG-rich islands at the human alpha-globin locus: implications for evolution of the alpha-globin pseudogene." EMBO J 6(4): 999-1004.

Bitsanis, D., K. Ghebremeskel, T. Moodley, M. A. Crawford and O. Djahanbakhch (2006). "Gestational diabetes mellitus enhances arachidonic and docosahexaenoic acids in placental phospholipids." Lipids 41(4): 341-346. Bjorbaek, C., J. K. Elmquist, P. Michl, R. S. Ahima, A. van Bueren, A. L. McCall and J. S. Flier (1998). "Expression of leptin receptor isoforms in rat brain microvessels." Endocrinology 139(8): 3485-3491.

Boileau, P., C. Mrejen, J. Girard and S. Hauguel-de Mouzon (1995). "Overexpression of GLUT3 placental glucose transporter in diabetic rats." $\underline{\mathrm{J} \text { Clin }}$ Invest 96(1): 309-317.

Burdge, G. C., J. Slater-Jefferies, C. Torrens, E. S. Phillips, M. A. Hanson and K. A. Lillycrop (2007). "Dietary protein restriction of pregnant rats in the F0 generation induces altered methylation of hepatic gene promoters in the adult male offspring in the F1 and F2 generations." Br J Nutr 97(3): 435-439. 
Campbell, D. M., M. H. Hall, D. J. Barker, J. Cross, A. W. Shiell and K. M. Godfrey (1996). "Diet in pregnancy and the offspring's blood pressure 40 years later." Br J Obstet Gynaecol 103(3): 273-280.

Campbell, F. M., P. G. Bush, J. H. Veerkamp and A. K. Dutta-Roy (1998). "Detection and cellular localization of plasma membrane-associated and cytoplasmic fatty acid-binding proteins in human placenta." Placenta 19(5-6): 409-415.

Castellucci, M., R. De Matteis, A. Meisser, R. Cancello, V. Monsurro, D. Islami, R. Sarzani, D. Marzioni, S. Cinti and P. Bischof (2000). "Leptin modulates extracellular matrix molecules and metalloproteinases: possible implications for trophoblast invasion." Mol Hum Reprod 6(10): 951-958.

CDC, N. ( 2015). "Underlying Cause of Death 1999-2013 " CDC WONDER Online Database,

Cetin, I., N. Giovannini, G. Alvino, C. Agostoni, E. Riva, M. Giovannini and G. Pardi (2002). "Intrauterine growth restriction is associated with changes in polyunsaturated fatty acid fetal-maternal relationships." Pediatr Res 52(5): 750755.

Challier, J., M. Galtier, T. Bintein, A. Cortez, J. Lepercq and S. Hauguel-de Mouzon (2003). "Placental leptin receptor isoforms in normal and pathological pregnancies." Placenta 24(1): 92-99.

Chan, J. L., K. Heist, A. M. DePaoli, J. D. Veldhuis and C. S. Mantzoros (2003). "The role of falling leptin levels in the neuroendocrine and metabolic adaptation to short-term starvation in healthy men." J Clin Invest 111(9): 1409-1421. 
Chehab, F. F., M. E. Lim and R. Lu (1996). "Correction of the sterility defect in homozygous obese female mice by treatment with the human recombinant leptin." Nat Genet 12(3): 318-320.

Chen, P. Y., A. Ganguly, L. Rubbi, L. D. Orozco, M. Morselli, D. Ashraf, A. Jaroszewicz, S. Feng, S. E. Jacobsen, A. Nakano, S. U. Devaskar and M. Pellegrini (2013). "Intrauterine calorie restriction affects placental DNA methylation and gene expression." Physiol Genomics 45(14): 565-576. Cinti, S., R. C. Frederich, M. C. Zingaretti, R. De Matteis, J. S. Flier and B. B. Lowell (1997). "Immunohistochemical localization of leptin and uncoupling protein in white and brown adipose tissue." Endocrinology 138(2): 797-804.

Cleal, J. K. and R. M. Lewis (2008). "The mechanisms and regulation of placental amino acid transport to the human foetus." J Neuroendocrinol 20(4): 419-426. Coan, P. M., E. Angiolini, I. Sandovici, G. J. Burton, M. Constancia and A. L. Fowden (2008). "Adaptations in placental nutrient transfer capacity to meet fetal growth demands depend on placental size in mice." J Physiol 586(18): 45674576.

Coan, P. M., A. C. Ferguson-Smith and G. J. Burton (2004). "Developmental dynamics of the definitive mouse placenta assessed by stereology." Biol Reprod 70(6): 1806-1813.

Coan, P. M., A. C. Ferguson-Smith and G. J. Burton (2005). "Ultrastructural changes in the interhaemal membrane and junctional zone of the murine

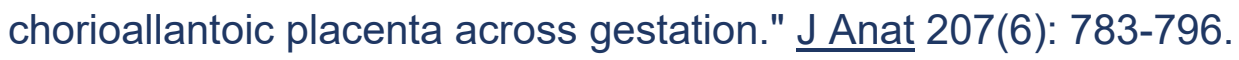


Coan, P. M., O. R. Vaughan, J. McCarthy, C. Mactier, G. J. Burton, M. Constancia and A. L. Fowden (2011). "Dietary composition programmes placental phenotype in mice." J Physiol 589(Pt 14): 3659-3670.

Coan, P. M., O. R. Vaughan, Y. Sekita, S. L. Finn, G. J. Burton, M. Constancia and A. L. Fowden (2010). "Adaptations in placental phenotype support fetal growth during undernutrition of pregnant mice." J Physiol 588(Pt 3): 527-538. Considine, R. V., M. K. Sinha, M. L. Heiman, A. Kriauciunas, T. W. Stephens, M. R. Nyce, J. P. Ohannesian, C. C. Marco, L. J. McKee, T. L. Bauer and et al. (1996). "Serum immunoreactive-leptin concentrations in normal-weight and obese humans." N Engl J Med 334(5): 292-295.

Cooney, C. A., A. A. Dave and G. L. Wolff (2002). "Maternal methyl supplements in mice affect epigenetic variation and DNA methylation of offspring." $\underline{\mathrm{J} \text { Nutr }}$ 132(8 Suppl): 2393S-2400S.

Copp, A. J. (1979). "Interaction between inner cell mass and trophectoderm of the mouse blastocyst. II. The fate of the polar trophectoderm." J Embryol Exp Morphol 51: 109-120.

Cowden Dahl, K. D., B. H. Fryer, F. A. Mack, V. Compernolle, E. Maltepe, D. M. Adelman, P. Carmeliet and M. C. Simon (2005). "Hypoxia-inducible factors 1alpha and 2alpha regulate trophoblast differentiation." Mol Cell Biol 25(23): 10479-10491.

Cross, J. C., D. G. Simmons and E. D. Watson (2003). "Chorioallantoic morphogenesis and formation of the placental villous tree." Ann N Y Acad Sci 995: 84-93. 
Curhan, G. C., G. M. Chertow, W. C. Willett, D. Spiegelman, G. A. Colditz, J. E. Manson, F. E. Speizer and M. J. Stampfer (1996). "Birth weight and adult hypertension and obesity in women." Circulation 94(6): 1310-1315.

Dahri, S., A. Snoeck, B. Reusens-Billen, C. Remacle and J. J. Hoet (1991). "Islet function in offspring of mothers on low-protein diet during gestation." Diabetes 40 Suppl 2: 115-120.

Dandrea, J., V. Wilson, G. Gopalakrishnan, L. Heasman, H. Budge, T. Stephenson and M. E. Symonds (2001). "Maternal nutritional manipulation of placental growth and glucose transporter 1 (GLUT-1) abundance in sheep." Reproduction 122(5): 793-800.

Das, U. G., J. He, R. A. Ehrhardt, W. W. Hay, Jr. and S. U. Devaskar (2000). "Time-dependent physiological regulation of ovine placental GLUT-3 glucose transporter protein." Am J Physiol Regul Integr Comp Physiol 279(6): R22522261.

de Rooij, S. R., R. C. Painter, T. J. Roseboom, D. I. Phillips, C. Osmond, D. J. Barker, M. W. Tanck, R. P. Michels, P. M. Bossuyt and O. P. Bleker (2006). "Glucose tolerance at age 58 and the decline of glucose tolerance in comparison with age 50 in people prenatally exposed to the Dutch famine." Diabetologia 49(4): 637-643.

Deaton, A. M. and A. Bird (2011). "CpG islands and the regulation of transcription." Genes Dev 25(10): 1010-1022. 
Desforges, M., H. A. Lacey, J. D. Glazier, S. L. Greenwood, K. J. Mynett, P. F. Speake and C. P. Sibley (2006). "SNAT4 isoform of system A amino acid transporter is expressed in human placenta." Am J Physiol Cell Physiol 290(1): C305-312.

Diaz, P., J. Harris, F. J. Rosario, T. L. Powell and T. Jansson (2015). "Increased placental fatty acid transporter 6 and binding protein 3 expression and fetal liver lipid accumulation in a mouse model of obesity in pregnancy." Am J Physiol Regul Integr Comp Physiol 309(12): R1569-1577.

Dolinoy, D. C., R. Das, J. R. Weidman and R. L. Jirtle (2007). "Metastable epialleles, imprinting, and the fetal origins of adult diseases." Pediatr Res 61 (5 Pt 2): $30 R-37 R$.

Duttaroy, A. K. (2009). "Transport of fatty acids across the human placenta: a review." Prog Lipid Res 48(1): 52-61.

Dwyer, C. M., A. J. Madgwick, A. R. Crook and N. C. Stickland (1992). "The effect of maternal undernutrition on the growth and development of the guinea pig placenta." J Dev Physiol 18(6): 295-302.

Edwards, L. J. and I. C. McMillen (2002). "Periconceptional nutrition programs development of the cardiovascular system in the fetal sheep." Am J Physiol Regul Integr Comp Physiol 283(3): R669-679.

El-Hashash, A. H., D. Warburton and S. J. Kimber (2010). "Genes and signals regulating murine trophoblast cell development." Mech Dev 127(1-2): 1-20. 
Eriksson, J., T. Forsen, J. Tuomilehto, C. Osmond and D. Barker (2000). "Fetal

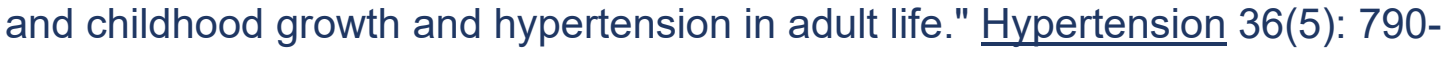
794.

Faichney, G. J. and G. A. White (1987). "Effects of maternal nutritional status on fetal and placental growth and on fetal urea synthesis in sheep." Aust J Biol Sci 40(4): 365-377.

Ferreira, G. D., R. B. Orcy, S. H. Martins-Costa, J. G. Ramos, I. S. Brum, H. Corleta and E. Capp (2011). "Insulin stimulation of Akt/PKB phosphorylation in the placenta of preeclampsia patients." Sao Paulo Med J 129(6): 387-391. Flegal, K. M., D. Kruszon-Moran, M. D. Carroll, C. D. Fryar and C. L. Ogden (2016). "Trends in Obesity Among Adults in the United States, 2005 to 2014." JAMA 315(21): 2284-2291.

Fleming, T. P., W. Y. Kwong, R. Porter, E. Ursell, I. Fesenko, A. Wilkins, D. J. Miller, A. J. Watkins and J. J. Eckert (2004). "The embryo and its future." Biol Reprod 71(4): 1046-1054.

Flier, J. S. (1997). "Leptin expression and action: new experimental paradigms." Proc Natl Acad Sci U S A 94(9): 4242-4245.

Forsdahl, A. (1977). "Are poor living conditions in childhood and adolescence an important risk factor for arteriosclerotic heart disease?" Br J Prev Soc Med 31(2): 91-95.

Forsen, T., J. Eriksson, J. Tuomilehto, A. Reunanen, C. Osmond and D. Barker (2000). "The fetal and childhood growth of persons who develop type 2 diabetes." Ann Intern Med 133(3): 176-182. 
Fowden, A. L., P. M. Coan, E. Angiolini, G. J. Burton and M. Constancia (2011). "Imprinted genes and the epigenetic regulation of placental phenotype." Prog Biophys Mol Biol 106(1): 281-288.

Fowden, A. L., A. J. Forhead, P. M. Coan and G. J. Burton (2008). "The placenta and intrauterine programming." $\mathrm{J}$ Neuroendocrinol 20(4): 439-450.

Fowden, A. L., A. N. Sferruzzi-Perri, P. M. Coan, M. Constancia and G. J. Burton (2009). "Placental efficiency and adaptation: endocrine regulation." J Physiol 587(Pt 14): 3459-3472.

Fowden, A. L., J. W. Ward, F. P. Wooding, A. J. Forhead and M. Constancia

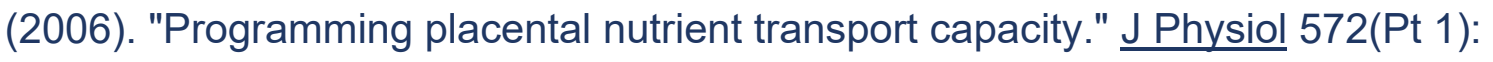
5-15.

Fraga, M. F., E. Ballestar, G. Montoya, P. Taysavang, P. A. Wade and M. Esteller (2003). "The affinity of different MBD proteins for a specific methylated locus depends on their intrinsic binding properties." Nucleic Acids Res 31(6): $1765-1774$.

Frankel, S., P. Elwood, P. Sweetnam, J. Yarnell and G. D. Smith (1996). "Birthweight, body-mass index in middle age, and incident coronary heart disease." Lancet 348(9040): 1478-1480.

Gardiner-Garden, M. and M. Frommer (1987). "CpG islands in vertebrate genomes." J Mol Biol 196(2): 261-282. 
Gardner, D. S., S. Pearce, J. Dandrea, R. Walker, M. M. Ramsay, T. Stephenson and M. E. Symonds (2004). "Peri-implantation undernutrition programs blunted angiotensin II evoked baroreflex responses in young adult sheep." $\underline{\text { Hypertension }}$ 43(6): 1290-1296.

Garris, D. R. (1983). "Regional variations in guinea pig uterine blood flow during pregnancy: relationship to intrauterine growth of the fetal-placental unit."

Teratology 27(1): 101-107.

Gauster, M., G. Desoye, M. Totsch and U. Hiden (2012). "The placenta and gestational diabetes mellitus." Curr Diab Rep 12(1): 16-23.

Ghilardi, N., S. Ziegler, A. Wiestner, R. Stoffel, M. H. Heim and R. C. Skoda (1996). "Defective STAT signaling by the leptin receptor in diabetic mice." Proc Natl Acad Sci U S A 93(13): 6231-6235.

Gillman, M. W. (2005). "Developmental origins of health and disease." $\underline{\text { Engl J }}$ Med 353(17): 1848-1850.

Gluckman, P. D. and M. A. Hanson (2004). "The developmental origins of the metabolic syndrome." Trends Endocrinol Metab 15(4): 183-187.

Gluckman, P. D. and M. A. Hanson (2006). "The Consequences of Being Born Small - An Adaptive Perspective." Hormone Research in Paediatrics 65(suppl 3)(Suppl. 3): 5-14.

Gluckman, P. D., M. A. Hanson, T. Buklijas, F. M. Low and A. S. Beedle (2009). "Epigenetic mechanisms that underpin metabolic and cardiovascular diseases." Nat Rev Endocrinol 5(7): 401-408. 
Gluckman, P. D., M. A. Hanson, C. Cooper and K. L. Thornburg (2008). "Effect of in utero and early-life conditions on adult health and disease." $\underline{\mathrm{N} \text { Engl J Med }}$ 359(1): 61-73.

Gluckman, P. D., K. A. Lillycrop, M. H. Vickers, A. B. Pleasants, E. S. Phillips, A. S. Beedle, G. C. Burdge and M. A. Hanson (2007). "Metabolic plasticity during mammalian development is directionally dependent on early nutritional status." Proc Natl Acad Sci U S A 104(31): 12796-12800.

Goldberg, A. D., C. D. Allis and E. Bernstein (2007). "Epigenetics: a landscape takes shape." Cell 128(4): 635-638.

Gresham, E. L., E. J. James, J. R. Raye, F. C. Battaglia, E. L. Makowski and G. Meschia (1972). "Production and excretion of urea by the fetal lamb." Pediatrics 50(3): 372-379.

Guo, L., S. Choufani, J. Ferreira, A. Smith, D. Chitayat, C. Shuman, R. Uxa, S. Keating, J. Kingdom and R. Weksberg (2008). "Altered gene expression and methylation of the human chromosome 11 imprinted region in small for gestational age (SGA) placentae." Dev Biol 320(1): 79-91.

Halaas, J. L., K. S. Gajiwala, M. Maffei, S. L. Cohen, B. T. Chait, D. Rabinowitz, R. L. Lallone, S. K. Burley and J. M. Friedman (1995). "Weight-reducing effects of the plasma protein encoded by the obese gene." Science 269(5223): 543-546. Hales, C. N. and D. J. Barker (1992). "Type 2 (non-insulin-dependent) diabetes mellitus: the thrifty phenotype hypothesis." Diabetologia 35(7): 595-601. 
Harper, J. L., G. A. Caesar, K. A. Pennington, J. W. Davis and L. C. Schulz (2015). "Placental changes caused by food restriction during early pregnancy in mice are reversible." Reproduction.

Harper, J. L., G. A. Caesar, K. A. Pennington, J. W. Davis and L. C. Schulz (2015). "Placental changes caused by food restriction during early pregnancy in mice are reversible." Reproduction 150(3): 165-172.

Havel, P. J., S. Kasim-Karakas, W. Mueller, P. R. Johnson, R. L. Gingerich and J. S. Stern (1996). "Relationship of plasma leptin to plasma insulin and adiposity in normal weight and overweight women: effects of dietary fat content and sustained weight loss." J Clin Endocrinol Metab 81(12): 4406-4413.

Heasman, L., L. Clarke, T. J. Stephenson and M. E. Symonds (1999). "The influence of maternal nutrient restriction in early to mid-pregnancy on placental and fetal development in sheep." Proc Nutr Soc 58(2): 283-288.

Heijmans, B. T., E. W. Tobi, A. D. Stein, H. Putter, G. J. Blauw, E. S. Susser, P. E. Slagboom and L. H. Lumey (2008). "Persistent epigenetic differences associated with prenatal exposure to famine in humans." Proc Natl Acad Sci U S A 105(44): 17046-17049.

Henson, M. C., K. F. Swan and J. S. O'Neil (1998). "Expression of placental leptin and leptin receptor transcripts in early pregnancy and at term." Obstet Gynecol 92(6): 1020-1028.

Herman, J. G. and S. B. Baylin (2003). "Gene silencing in cancer in association with promoter hypermethylation." N Engl J Med 349(21): 2042-2054. 
Holemans, K. (1999). "Maternal food restriction in the second half of pregnancy affects vascular function but not blood pressure of rat female offspring." British Journal of Nutrition: 73-79.

Holemans, K., J. Verhaeghe, J. Dequeker and F. A. Van Assche (1996). "Insulin sensitivity in adult female rats subjected to malnutrition during the perinatal period." J Soc Gynecol Investig 3(2): 71-77.

Holliday, R. and J. E. Pugh (1975). "DNA modification mechanisms and gene activity during development." Science 187(4173): 226-232.

Iglesias-Barreira, V., M. T. Ahn, B. Reusens, S. Dahri, J. J. Hoet and C. Remacle (1996). "Pre- and postnatal low protein diet affect pancreatic islet blood flow and insulin release in adult rats." Endocrinology 137(9): 3797-3801.

Jansson, N., J. Pettersson, A. Haafiz, A. Ericsson, I. Palmberg, M. Tranberg, V. Ganapathy, T. L. Powell and T. Jansson (2006). "Down-regulation of placental transport of amino acids precedes the development of intrauterine growth restriction in rats fed a low protein diet." J Physiol 576(Pt 3): 935-946.

Jansson, T. and T. L. Powell (2007). "Role of the placenta in fetal programming: underlying mechanisms and potential interventional approaches." $\underline{\text { Clin Sci (Lond) }}$ 113(1): 1-13.

Jansson, T., M. Wennergren and T. L. Powell (1999). "Placental glucose transport and GLUT 1 expression in insulin-dependent diabetes." Am J Obstet Gynecol 180(1 Pt 1): 163-168. 


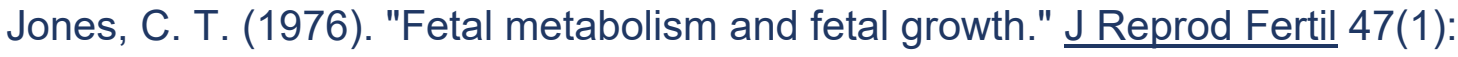
189-201.

Jones, H. N., L. A. Woollett, N. Barbour, P. D. Prasad, T. L. Powell and T. Jansson (2009). "High-fat diet before and during pregnancy causes marked upregulation of placental nutrient transport and fetal overgrowth in C57/BL6 mice." FASEB J 23(1): 271-278.

Kim, D. D. and A. Basu (2016). "Estimating the Medical Care Costs of Obesity in the United States: Systematic Review, Meta-Analysis, and Empirical Analysis." Value Health 19(5): 602-613.

Klein, S., S. W. Coppack, V. Mohamed-Ali and M. Landt (1996). "Adipose tissue leptin production and plasma leptin kinetics in humans." Diabetes 45(7): 984-987. Kochanek, K. D., J. Xu, S. L. Murphy, A. M. Minino and H. C. Kung (2011). "Deaths: final data for 2009." Natl Vital Stat Rep 60(3): 1-116.

Kolaczynski, J. W., R. V. Considine, J. Ohannesian, C. Marco, I. Opentanova, M. R. Nyce, M. Myint and J. F. Caro (1996). "Responses of leptin to short-term fasting and refeeding in humans: a link with ketogenesis but not ketones themselves." Diabetes 45(11): 1511-1515.

Kolaczynski, J. W., J. P. Ohannesian, R. V. Considine, C. C. Marco and J. F. Caro (1996). "Response of leptin to short-term and prolonged overfeeding in humans." J Clin Endocrinol Metab 81(11): 4162-4165. 
Kwong, W. Y., A. E. Wild, P. Roberts, A. C. Willis and T. P. Fleming (2000). "Maternal undernutrition during the preimplantation period of rat development causes blastocyst abnormalities and programming of postnatal hypertension." Development 127(19): 4195-4202.

Lager, S., V. I. Ramirez, F. Gaccioli, B. Jang, T. Jansson and T. L. Powell (2016). "Protein expression of fatty acid transporter 2 is polarized to the trophoblast basal plasma membrane and increased in placentas from overweight/obese women." Placenta 40: 60-66.

Langley, S. C. and A. A. Jackson (1994). "Increased systolic blood pressure in adult rats induced by fetal exposure to maternal low protein diets." $\underline{\text { Clin Sci }}$ (Lond) 86(2): 217-222; discussion 121.

Langley-Evans, S. C. and A. A. Jackson (1995). "Captopril normalises systolic blood pressure in rats with hypertension induced by fetal exposure to maternal low protein diets." Comp Biochem Physiol A Physiol 110(3): 223-228. Langley-Evans, S. C., S. J. Welham and A. A. Jackson (1999). "Fetal exposure to a maternal low protein diet impairs nephrogenesis and promotes hypertension in the rat." Life Sci 64(11): 965-974.

Larque, E., S. Krauss-Etschmann, C. Campoy, D. Hartl, J. Linde, M. Klingler, H. Demmelmair, A. Cano, A. Gil, B. Bondy and B. Koletzko (2006). "Docosahexaenoic acid supply in pregnancy affects placental expression of fatty acid transport proteins." Am J Clin Nutr 84(4): 853-861. 
Law, C. M., M. de Swiet, C. Osmond, P. M. Fayers, D. J. Barker, A. M. Cruddas and C. H. Fall (1993). "Initiation of hypertension in utero and its amplification throughout life." BMJ 306(6869): 24-27.

Lee, G. H., R. Proenca, J. M. Montez, K. M. Carroll, J. G. Darvishzadeh, J. I. Lee and J. M. Friedman (1996). "Abnormal splicing of the leptin receptor in diabetic mice." Nature 379(6566): 632-635.

Lesage, J., D. Hahn, M. Leonhardt, B. Blondeau, B. Breant and J. P. Dupouy (2002). "Maternal undernutrition during late gestation-induced intrauterine growth restriction in the rat is associated with impaired placental GLUT3 expression, but does not correlate with endogenous corticosterone levels." $\underline{\mathrm{J} \text { Endocrinol }}$ 174(1): $37-43$.

Levy, L. and A. A. Jackson (1993). "Modest restriction of dietary protein during

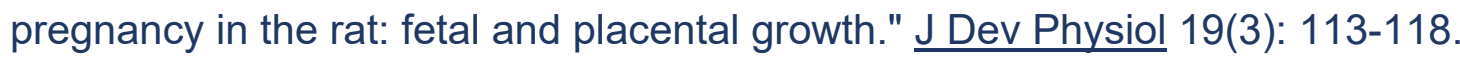
Li, E. (2002). "Chromatin modification and epigenetic reprogramming in mammalian development." Nat Rev Genet 3(9): 662-673.

Li, E., T. H. Bestor and R. Jaenisch (1992). "Targeted mutation of the DNA methyltransferase gene results in embryonic lethality." Cell 69(6): 915-926. Lillycrop, K. A., E. S. Phillips, A. A. Jackson, M. A. Hanson and G. C. Burdge (2005). "Dietary protein restriction of pregnant rats induces and folic acid supplementation prevents epigenetic modification of hepatic gene expression in the offspring." J Nutr 135(6): 1382-1386. 
Lillycrop, K. A., E. S. Phillips, C. Torrens, M. A. Hanson, A. A. Jackson and G. C. Burdge (2008). "Feeding pregnant rats a protein-restricted diet persistently alters the methylation of specific cytosines in the hepatic PPAR alpha promoter of the offspring." Br J Nutr 100(2): 278-282.

Lillycrop, K. A., J. L. Slater-Jefferies, M. A. Hanson, K. M. Godfrey, A. A. Jackson and G. C. Burdge (2007). "Induction of altered epigenetic regulation of the hepatic glucocorticoid receptor in the offspring of rats fed a protein-restricted diet during pregnancy suggests that reduced DNA methyltransferase-1 expression is involved in impaired DNA methylation and changes in histone modifications." $\mathrm{Br}$ Nutr 97(6): 1064-1073.

Livak, K. J. and T. D. Schmittgen (2001). "Analysis of relative gene expression data using real-time quantitative PCR and the 2(-Delta Delta $\mathrm{C}(\mathrm{T})$ ) Method." Methods 25(4): 402-408.

Lumey, L. H. (1998). "Compensatory placental growth after restricted maternal nutrition in early pregnancy." Placenta 19(1): 105-111.

Lumey, L. H., A. D. Stein and H. Kahn (2009). Food restriction during gestation and impaired fasting glucose or glucose tolerance and type 2 diabetes mellitus in adulthood: Evidence from the DutchHunger Winter Families Study.

Lumey, L. H., A. D. Stein and A. C. Ravelli (1995). "Timing of prenatal starvation in women and birth weight in their first and second born offspring: the Dutch Famine Birth Cohort study." Eur J Obstet Gynecol Reprod Biol 61(1): 23-30. Lunney, L. H. (1998). "Compensatory placental growth after restricted maternal nutrition in early pregnancy." Placenta 19(1): 105-111. 
MacLaughlin, S. M., S. K. Walker, C. T. Roberts, D. O. Kleemann and I. C. McMillen (2005). "Periconceptional nutrition and the relationship between maternal body weight changes in the periconceptional period and feto-placental growth in the sheep." J Physiol 565(Pt 1): 111-124.

Maffei, M., J. Halaas, E. Ravussin, R. E. Pratley, G. H. Lee, Y. Zhang, H. Fei, S. Kim, R. Lallone, S. Ranganathan and et al. (1995). "Leptin levels in human and rodent: measurement of plasma leptin and ob RNA in obese and weight-reduced subjects." Nat Med 1(11): 1155-1161.

Malandro, M. S., M. J. Beveridge, M. S. Kilberg and D. A. Novak (1996). "Effect of low-protein diet-induced intrauterine growth retardation on rat placental amino acid transport." Am J Physiol 271(1 Pt 1): C295-303.

Margetic, S., C. Gazzola, G. G. Pegg and R. A. Hill (2002). "Leptin: a review of its peripheral actions and interactions." Int J Obes Relat Metab Disord 26(11): 14071433.

Maroni, P., P. Bendinelli and R. Piccoletti (2005). "Intracellular signal transduction pathways induced by leptin in C2C12 cells." Cell Biol Int 29(7): 542550.

Masuzaki, H., Y. Ogawa, N. Sagawa, K. Hosoda, T. Matsumoto, H. Mise, H. Nishimura, Y. Yoshimasa, I. Tanaka, T. Mori and K. Nakao (1997). "Nonadipose tissue production of leptin: leptin as a novel placenta-derived hormone in humans." Nat Med 3(9): 1029-1033.

Mayer, W., A. Niveleau, J. Walter, R. Fundele and T. Haaf (2000).

"Demethylation of the zygotic paternal genome." Nature 403(6769): 501-502. 
Mayhew, T. M. (2009). "A stereological perspective on placental morphology in normal and complicated pregnancies." J Anat 215(1): 77-90.

McCrabb, G. J., A. R. Egan and B. J. Hosking (1991). "Maternal undernutrition during mid-pregnancy in sheep. Placental size and its relationship to calcium transfer during late pregnancy." Br J Nutr 65(2): 157-168.

McGivan, J. D. and M. Pastor-Anglada (1994). "Regulatory and molecular aspects of mammalian amino acid transport." Biochem J 299 ( Pt 2): 321-334.

McMillen, I. C. and J. S. Robinson (2005). "Developmental origins of the metabolic syndrome: prediction, plasticity, and programming." Physiol Rev 85(2): 571-633.

Mercer, J. G., N. Hoggard, L. M. Williams, C. B. Lawrence, L. T. Hannah and P. Trayhurn (1996). "Localization of leptin receptor mRNA and the long form splice variant $(\mathrm{Ob}-\mathrm{Rb})$ in mouse hypothalamus and adjacent brain regions by in situ hybridization." FEBS Lett 387(2-3): 113-116.

Morgan, H. D., F. Santos, K. Green, W. Dean and W. Reik (2005). "Epigenetic reprogramming in mammals." Hum Mol Genet 14 Spec No 1: R47-58.

Mu, J., J. C. Slevin, D. Qu, S. McCormick and S. L. Adamson (2008). "In vivo quantification of embryonic and placental growth during gestation in mice using micro-ultrasound." Reprod Biol Endocrinol 6: 34.

Myatt, L. (2006). "Placental adaptive responses and fetal programming." $\underline{\mathrm{J}}$ Physiol 572(Pt 1): 25-30. 
Nam, J., E. Greenwald, C. Jack-Roberts, T. T. Ajeeb, O. V. Malysheva, M. A. Caudill, K. Axen, A. Saxena, E. Semernina, K. Nanobashvili and X. Jiang (2017). "Choline prevents fetal overgrowth and normalizes placental fatty acid and glucose metabolism in a mouse model of maternal obesity." $\mathrm{J}$ Nutr Biochem 49: 80-88.

Natale, D. R., M. Starovic and J. C. Cross (2006). "Phenotypic analysis of the mouse placenta." Methods Mol Med 121: 275-293.

Netherlands, M. Committee on, G. C. E. Burger, J. C. Drummond and H. R. Sandstead (1948). Malnutrition and starvation in Western Netherlands: September 1944 - July 1945 Pt. 1. Pt. 1. The Hague, General State Print. Office. Nilsson, E., P. A. Jansson, A. Perfilyev, P. Volkov, M. Pedersen, M. K. Svensson, P. Poulsen, R. Ribel-Madsen, N. L. Pedersen, P. Almgren, J. Fadista, T. Ronn, B. Klarlund Pedersen, C. Scheele, A. Vaag and C. Ling (2014). "Altered DNA methylation and differential expression of genes influencing metabolism and inflammation in adipose tissue from subjects with type 2 diabetes." Diabetes 63(9): 2962-2976.

Ogden, C. L., M. D. Carroll, B. K. Kit and K. M. Flegal (2014). "Prevalence of childhood and adult obesity in the United States, 2011-2012." JAMA 311(8): 806814.

Okano, M., D. W. Bell, D. A. Haber and E. Li (1999). "DNA methyltransferases Dnmt3a and Dnmt3b are essential for de novo methylation and mammalian development." Cell 99(3): 247-257. 
Okano, M., S. Xie and E. Li (1998). "Cloning and characterization of a family of novel mammalian DNA (cytosine-5) methyltransferases." Nat Genet 19(3): 219220.

Orcy, R. B., S. Schroeder, S. H. Martins-Costa, J. G. Ramos, W. Schechinger, H. Klein, I. S. Brum, H. von Eye Corleta and E. Capp (2008). "Signalization of Akt/PKB in the placenta, skeletal muscle and adipose tissue of preeclampsia patients." Gynecol Obstet Invest 66(4): 231-236.

Outhwaite, J. E., V. McGuire and D. G. Simmons (2015). "Genetic ablation of placental sinusoidal trophoblast giant cells causes fetal growth restriction and embryonic lethality." Placenta 36(8): 951-955.

Ozaki, T., H. Nishina, M. A. Hanson and L. Poston (2001). "Dietary restriction in pregnant rats causes gender-related hypertension and vascular dysfunction in offspring." J Physiol 530(Pt 1): 141-152.

Ozanne, S. E., R. Lewis, B. J. Jennings and C. N. Hales (2004). "Early programming of weight gain in mice prevents the induction of obesity by a highly palatable diet." Clin Sci (Lond) 106(2): 141-145.

Painter, R. C., S. R. de Rooij, P. M. Bossuyt, T. A. Simmers, C. Osmond, D. J. Barker, O. P. Bleker and T. J. Roseboom (2006). "Early onset of coronary artery disease after prenatal exposure to the Dutch famine." Am J Clin Nutr 84(2): 322327; quiz 466-327.

Pardi, G., I. Cetin, A. M. Marconi, A. Lanfranchi, P. Bozzetti, E. Ferrazzi, M. Buscaglia and F. C. Battaglia (1993). "Diagnostic value of blood sampling in

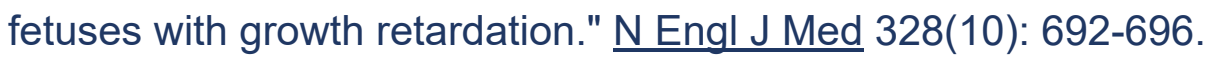


Peelman, F., L. Zabeau, K. Moharana, S. N. Savvides and J. Tavernier (2014). "20 years of leptin: insights into signaling assemblies of the leptin receptor." $\underline{\mathrm{J}}$ Endocrinol 223(1): T9-23.

Pelleymounter, M. A., M. J. Cullen, M. B. Baker, R. Hecht, D. Winters, T. Boone and F. Collins (1995). "Effects of the obese gene product on body weight regulation in ob/ob mice." Science 269(5223): 540-543.

Pennington, K. A., J. L. Harper, A. N. Sigafoos, L. M. Beffa, S. M. Carleton, C. L. Phillips and L. C. Schulz (2012). "Effect of food restriction and leptin supplementation on fetal programming in mice." Endocrinology 153(9): 45564567.

Pinheiro, L. C., J. E. Tanus-Santos and M. M. Castro (2017). "The potential of stimulating nitric oxide formation in the treatment of hypertension." Expert Opin Ther Targets 21(5): 543-556.

Plant, T. M. and A. J. Zeleznik (2014). Knobil and Neill's Physiology of Reproduction, Elsevier Science.

Rahnama, F., F. Shafiei, P. D. Gluckman, M. D. Mitchell and P. E. Lobie (2006). "Epigenetic regulation of human trophoblastic cell migration and invasion." Endocrinology 147(11): 5275-5283.

Ramachandran, V. and R. Saravanan (2015). "Glucose uptake through translocation and activation of GLUT4 in PI3K/Akt signaling pathway by asiatic acid in diabetic rats." Hum Exp Toxicol 34(9): 884-893. 
Ravelli, A. C., O. P. Bleker, T. J. Roseboom, G. A. van Montfrans, C. Osmond and D. J. Barker (2005). "Cardiovascular disease in survivors of the Dutch famine." Nestle Nutr Workshop Ser Pediatr Program 55: 183-191; discussion 191-185.

Ravelli, A. C., J. H. van der Meulen, R. P. Michels, C. Osmond, D. J. Barker, C. N. Hales and O. P. Bleker (1998). "Glucose tolerance in adults after prenatal exposure to famine." Lancet 351(9097): 173-177.

Ravelli, A. C., J. H. van Der Meulen, C. Osmond, D. J. Barker and O. P. Bleker (1999). "Obesity at the age of $50 \mathrm{y}$ in men and women exposed to famine prenatally." Am J Clin Nutr 70(5): 811-816.

Ravelli, G. P., Z. A. Stein and M. W. Susser (1976). "Obesity in young men after famine exposure in utero and early infancy." N Engl J Med 295(7): 349-353.

Rees, W. D., S. M. Hay, D. S. Brown, C. Antipatis and R. M. Palmer (2000). "Maternal protein deficiency causes hypermethylation of DNA in the livers of rat fetuses." J Nutr 130(7): 1821-1826.

Reik, W. and W. Dean (2001). "DNA methylation and mammalian epigenetics." Electrophoresis 22(14): 2838-2843.

Reynolds, L. P., P. P. Borowicz, K. A. Vonnahme, M. L. Johnson, A. T. GrazulBilska, J. M. Wallace, J. S. Caton and D. A. Redmer (2005). "Animal models of placental angiogenesis." Placenta 26(10): 689-708. 
Rich-Edwards, J. W., M. J. Stampfer, J. E. Manson, B. Rosner, S. E. Hankinson, G. A. Colditz, W. C. Willett and C. H. Hennekens (1997). "Birth weight and risk of cardiovascular disease in a cohort of women followed up since 1976." BMJ 315(7105): 396-400.

Roberts, C. T., A. Sohlstrom, K. L. Kind, R. A. Earl, T. Y. Khong, J. S. Robinson, P. C. Owens and J. A. Owens (2001). "Maternal food restriction reduces the exchange surface area and increases the barrier thickness of the placenta in the guinea-pig." Placenta 22(2-3): 177-185.

Rodriguez, T. A., D. B. Sparrow, A. N. Scott, S. L. Withington, J. I. Preis, J. Michalicek, M. Clements, T. E. Tsang, T. Shioda, R. S. Beddington and S. L. Dunwoodie (2004). "Cited1 is required in trophoblasts for placental development and for embryo growth and survival." Mol Cell Biol 24(1): 228-244.

Rosario, F. J., N. Jansson, Y. Kanai, P. D. Prasad, T. L. Powell and T. Jansson (2011). "Maternal protein restriction in the rat inhibits placental insulin, mTOR, and STAT3 signaling and down-regulates placental amino acid transporters." Endocrinology 152(3): 1119-1129.

Roseboom, T. J., J. H. van der Meulen, C. Osmond, D. J. Barker, A. C. Ravelli, J. M. Schroeder-Tanka, G. A. van Montfrans, R. P. Michels and O. P. Bleker (2000). "Coronary heart disease after prenatal exposure to the Dutch famine, 1944-45." Heart 84(6): 595-598. 
Rosenblum, C. I., M. Tota, D. Cully, T. Smith, R. Collum, S. Qureshi, J. F. Hess, M. S. Phillips, P. J. Hey, A. Vongs, T. M. Fong, L. Xu, H. Y. Chen, R. G. Smith, C. Schindler and L. H. Van der Ploeg (1996). "Functional STAT 1 and 3 signaling by the leptin receptor (OB-R); reduced expression of the rat fatty leptin receptor in transfected cells." Endocrinology 137(11): 5178-5181.

Rossant, J. and J. C. Cross (2001). "Placental development: lessons from mouse mutants." Nat Rev Genet 2(7): 538-548.

Rutland, C. S., A. O. Latunde-Dada, A. Thorpe, R. Plant, S. Langley-Evans and L. Leach (2007). "Effect of gestational nutrition on vascular integrity in the murine placenta." Placenta 28(7): 734-742.

Saintonge, J. and P. Rosso (1981). "Placental blood flow and transfer of nutrient analogs in large, average, and small guinea pig littermates." Pediatr Res 15(2): 152-156.

Santos, F., B. Hendrich, W. Reik and W. Dean (2002). "Dynamic reprogramming of DNA methylation in the early mouse embryo." Dev Biol 241(1): 172-182.

Sasaki, H. and Y. Matsui (2008). "Epigenetic events in mammalian germ-cell development: reprogramming and beyond." Nat Rev Genet 9(2): 129-140. Scacheri, P. C., S. Davis, D. T. Odom, G. E. Crawford, S. Perkins, M. J. Halawi, S. K. Agarwal, S. J. Marx, A. M. Spiegel, P. S. Meltzer and F. S. Collins (2006). "Genome-wide analysis of menin binding provides insights into MEN1 tumorigenesis." PLoS Genet 2(4): e51. 
Schubring, C., W. Kiess, P. Englaro, W. Rascher, J. Dotsch, S. Hanitsch, A. Attanasio and W. F. Blum (1997). "Levels of leptin in maternal serum, amniotic fluid, and arterial and venous cord blood: relation to neonatal and placental weight." J Clin Endocrinol Metab 82(5): 1480-1483.

Schulz, L. C. (2010). "The Dutch Hunger Winter and the developmental origins of health and disease." Proc Natl Acad Sci U S A 107(39): 16757-16758.

Schulz, L. C., J. M. Schlitt, G. Caesar and K. A. Pennington (2012). "Leptin and the placental response to maternal food restriction during early pregnancy in mice." Biol Reprod 87(5): 120.

Sciullo, E., G. Cardellini, M. Baroni, P. Torresi, F. Mazziotti, P. Pozzilli and F. Fallucca (1997). "Glucose transporters (GLUT 1, GLUT 3) mRNA in human placenta of diabetic and non-diabetic pregnancies." Ann Ist Super Sanita 33(3): 361-365.

Seckl, J. R. (2004). "11beta-hydroxysteroid dehydrogenases: changing glucocorticoid action." Curr Opin Pharmacol 4(6): 597-602.

Seki, Y., L. Williams, P. M. Vuguin and M. J. Charron (2012). "Minireview:

Epigenetic programming of diabetes and obesity: animal models." Endocrinology 153(3): 1031-1038.

Serman, L., M. Vlahovic, M. Sijan, F. Bulic-Jakus, A. Serman, N. Sincic, R. Matijevic, G. Juric-Lekic and A. Katusic (2007). "The impact of 5-azacytidine on placental weight, glycoprotein pattern and proliferating cell nuclear antigen expression in rat placenta." Placenta 28(8-9): 803-811. 
Shafiee, A., J. Patel, D. W. Hutmacher, N. M. Fisk and K. Khosrotehrani (2018). "Meso-Endothelial Bipotent Progenitors from Human Placenta Display Distinct Molecular and Cellular Identity." Stem Cell Reports 10(3): 890-904.

Shimabukuro, M., K. Koyama, G. Chen, M. Y. Wang, F. Trieu, Y. Lee, C. B. Newgard and R. H. Unger (1997). "Direct antidiabetic effect of leptin through triglyceride depletion of tissues." Proc Natl Acad Sci U S A 94(9): 4637-4641.

Simmons, D. G., S. Rawn, A. Davies, M. Hughes and J. C. Cross (2008). "Spatial and temporal expression of the 23 murine Prolactin/Placental Lactogen-related genes is not associated with their position in the locus." BMC Genomics 9: 352. Sinclair, K. D., C. Allegrucci, R. Singh, D. S. Gardner, S. Sebastian, J. Bispham, A. Thurston, J. F. Huntley, W. D. Rees, C. A. Maloney, R. G. Lea, J. Craigon, T. G. McEvoy and L. E. Young (2007). "DNA methylation, insulin resistance, and blood pressure in offspring determined by maternal periconceptional B vitamin and methionine status." Proc Natl Acad Sci U S A 104(49): 19351-19356.

Sivan, E., P. G. Whittaker, D. Sinha, C. J. Homko, M. Lin, E. A. Reece and G. Boden (1998). "Leptin in human pregnancy: the relationship with gestational hormones." Am J Obstet Gynecol 179(5): 1128-1132.

Smith, Z. D. and A. Meissner (2013). "DNA methylation: roles in mammalian development." Nat Rev Genet 14(3): 204-220.

Snoeck, A., C. Remacle, B. Reusens and J. J. Hoet (1990). "Effect of a low protein diet during pregnancy on the fetal rat endocrine pancreas." Biol Neonate 57(2): 107-118. 
Sood, R., J. L. Zehnder, M. L. Druzin and P. O. Brown (2006). "Gene expression patterns in human placenta." Proc Natl Acad Sci U S A 103(14): 5478-5483.

Stein, A. D., H. S. Kahn, A. Rundle, P. A. Zybert, K. van der Pal-de Bruin and L. H. Lumey (2007). "Anthropometric measures in middle age after exposure to famine during gestation: evidence from the Dutch famine." Am J Clin Nutr 85(3): 869-876.

Stephens, T. W., M. Basinski, P. K. Bristow, J. M. Bue-Valleskey, S. G. Burgett, L. Craft, J. Hale, J. Hoffmann, H. M. Hsiung, A. Kriauciunas and et al. (1995). "The role of neuropeptide $\mathrm{Y}$ in the antiobesity action of the obese gene product." Nature 377(6549): 530-532.

Stock, S. M., E. M. Sande and K. A. Bremme (1999). "Leptin levels vary significantly during the menstrual cycle, pregnancy, and in vitro fertilization treatment: possible relation to estradiol." Fertil Steril 72(4): 657-662.

Takai, D. and P. A. Jones (2002). "Comprehensive analysis of CpG islands in human chromosomes 21 and 22." Proc Natl Acad Sci U S A 99(6): 3740-3745.

Thaler, M. M. (1972). "Effects of starvation on normal development of hydroxybutyrate dehydrogenase activity in foetal and newborn rat brain." Nat New Biol 236(66): 140-141.

Tobi, E. W., L. H. Lumey, R. P. Talens, D. Kremer, H. Putter, A. D. Stein, P. E. Slagboom and B. T. Heijmans (2009). "DNA methylation differences after exposure to prenatal famine are common and timing- and sex-specific." $\underline{\text { Hum Mol }}$ Genet 18(21): 4046-4053. 
Townsend, K. L., M. M. Lorenzi and E. P. Widmaier (2008). "High-fat dietinduced changes in body mass and hypothalamic gene expression in wild-type and leptin-deficient mice." Endocrine 33(2): 176-188.

Tritos, N. A. and C. S. Mantzoros (1997). "Leptin: its role in obesity and beyond." Diabetologia 40(12): 1371-1379.

Trogdon, J. G., E. A. Finkelstein, T. Hylands, P. S. Dellea and S. J. Kamal-Bahl (2008). "Indirect costs of obesity: a review of the current literature." Obes Rev 9(5): 489-500.

Tsoulos, N. G., J. R. Colwill, F. C. Battaglia, E. L. Makowski and G. Meschia (1971). "Comparison of glucose, fructose, and O2 uptakes by fetuses of fed and starved ewes." Am J Physiol 221(1): 234-237.

Uauy, R., J. Kain and C. Corvalan (2011). "How can the Developmental Origins of Health and Disease (DOHaD) hypothesis contribute to improving health in developing countries?" Am J Clin Nutr 94(6 Suppl): 1759S-1764S.

Vaisse, C., J. L. Halaas, C. M. Horvath, J. E. Darnell, Jr., M. Stoffel and J. M.

Friedman (1996). "Leptin activation of Stat3 in the hypothalamus of wild-type and ob/ob mice but not db/db mice." Nat Genet 14(1): 95-97.

Vambergue, A. and I. Fajardy (2011). "Consequences of gestational and pregestational diabetes on placental function and birth weight." World J Diabetes 2(11): 196-203. 
Vickers, M. H., B. H. Breier, W. S. Cutfield, P. L. Hofman and P. D. Gluckman (2000). "Fetal origins of hyperphagia, obesity, and hypertension and postnatal amplification by hypercaloric nutrition." Am J Physiol Endocrinol Metab 279(1): E83-87.

Vickers, M. H., P. D. Gluckman, A. H. Coveny, P. L. Hofman, W. S. Cutfield, A. Gertler, B. H. Breier and M. Harris (2005). "Neonatal leptin treatment reverses developmental programming." Endocrinology 146(10): 4211-4216.

Vlahovic, M., F. Bulic-Jakus, G. Juric-Lekic, A. Fucic, S. Maric and D. Serman (1999). "Changes in the placenta and in the rat embryo caused by the demethylating agent 5-azacytidine." Int J Dev Biol 43(8): 843-846.

Vonnahme, K. A. and S. P. Ford (2004). "Differential expression of the vascular endothelial growth factor-receptor system in the gravid uterus of yorkshire and Meishan pigs." Biol Reprod 71(1): 163-169.

Vonnahme, K. A., M. J. Zhu, P. P. Borowicz, T. W. Geary, B. W. Hess, L. P. Reynolds, J. S. Caton, W. J. Means and S. P. Ford (2007). "Effect of early gestational undernutrition on angiogenic factor expression and vascularity in the bovine placentome." J Anim Sci 85(10): 2464-2472.

Waddington, C. H. (2012). "The epigenotype. 1942." Int J Epidemiol 41(1): 10-13. Wallace, J. M., R. P. Aitken, J. S. Milne and W. W. Hay, Jr. (2004). "Nutritionally mediated placental growth restriction in the growing adolescent: consequences for the fetus." Biol Reprod 71(4): 1055-1062. 
Waterland, R. A., D. C. Dolinoy, J. R. Lin, C. A. Smith, X. Shi and K. G. Tahiliani (2006). "Maternal methyl supplements increase offspring DNA methylation at Axin Fused." Genesis 44(9): 401-406.

Waterland, R. A. and R. L. Jirtle (2003). "Transposable elements: targets for early nutritional effects on epigenetic gene regulation." Mol Cell Biol 23(15): 5293-5300.

Wen, H., L. Chen, J. He and J. Lin (2017). "MicroRNA expression profiles and networks in placentas complicated with selective intrauterine growth restriction." Mol Med Rep 16(5): 6650-6673.

Widdowson, E. M. (1974). "Immediate and long term consequences of being large or small at birth: a comparative approach. In size at birth:." (27): 65-76 Widdowson, E. M. and R. A. McCance (1975). "A review: new thoughts on growth." Pediatr Res 9(3): 154-156.

Wolf, A. M. (1998). "What is the economic case for treating obesity?" Obes Res 6 Suppl 1: 2S-7S.

Wolf, A. M. and G. A. Colditz (1998). "Current estimates of the economic cost of obesity in the United States." Obes Res 6(2): 97-106.

Wolf, S. F., D. J. Jolly, K. D. Lunnen, T. Friedmann and B. R. Migeon (1984). "Methylation of the hypoxanthine phosphoribosyltransferase locus on the human X chromosome: implications for X-chromosome inactivation." Proc Natl Acad Sci U S A 81(9): 2806-2810.

Wooding, F. B. and A. L. Fowden (2006). "Nutrient transfer across the equine placenta: correlation of structure and function." Equine Vet J 38(2): 175-183. 
Wooding, F. B., A. L. Fowden, A. W. Bell, R. A. Ehrhardt, S. W. Limesand and W. W. Hay (2005). "Localisation of glucose transport in the ruminant placenta: implications for sequential use of transporter isoforms." Placenta 26(8-9): 626640.

Zhou, J. and C. A. Bondy (1993). "Placental glucose transporter gene expression and metabolism in the rat." $\mathrm{J}$ Clin Invest 91(3): 845-852.

Zhu, J. K. (2009). "Active DNA demethylation mediated by DNA glycosylases." Annu Rev Genet 43: 143-166. 


\section{CONCLUSION}

Maternal undernutrition during early pregnancy affected not only the women and their offspring exposed during the Dutch Hunger famine but the effects of poor maternal nutrition during pregnancy is prevalent in societies even today. In the U.S., women of low socio-economic background may be exposed to lack of adequate nutrients during pregnancy. WIC and other interventions to ensure women are properly fed during pregnancy are strategies to help prevent chronic adult diseases. Women however may be well into the second trimester before using the benefits of such programs. Several studies as previously discussed suggests periconceptionally and the first trimester as periods which are more critical to proper fetal development and the promotion of metabolic diseases as an adult. As such a better understanding on the molecular mechanism by which maternal nutrition during early gestation alters placental development to subsequently affect fetal and adult health needed to be further elucidated.

One of the goals of my study was to determine whether, in mice, the periconceptional period is a critical time in which maternal total caloric restriction can permanently alter placental development and function. Here we found maternal under nutrition periconceptionally followed by an adequate fed diet in late gestation altered placental morphology and nutrient transport. This suggests maternal diet prior to conception could change potential affect the transport of nutrients across the placenta to change the trajectory of fetal development which may subsequently affect adult health. Timing of the maternal nutritional insult to 
have these lasting consequences on offspring health is also critical. In our lab, in mice we noticed that an adverse maternal environment such as a total caloric nutrient restriction that occurred in early gestation caused the placenta to be smaller when examined at mid-gestation. When however, the mothers are returned to an adequate fed diet in the latter half of gestation these alterations in placental development were ameliorated. This suggested that policies such a WIC and other interventions to ensure women are properly fed during pregnancy are effective at eradicating the long-term consequences of improper diet during pregnancy of fetal health and subsequent adult health to reduce the burden on society.

One reason as to why maternal diet may during the periconception period and early gestation may alter fetal development to affect adult health is that there is oocyte selection and two rounds of DNAM methylation programming occurring at this period of development.

Additionally, MUN during early gestation followed by adequate diet in late gestation altered placental DNA methylation in term placenta. These changes in DNA methylation were associated with changes in genes whose expression were involved in the regulation of metabolic diseases. Further studies need to be done to elucidate the function of these genes in placental development. This improved understanding could lead to the development of better interventional strategies that target these critical developmental periods to result in a reduction in the long-term consequences maternal nutrition prior to and during early gestation have on placental development to affect fetal and adult health. 
Further studies are needed to determine the specific CpG loci which responded to maternal food restriction to alter placental DNA methylation and structural development. Understanding the mechanism by which maternal nutrition alter placental development would aid scientists in possibly using the placental as a tissue to identify key biomarkers to predict adult disease. 
Gerialisa Allison Marcella Van Gronigen Case was born on the September $11^{\text {th }}$, 1979 in Guyana, South America to the parents of Oswald Case and Burgette Van Gronigen Case and is the older sibling to Zoisha Molden. Gerialisa attended President's College in Guyana South. She immigrated to the United States and attended Medgar Evers College for undergraduate degrees where she graduated cum laude with both an Associates in Science and a Bachelor of Science. Gerialisa had always had a passion for biology, however did not initially pursue this. Her interest in the science was nurtured by her undergraduate mentor, Dr. Margaret Carroll who encouraged her to pursue research. Gerialisa first research experience was in her senior year where she was accepted in the Summer Multicultural Access Research Training program at the University of ColoradoBoulder under the mentorship of Dr. Jennifer Martin. It was here she found she had an aptitude for research. Gerialisa returned to her undergraduate institution where she attended conferences to present her summer research experience and was awarded the Collegiate Science and Technology Entry Program second place in the Natural Sciences 111 category for her oral presentation. After graduating, Gerialisa conducted research with Dr. Sandra Petersen at the University of Massachusetts-Amherst. She started the Post Baccalaureate Research Education Program at the University of Missouri and later joined the Division of Biological Sciences as a graduate student in Dr. Laura Schulz lab. Her graduate work was to investigate the effects of maternal nutrition during early pregnancy on placental development. 